Technical Note N-1144

MOBILE OCEAN BAS ING SYSTEMS - A CONCRETE CONCEPT

By

J. J. Hromadik, D. A. Davis, D. F. Griffin, W. R. Lorman, M. J. Wolfe and H. S. Zwibe1

January 1971

\title{
OEC 191971
}
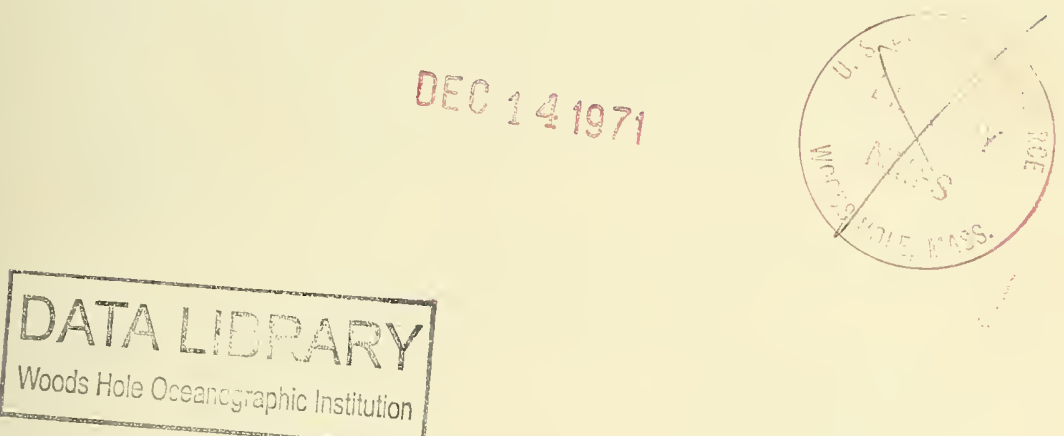

Distribution limited to U. S. Government agencies only; proprietary information; January 1971. Other requests for this document must be referred to the Naval Civil Engineering Laboratory.

NAVAL CIVIL ENGINEERING LABORATORY

Port Hueneme, California 93043

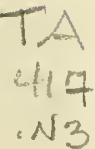


MOBILE OCEAN BASING SYSTEMS - A CONCRETE CONCEPT

Techncial Note $\mathrm{N}-1144$

YF 51.543.009.01.001

by

J. J. Hromadik, D. A. Davis, D. F. Griffin, W. R. Lorman, M. J. Wolfe and H. S. Zwibe1

\section{ABSTRACT}

Large floating ocean platforms are envisioned as satisfying basing requirements of the Navy in the mid $80^{\prime} \mathrm{s}$. The floating platforms would consist of structural components mass-produced, constructed into modules ashore, launched, towed to the site and assembled into platforms.

This investigation studied various configurations using concrete as the construction material. The scope of effort included synthesis of concepts, concrete production, construction methodology and cost, and an RDT\&E plan. It is concluded that concrete is a feasible and practical construction material for large ocean platforms.

Distribution 1 imited to U. S. Government agencies only; proprietary information; January 1971. Other requests for this document must be referred to the Naval Civil Engineering Laboratory. 
From: Commanding Officer

To: $\quad$ Distribution Addressees

Subj: Distribution Statement for NCEL Technical Note N-1144, Mobile Ocean Basing Systems-A Concrete Concept, by J. J. Hromadik, D. A. Davis, D. F. Griffin, W. R. Lorman, M. J. Wolfe \& H. S. Zwibel dated January 1971; change of

1. The subject report was printed with a distribution statement limiting transmittal of the document to agencies of the U. S. Government without approval of the Naval Civil Engineering Laboratory.

2. This report has now been reviewed and cleared for public release. Accordingly, it is requested that the distribution limitation currently found on the report be deleted and replaced with the following distribution statement.

"Approved for public release and sale; its distribution is unlimited."

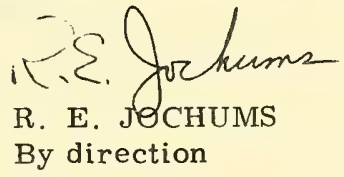




$$
\text { . }
$$


TABLE OF CONTENTS

PART ONE - INTRODUCTION

BACKGROUND . . . . . . . . . . . . . . . . . . . . 1-1

SCOPE OF INVESTIGATION . . . . . . . . . . . . . . . 1-3

PART TWO - HISTORY OF CONCRETE STRUCTURES IN A MARINE ENVIRONMENT

SIGNIFICANT FIXED STRUCTURES . . . . . . . . . . . . . . 2-1

SIGNIFICANT FLOATING STRUCTURES . . . . . . . . . . . . . 2-8

FRESHWATER STRUCTURES . . . . . . . . . . . . . . . 2-15

PART THREE - SYNTHES IS OF CONCEPTS

DESCRIPTION OF CONCEPTS ................... 3-1

Elevated Platforms .............. . . 3-1

Barge Platforms . . . . . . . . . . . . . 3-4

Semi-Submersible Platform . . . . . . . . . . . 3-7

Other Concepts . . . . . . . . . . . . 3-11

CONCEPT OPTIMIZATION . . . . . . . . . . . . . . . 3-12

Elevated Platform . . . . . . . . . . . . 3-14

Semi-Submersible Platform . . . . . . . . . . 3-17

Barge Platform . . . . . . . . . . . . 3-17

PRELIMINARY DESIGN . . . . . . . . . . . . . . . . . 3-18

Structural Design Assumptions and Criteria . . . . . 3-18

Structural Design Approach . . . . . . . . . . 3-19

Hydrodynamic Design - Assumptions and Procedure . . . . 3-21

Results............... . . . . . . . . 22

PART FOUR - CONCRETE PRODUCTION

RESOURCES . . . . . . . . . . . . . . . . . 4-1

Construction Site... . . . . . . . . . . . 4-1

Materials of Construction . . . . . . . . . . . 4-1

PRODUCTION . . . . . . . . . . . . . . . . . . . 4-7

Production Plants.............. . . . 4-7

Quality Control in Production . . . . . . . . . . 4-11

Requirements in CONUS or Remote........... . 4-12 
CONSTRUCTION PROCEDURES . . . . . . . . . . . . . . . . . 5-1

Location of Construction . . . . . . . . . . . 5-1

Concrete Construction Practice . . . . . . . . . 5-7

Fabrication of Cylindrical Elements . . . . . . . . . 5-9

Fabrication of Deck and Hull Elements . . . . . . . . 5-13

Requirements for a Baseline Batching and Mixing Plant . . 5-14

Materials . . . . . . . . . . . . . 5-15

CONSTRUCTION TIME AND COST . . . . . . . . . . . . . 5-15

Cost...................... . . . . . 15

ASSEMBLY TECHNIQUES • . . . . . . . . . . . . . . . . 5-19

Elevated Platforms . . . . . . . . . . . . 5-19

Semi-Submersible Platform . . . . . . . . . . 5-20

Barge Platforms . . . . . . . . . . . . . 5-20

PLATFORM TRANSPORT . . . . . . . . . . . . . . . . . . 5-23

Elements Transported as Cargo . . . . . . . . . 5-23

Surface Transport - Towing . . . . . . . . . . 5-23

Past Examples of Long Tows . . . . . . . . . . 5-28

PART SIX - SUMMARY AND RDT\&E PLAN

CONSTRUCTION PROCEDURES - SUMMARY . . . . . . . . . . . . 6-1

Elevated Platform . . . . . . . . . . . . . 6-1

Semi-Submersible Platforms . . . . . . . . . 6-2

Barge Platforms . . . . . . . . . . . . 6-2

METHODOLOGY FOR COMPARING CANDIDATE PLATFORMS . . . . . . . 6-2

Performance Criteria . . . . . . . . . . . . 6-3

Performance Record .. . . . . . . . . . . . 6-4

Costs . . . . . . . . . . . . . . . . 6-4

Analysis . . . . . . . . . . . . . 6-5

RDT\&E PLAN - 1970 AND BEYOND . . . . . . . . . . . 6-7

Structural/Materials Investigation . . . . . . . . 6-7

Hydrodynamic Response . . . . . . . . . . . . 6-8

Operational/Logistic Requirements . . . . . . . . .6-8

Vulnerability . . . . . . . . . . . . . . 6-9

Scheduling . . . . . . . . . . . . . . 6-9 
REFERENCES •. . . . . . . . . . . . . . . . . . . . . R-1 APPENDIX A - HEAVE RESPONSE OF AN ELEVATED PLATFORM . . . . . . . A-1 APPENDIX B - MATERIALS . . . . . . . . . . . . . . . . B-1 



\author{
PART ONE - INTRODUCTION \\ by J. J. Hromadik
}

\title{
BACKGROUND
}

U. S. Nava1 power overseas is brought to bear primarily through fast carrier strike groups, seaborne landing forces, and missile launching submarines. The efficient use of these forces is dependent upon advanced logistics, maintenance, and support facilities. The Advanced Base - also called Forward Area Base - is a major element in supporting the operating forces in remote areas. A vast real estate potential exists in mobile ocean basing systems; large floating platforms that can essentially occupy any ocean site are seen as a means for meeting forward area surveillance and basing requirements of the Navy in the mid 80 's. Such platforms as shown in Figure 1.1, could increase Task Force effectiveness by providing a greater time on combat station; they avoid most of the problems of foreign bases without sacrificing any of the advantages of forward deployment.

The floating platforms are seen as consisting of components mass produced ashore, constructed in modules, launched, towed to the site, and assembled. Such a capability to support occupancy of a particular ocean region for the performance of specified operational tasks exists. It does not appear to require major scientific discoveries or technical breakthroughs; it does require systematic development with accompanying RDT\&E to update and extend current technology. While available materials of construction provide a designer's choice, concrete does appear to stand out. It is readily available, economical, can be mass produced and lends itself to repetitive large-scale constructions. With concrete, it is not necessary to bring the project to the industrial plant, the production processes can go to the site. Moreover, the history of concrete in a marine environment speaks for itself. (See Part Two.)

Raw materials* are plentiful and are not known to be scarce even during periods of national crises. The cement industry is experiencing a steady growth. U. S. shipments reached an a11 time high of about 400 million barrels per year (bpy) in 1968. New plants in operation, together with modernization and expansion of existing plants were expected to increase production capacity by some 20 million bpy by 1970 ; the capacity at the close of 1968 was slightly more than 500 million bpy. Prognostications for cement shipments by 1980 range from a low of 625 million to a high of 717 million bpy.

The fastest growing segment of the rock products group is the 1ightweight aggregates. Output has increased by 80 percent in the last decade to reach an annual high of $10 \mathrm{million}$ tons in 1968. Production is expected to double by 1975 (Grancher, 1969).

* Production quantities are discussed in Part Four. 


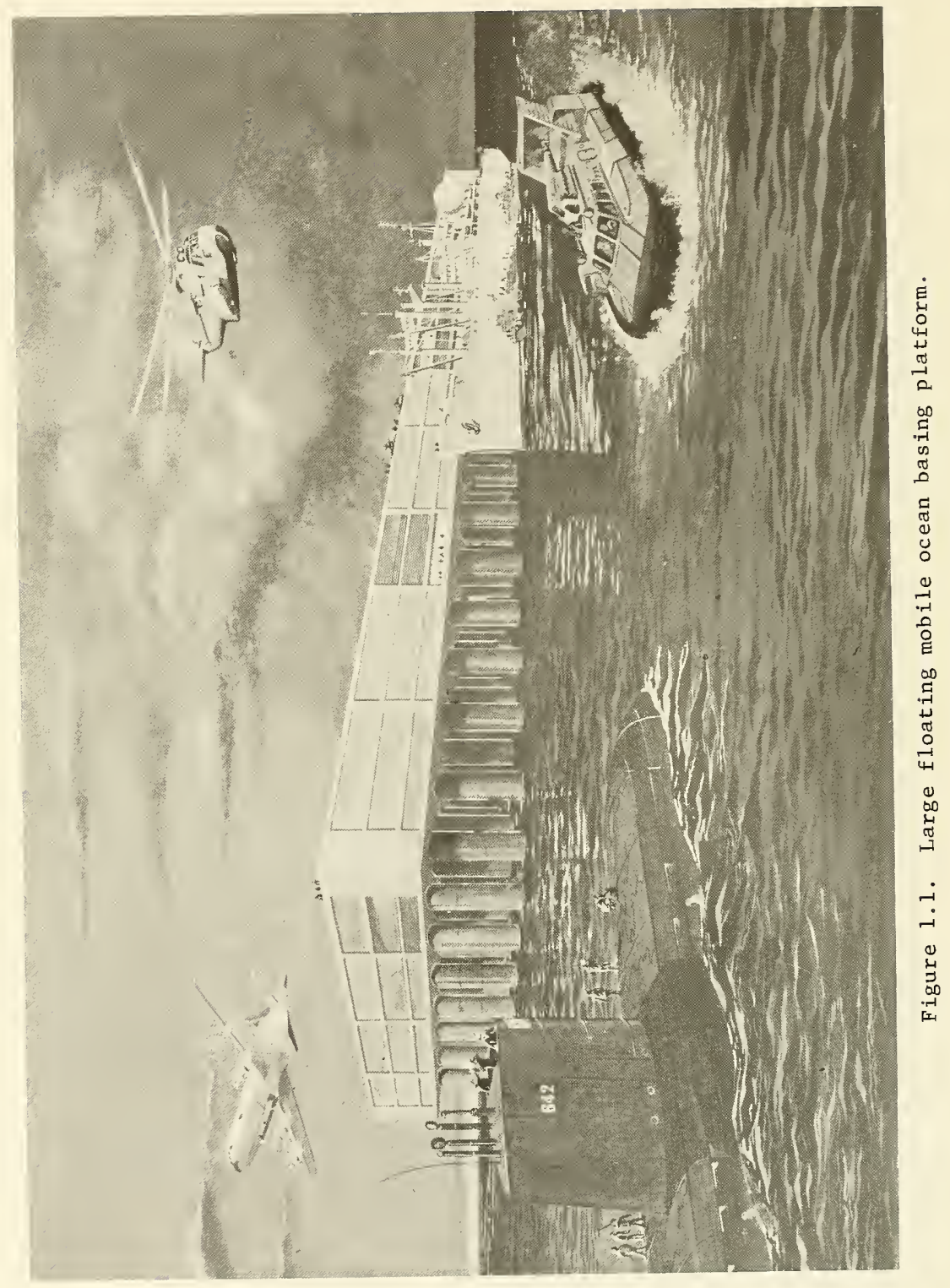


Not only is concrete cost competitive ${ }^{*}$ in today's market, but current trends are indicative of its retaining a favorable position. It is postulated that automation in the cement industry has brought about a tremendous gain in manufacturing output. The output index shows the cement industry below steel in 1950, catching up in the late ' 50 's, and surpassing in the $60^{\prime} \mathrm{s}$ with a significant margin. Cement prices during all of the $60^{\prime} \mathrm{s}$ did not exceed the 1960 cost. The wholesale price cost index shows that not only is cement in a favorable competitive position, but also reinforcing steel and concrete products. (See Figure 1.2).

Mass production of concrete products is demonstrated daily. Some 395 firms in the United States and Canada produce precast, repetitive elements for custom design. And recently, a new and daring modular construction was demonstrated with the completion of the 21-story Hilton Palacio Del Rio Hotel in San Antonio. Completely precast concrete boxes (room-size modules) together with all necessary service accessories and furnishings were moved to the construction site for erection. The reported cost of the structure was $\$ 10$ per square foot (Architectural Records, 1968).

The feasibility and practicability of establishing aggregate plants at remote sites was demonstrated by a British Columbia project (Western Construction, 1967). Routledge Gravel Contractors of Vancouver, British Columbia, were faced with producing one million tons of concrete aggregates for Arrow Dam on the Columbia River, some 400 miles inland from Routledge's stationary plants on the coast. Since the dam could not be brought to Vancouver, it was necessary to bring the production and quality to the dam site, which Routledge did, assemblying the plant component by component inland. Routledge operations not only met an ambitious 3,000 ton per day schedule, but handled stepped-up demands. In $5 \frac{1}{2}$ months the plant produced nearly half of its million-ton commitment. Concrete is an exotic material, not by itself, but through applications that have evolved as a result of recent developments. . . improvements in handling and placing, and in the design and control of concrete mixtures . . higher strengths with improved cement formulations and reinforcing techniques . . . innovations in thin-shell construction, longer spans, and not entirely precast systems. These developments are leading not only to improvements in quality, but also to techniques that are ever broadening the applications, enabling an efficiency in modern concrete structures never before realized.

\section{SCOPE OF INVESTIGAT ION}

The investigation documented in this report was sponsored jointly by the Office of Naval Research and the Naval Facilities Engineering Command. It dealt with one of the technological areas requiring an early investigation, that of construction - materials, fabrication and assembly. The practicability of constructing large platforms depends on the availability of a suitable site, while the configuration and

\footnotetext{
Construction cost estimates are presented in Part Five.
} 
maximum practical size modules - units to be launched for subsequent assembly at sea - and structural elements that make up the modules depend on such state-of-the-art factors as fabrication techniques, materials of construction, materials handling equipment and assembly methods. This report documents results of the preliminary investigations into the fabrication of various configured concepts and notes areas where further RDT\&E efforts are warranted. Also included is a history of concrete structures in a marine environment. Based on operational analyses, three platform sizes were investigated:* $300 \times 300,400 \times$ 1200 , and $1000 \times 4000$, with dimensions given in feet (Figure 1.3). Various configurations of three basic types were considered, (a) elevated decks on columnar, vertical supports for providing buoyancy, (b) elevated decks with semi-submersible type horizontal hulls and (c) elevated decks with barge-type hulls for floatation.

By definition, the construction process is basically in four stages, as illustrated in the below diagram.

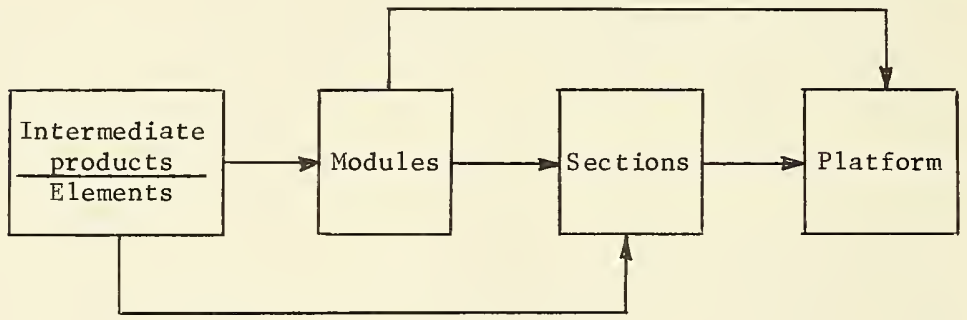

Intermediate products, or elements, are major precast units that go to make up modules, the smallest units to be launched. The modules, are then assembled at sea into sections, and these in turn into the platform (See Figure 1.4). Requirements on size, configuration and deployment may dictate a final design where either of the intermediate stages, modules or sections, may be unnecessary. Reference is made to these four stages of construction throughout the report in context with the above definition.

*Joint laboratories report on mission analysis (1970), in preparation. 

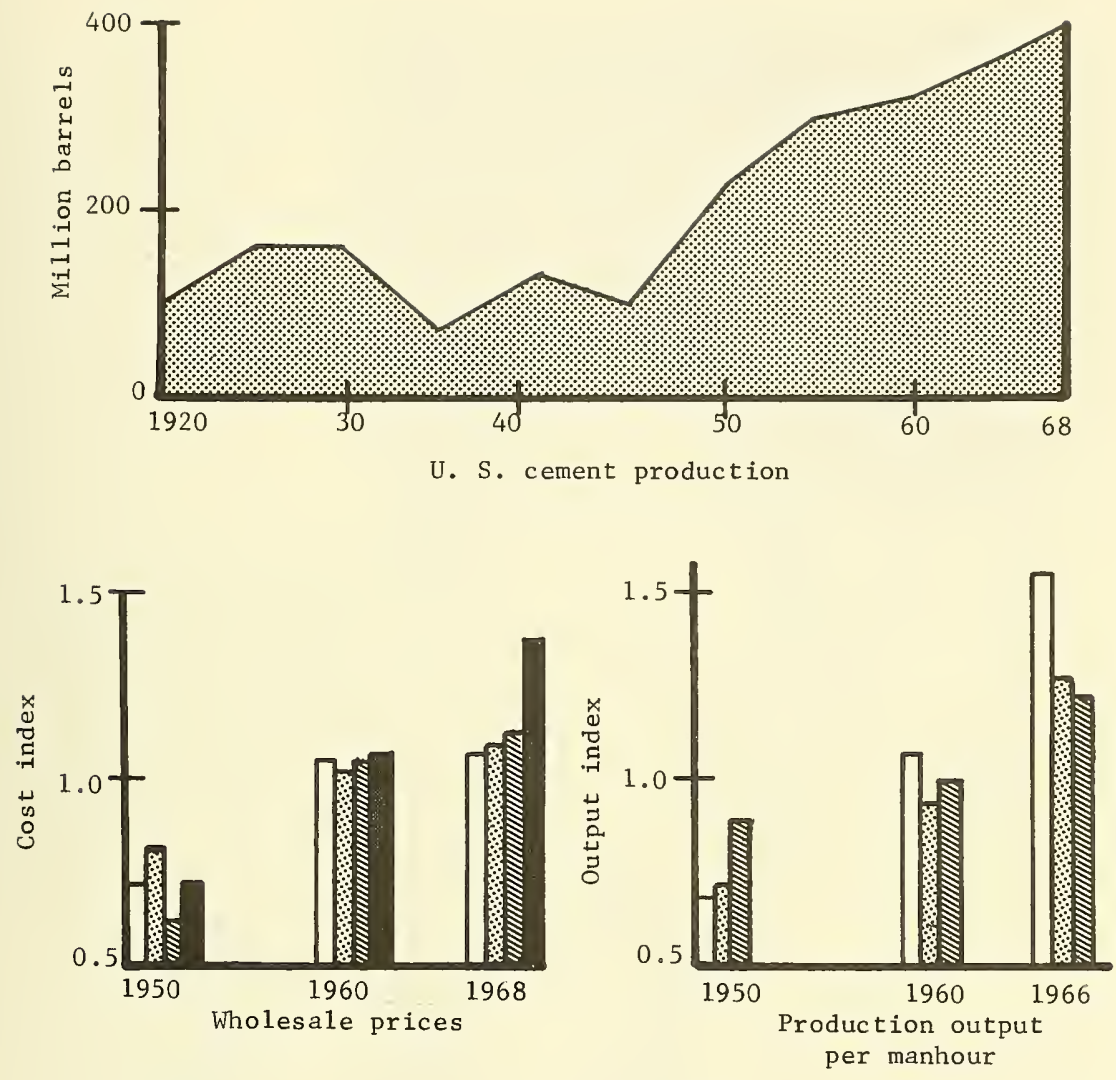

Figure 1.2. Production data (Scource:

Statistical Abstracts of the United States, 90 th Edition, 1969) 


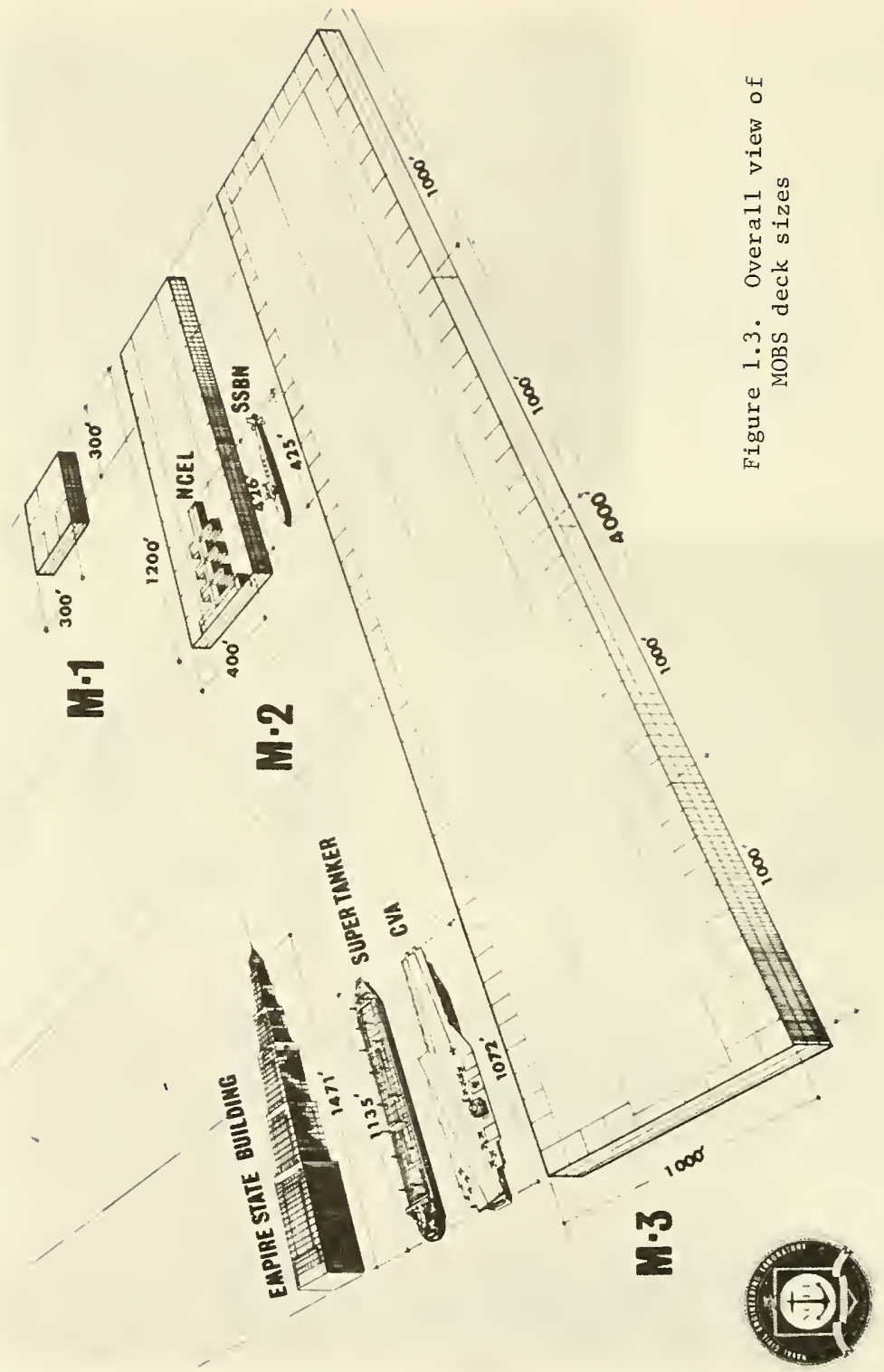




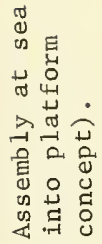

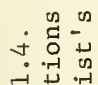

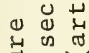

$$
\begin{aligned}
& \text { 为 } \\
& \text {. }
\end{aligned}
$$

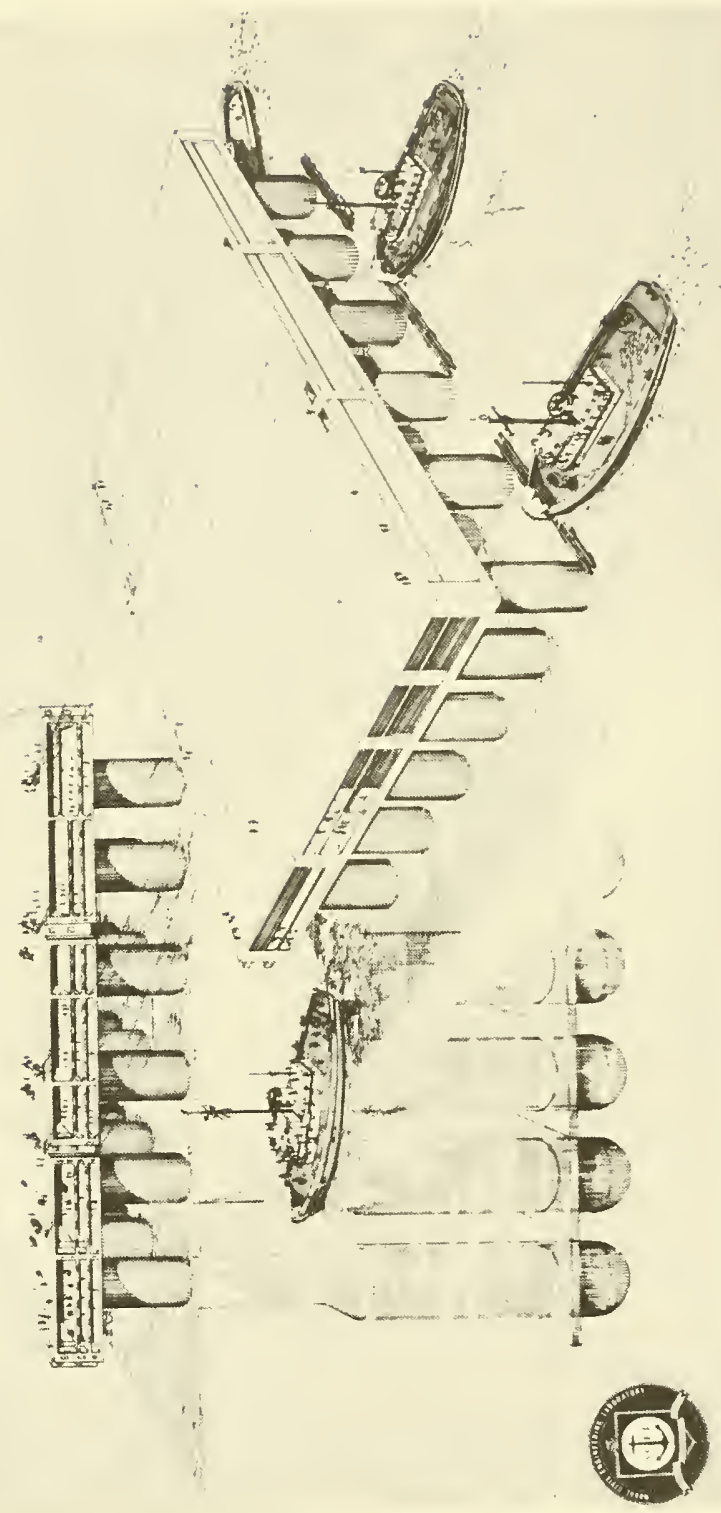


The report is divided into six parts as follows:

Part 1 -.-- Introduction

Part 2 -.-- General history of large concrete structures in a marine environment.

Part 3 -.-- Various platform concepts, their characteristics and suggested configurations.

Part 4 -.--- Concrete production, concerning such topics as production quantities, rates and costs, plant operations, and quality.

Part 5 -.-- Methodology associated with large platform construction, at-sea assembly, and towing. Comparative construction costs for various platforms are included.

Part 6 --.-- Construction summary, with comments on methodology for comparing platforms and a suggested RDT\&E plan. 


\section{PART TWO - HISTORY OF CONCRETE STRUCTURES \\ IN A MARINE ENVIRONMENT \\ by $W$. R. Lorman}

\section{SIGNIFICANT FIXED STRUCTURES}

The earliest known use of concrete in a marine environment is an ancient waterfront structure, the remnants of which are in evidence today on the Italian coast near Naples. Early in the 1st century, sometime between 12 and 41 A.D., the Romans constructed concrete pillars as supports for a large wharf in the Bay of Pozzuoli. In 1954, after 19 centuries of submergence in seawater, the concrete was considered still serviceable on the basis of scientifice examination of various samples retrieved from the structure. This installation is believed to be the oldest known example of concrete in seawater. The Roman engineers utilized the fact that pozzolanic material, in the form of volcanic ash from nearby Mt. Vesuvius, reacts with lime to create a cementitious compound that hardens underwater. Along the coast between Naples and Gaeta to the north there are great masses of Roman concrete still extant, as evidence of the resistance of plain (non-reinforced) concrete to the action of the sea.

According to Vitruvius, Roman concrete structures consisted of a calcareous mixture, which actually was a combination of Iime, natural pozzolana, and water, placed over and around broken stone (rubble) and built up as layers of concrete. Wooden formwork was sometimes used. The usual mix proportions of the solids in the mortar were 2 parts of lime and 5 parts of pozzolana.

As the result of the demise of the Roman Western Empire in 476, the use of pozzolanic mixtures declined by the end of the 5 th century and the knowledge was forgotten during the dark ages. During the middle ages the mortars used in stone masonry construction were usually mixtures of lime, sand, and water, but such construction was limited to structures on land.

In the 18th century the Italian and French engineers followed the principles laid down by Vitruvius. In 1748 one of the jetties at Toulon, France, was made entirely of concrete; in 1774 the drydock at Toulon was constructed of similar materials (Rennie, 1857). In 1756 the concrete used in constructing the base of the stone lighthouse on Eddystone Rock, situated on the Cornish coast of England, consisted of pozzolana mixed with hydraulic lime containing a considerable amount of clay. This was the first instance of an improvement (Lea, 1956) on the Roman mixture of lime and natural pozzolana, up to that time the only suitable cementitious material for structures under or exposed to water. The base and first floor of the Eddystone lighthouse still remain today although the lighthouse proper was dismantled and relocated at nearby Plymouth where it now stands. 
Concrete incorporating portland cement was used in England as early as 1928 for plugging a break in the wall of the Thames River tunnel that was under construction. One of the early instances of portland cement concrete exposed continually to seawater was the construction of a coral concrete base for the Daedalus 1ighthouse which was erected in 1862 on a cora1 reef in the Red Sea (Parkes, 1863). When the Daedalus lighthouse was replaced in 1930, the coral concrete base (actually a plain concrete layer or slab over the reef) was replaced with ordinary sand and gravel concrete (Fatim, 1954).

From the middle to the end of the 19 th century, docks and wharves built of concrete were invariably of plain concrete. Most of these proved durable and are still in use.

The first maritime reinforced concrete structure in Great Britain was built in 1899 at Southampton; it consisted of a reinforced concrete deck, 100 by 40 feet, resting on reinforced concrete piles. The strucure, which was still in service and in excellent condition in 1955, was made with a "very dry" concrete (i. e., concrete of a low water/cement ratio). In 1902, also at Southampton, another reinforced concrete pier was erected; its deck was 360 feet by 20 feet and about 34 feet high. This second facility was made with "rather wet" concrete as it was considered that the resultant workability would assure better passage through the maze of reinforcement than would be possible with a concrete of stiff consistency. In a few years the latter pier exhibited deterioration which was partly due to the fact that the wet mixture tended to shrink away from the reinforcement while undergoing set (the excessive air voids accompanying a high water/cement ratio tending toward a weak and permeable concrete), and partly due to electrolytic action resulting from the electric cranes being grounded to the pier (Wentworth-Shields, 1956).

In Japan ear $1 y$ in the 20 th century, immense precast concrete blocks were used (Hiroi, 1904) in constructing jetties, and, as far as known, are in service today. During the period 1909 to 1918 , the USN graving dock at Pearl Harbor was constructed of reinforced concrete (Stanford, 1916). It is over 1000 feet long and is still in serviceable condition today.

For the past 60 years the Port of Los Angeles has successfully used reinforced portland cement concrete for wharf construction (Wakeman, et. a1., 1958). Two exceptions have detracted from an extraordinary record of performance in sea water (Lorman, 1965). Berths 57 through 60 were built in 1914 , but 10 years later the longitudinal reinforcing stee 1 had become exposed by the cracks in the concrete cover; shotcrete was used for restoration and 40 years later the structures were still intact. The second exception to outstanding performance occurred in 1960 at Berths 135 and 187, which were built in 1920, although necessary precautions had been taken relative to mix proportions, placement, curing, and structural design; the difficulty was traced to contaiminated cement; the cracks were sealed in 1960 by grouting with pressurized epoxy. The admirable performance of waterfront structures at the Port 
of Los Angeles has been accomplished by observing established facts regarding concrete, applying the best constructional procedures, and adhering to principles of good workmanship, all of which necessitated correctly written specifications and assiduous inspection.

Service records of 27 specific American concrete waterfront structures, built during the period 1904 to 1951, have been briefly presented in geographic sequence (Mather, 1957). The north and central Atlantic Coast, from Canada to North Carolina, is a zone in which the dominant influence on durability is characterized by freezing and thawing. The south Atlantic Coast, the Gulf Coast, and most of the Pacific Coast are zones where chemical factors are dominant relative to influencing concrete durability.

Service records of 105 concrete structures in seawater were studied from 1922 to 1924 and certain conclusions deduced (Atwood and Johnson, 1924). Maritime structures included 31 facilities in foreign nations (built during the period 1855 to 1911) and 74 American structures (built during the period 1889 to 1919). The evidence showed great variations in the serviceability of both plain and reinforced concrete waterfront structures. The durability of the cementitious matrices in general use as of 1924 seemed to be questionable. Plain concrete in seawater may deteriorate as the result of chemical action of sulfates (in the seawater) on the constituents of the concrete and mechanical action of water, ice, and debris. Reinforced concrete in seawater may deteriorate not only because of such chemical and mechanical actions, but also because of the splitting and spalling brought about by the corrosion of the steel reinforcement. The rate of deterioration is related to the permeability and porosity of the concrete. Most of the deterioration, in both plain and reinforced concrete, occurs above low tide level; good concrete seldom suffers below this level. "Deterioration of well built reinforced concrete does not often indicate its presence by rust stains in much less than 10 years." Disintegration by the chemical action of magnesium sulfate in seawater $c$ an be prevented by incorporating siliceous materials in the concrete; such materials (volcanic origin) are pozzolana from Italy, Santorin earth from Greece, trass from Germany, and tuff from California. Other siliceous materials are diatomaceous earth from Denmark and California, certain blast furnace slags, and some burned clays.

In Norway, during the period from 1962 to 1968, comprehensive field inspections of 219 reinforced concrete wharves (among a total of 716 concrete maritime structures erected since about 1910) disclosed that deterioration developed very slowly within the tidal zone. Above high tide level the deck beams were especially vulnerable to corrosion of steel reinforcement. However, neither the deck slabs nor seawalls underwent any serious impairment of strength during a half century of service. The wharves inspected involved over $2,000,000$ square feet of reinforced concrete decks supported by more than 5000 reinforced concrete pillars. Evidence indicated that deck beams should be either very shallow or, preferably, avoided altogether in order to assure good performance of concrete wharves under severe marine environment (Gjorv, 1969). 
The many adverse effects of ice on concrete marine structures have been described (Peyton, 1968). These effects have been experienced at oil drilling platforms (Cloyd, 1969) and concrete piers in Alaska where it has been demonstrated that the magnitude of forces due to ice flows must be carefully provided for if the structures are to successfully meet operational requirements.

The Posey Tube, a two-lane subway nearly one mile long under the estuary between Alameda and Oakland, California, is another significant concrete maritime structure. Constructed in 1927, and in continual use to the present, it included 12 precast reinforced concrete tubes, each 203 feet long, which were fabricated at Hunter's Point near San Francisco and then floated across the Bay, sunk in place, and joined underwater (Horwege, 1929).

Precast reinforced concrete units for wharves exposed to seawater were used in constructing harbor facilities at Aberdeen, England and at Tanga, East Africa during the period 1908 to 1912 (Billig, 1955). These structures are probably the earliest examples of precasting methods necessitated by economic reasons (e. g., excessive cost of hauling raw materials to the construction site or shortage of skilled labor or both).

A more recent example of precast concrete is found in the San MateoHayward Bridge, constructed in 1928 and 1929, in San Francisco Bay. The total length, including approaches, is nearly $12 \mathrm{miles,}$ of which, 7 miles consists of the concrete trestle portion. The concrete deck slabs were precast on shore, barged to the site, and installed over precast piles. Within 8 years serious cracking was evident (Gewertz, 1958) and repairs were made intermittently until 1951, when the California State Highway Division purchased the bridge. Repairs have been continued to the present; portions previously restored have undergone more recent restoration. Extensive investigations of the structure indicate that rupture and spalling of the concrete were caused by the reinforcing steel suffering from corrosion promoted by the chemical action of sodium chloride and sea mist (Temper and Bright, 1958).

Many of the cast-in-situ reinforced concrete structures built during the early decades of the 20th century now appear rather ponderous when compared with currently built structures which are comprised of slender precast members made of higher strength concrete.

During 1946 and 1947, a 3800 feet long by 26 feet wide causeway and a 3500 feet long by 120 feet wide wharf, both of reinforced concrete, were constructed in San Francisco Bay at Richmond (Gerwick, 1948). Precast deck slabs and precast piles were transported to the site by barge. Pile caps were cast in place using precast concrete forms designed to slip over the precast piles. This construction job typified most of the principles of precast concrete for maritime use. The central casting yard, suitably located relative to transportation facilities, was: leve1, yet drained readily; (b) did not settle under extremely heavy loads; (c) equipped with slabs for precasting operations; (d) had facilities for unloading and installing reinforcing steel, moving the forms, placing freshly mixed concrete, lifting and storing completed 
units, and loading complete units for shipment to the construction site. Barges were used for transporting the precast members to the site because this was most economical. Equipment for driving the piles and for setting the structural members had to accomodate 25-ton loads with precision and speed. All personnel were well-experienced in fast and accurate contructional procedures required in meeting the schedules of erection. Each precast deck slab was 20 feet long by nearly 7 feet wide and weighed 13 tons. The precast piles were 1.5 by 1.5 feet in cross-section and lengths were as great as 115 feet.

Several years later, during the period 1953 to 1955, hollow precast concrete units about 12 feet high were used in constructing the piers for the Richmond-San Rafael Bridge in San Francisco Bay (Gerwick, 1954). The 47 precast units, which were pairs of hollow truncated cones in configuration and named "2-bel1" or "4-bel1" units, had walls 8 inches thick. Each 130-ton unit was lowered underwater to rest on previously placed precast concrete grids and filled with tremie concrete. The cost of the substructure for the $4 \mathrm{mile}$ long bridge was $\$ 14,234,000$. During 1956 and 1957 the Eisenhower Lock and the Sne11 Lock were built on the St. Lawrence Seaway. These concrete structures began operating in 1958 and in the subsequent 10 year accomodated nearly $50,000,000$ tons of shipping which involved over 7000 lockages at each lock. Winter weather is severe and long; mean minimum air temperature is $7^{\circ} \mathrm{F}$ and termperatures as $10 \mathrm{w}$ as $-44^{\circ} \mathrm{F}$ have been experienced. Deterioration of concrete in the Eisenhower Lock first appeared in 1962 and has been undergoing distress to the present (Waugh, 1969). The nearby Snell Lock, built under similar specifications, remains sound. It is believed that water forced into all voids in the concrete by successive filling and emptying, followed by freezing while dewatered during winter, is the primary cause of trouble. As late as 1968 cracking was being corrected by post-tensioning of steel tendons anchored in the good concrete of each 44-foot monolith and replacing al1 deteriorated concrete with new concrete. The history of this structure is an example of the combined effects of stresses caused by contraction of concrete due to thermal decrease, differential shrinkage due to moisture changes, and tension due to live loads.

The most recent precast concrete work of major magnitude, and probably the most significant in the category of fixed maritime concrete structures, began in 1966 when the first of 57 tube sections was fabricated for use in the San Francisco Bay Area Rapid Transit System (BART). The precast tube sections (See Figure 2.1) vary in length between 273 and 367 feet; 36 are straight, 19 have either horizontal or vertical miters, and two have both types of miter. Mitered tube sections allow for vertical and horizontal curves in the nearly 4 mile long underwater tube alignment. Each section is 24 feet high and 47 feet wide, and in cross-section resembles the outer end of binoculars; each hole, which serves to accommodate a one-way track, is 17 feet in diameter (Murphy \& Tanner, 1966). The installation of the last tube section was completed 
early in 1970. Each tube section consists of a 3/8-inch thick stee 1 she11, the interior of which is covered with a 27-inch thick 1 ining of reinforced concrete. Each steel shell is stiffened transversely by 8-inch structural steel tees spaced at 6 -foot centers. The steel shells were fabricated at South San Francisco on shipways, launched, and towed to a nearby wharf for concreting while afloat. Concrete placement sequence was in four stages so as to keep each tube section trim in the seawater and avoid high stresses in the shell. The first stage was the floor; second, the straight central wal1; third, the curved side walls; and fourth, the crown. Unit weight of the concrete was critical; at 145 pcf the complete tube section would float satisfactorily, but at 150 pcf it would sink (Western Construction, 1967). After being concreted, the weight of a tube section ranged between 9,000 and 9,500 tons; these weights were a few hundred tons less than needed for sinking. A decrease of $1 \%$ in density of seawater would affect the buoyancy as much as 100 tons for a structure of this displacement. The typical tube section contained 4,200 cubic yards of concrete which had been transferred from the transit mixers by means of 10 -cubic yard buckets operated by gantry cranes. $*$ The cranes, which were 70 feet high and equipped with 100-foot booms, moved along a 15foot gage track. Each completed tube section was equipped with temporary water tight bulkheads. After a section was lowered about 130 feet into a trench on the floor of the Bay and coupled to the preceding section, the seawater trapped between the adjoining bulkheads was pumped out. Removal of the water in the joint between two sections created sufficient hydrostatic pressure at the outboard end of the lowered section to cause the joint gasket to compress longitudinally and form a water tight seal.

Since 1946 there has been an extensive application of prestressing and post-tensioning techniques in the area of concrete structures. Included are pipes, piles, long-span beams and slabs, bridges, piers, walls, roofs, and offshore platforms; additionally, there are many miscellaneous items (e. g., electric light poles and railroad ties). Modern methods of fabricating precast prestressed concrete structural members have assured the production of much larger units than would otherwise have been possible; prestressed pavements, aircraft runways, tanks, tunnels, folded plate roofs, and thin shell structures are examples. Nevertheless, prestressed concrete is a material requiring specialized knowledge. The structural design must be entrusted to a specialist in this area of structural engineering, the production of precast units requires unusually high standards of workmanship, and the assembly and erection necessitates considerably more technical detail than is the case with conventional reinforced concrete.

The largest group of marine structures consisting of prestressed concrete are wharves (Gerwick, 1959).

*/

Information on concrete production for BART is contained in Part Four of this report. 


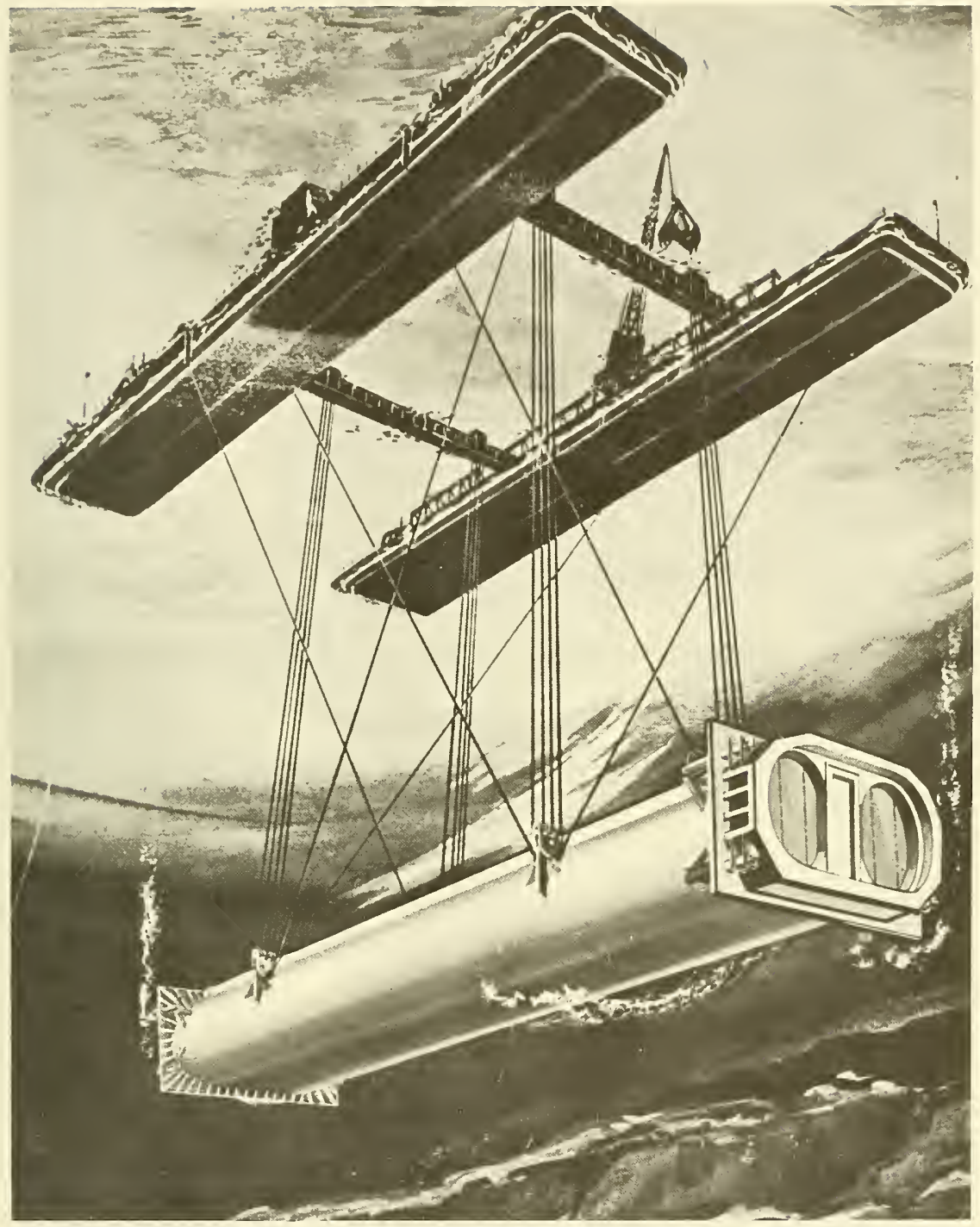

Figure 2.1. Schematic of a BART section emplacement. 
An example of precast prestressed concrete construction in a marine environment is found in the oil-storage platform situated 35 miles offshore in the Gulf of Mexico. The platform supports two 5,000bbl tanks on a prestressed piles some of which are 192 feet long (Bruce, 1956). This structure is situated in 37-foot-deep seawater and rises 41 feet above mean high tide level. It is designed to withstand a hurricane load of 62 psf and 36-foot high waves. The piles having an outside diameter of 54 inches and a wall thickness of 4 inches, are braced horizontally and diagonally by steel pipe. The sections composing the platform deck are prestressed concrete slabs 48 feet long and nearly 17 feet wide.

Another example of a prestressed concrete platform, 254 by 136 feet in area and supported by 192-foot long precast prestressed concrete piles, is situated 28 miles offshore in the 81 -feet-deep water of Lake Maracaibo in Venezuela. The structure was erected in conjunction with an offshore natural gas conservation plant. The centrifugally spun piles are hollow, 3 feet in diameter, wall thickness 5 inches, and each prestressed by 12 cables in addition to longitudinal and spiral reinforcement ( $0^{\prime}$ Connor, 1964).

In 1968 the Federation Internationale de la Precontrainte's Commission on Durability authorized a survey of the performance of prestressed concrete structures in America, Canada, Guam, Australia, New Zealand, Japan, Republic of China, India, and Ceylon (Szilard, 1969). Among eight categories of structures was the category "Wharves, Piers, and Quays." In a total of 103 of these maritime facilities, representing those in America (72), Canada (1), Austrialia (10), and New Zealand (2), only one structure showed evidence of damage. In the category "Bridges", in America the most serious case of damage to prestressing tendons (caused by corrosion) was found in the Lake Washington floating bridge. The survey revealed that instances of distress or failures were very few. The report indicates that distress is mostly the result of improper constructional techniques; it is also due to improper structural design, faulty materials, insufficiently detailed specifications, and insufficiently strict inspection and quality control of concrete.

\section{SIGNIFICANT FLOATING STRUCTURES}

The first floating structures made of portland cement mortar, the forerunner of today's ferro-cement type of construction, were the 10foot long reinforced mortar rowboats built in 1848 or 1849 by $\mathrm{J}$. L. Lambot on France (Cassie, 1967 and Morgan, 1968). This patent, issued in 1856, describes how the mortar hull is reinforced with wire fabric and iron grid. More than a centruy later, one of the aforementioned boats was afloat (at age 118 years) in the freshwater pond on Lambot's estate; this boat is now on display in a French museum and a companion boat, 1 year younger, is boxed and in storage at Paris. 
Lambot's principles have been used by many boat builders. An early application is the small concrete scow which has been in continual use at the Amsterdam Zoo since 1887.

As accepted at present, ferro-cement construction was developed by the Italian structural engineer P. L. Nervi who in 1943 began building a series of surface craft constructed of ferro-cement (Nervi, 1956). Nervi's smallest boat, the 38 foot ketch Nennele, was built in 1948; she was still in sound condition in 1968 although the hull is only $1 / 2$ inch thick and reinforced by seven layers of wire fabric and one layer of $1 / 4$ inch round longitudinal reinforcing bars spaced 2 inches apart. After 5 years of extensive use in seawater, there was no evidence of leakage and no maintenance was required; information concerning subsequent performance is unavailable.

In 1946 Nervi built his largest ferro-cement vessel, the Irene, which displaced 165 tons. Her hull was rearly 1-1/2 inches thick and reinforcement consisted of three layers of $1 / 4$ inches round steel bars at 4 inch centers and eight layers of wire fabric (four layers on each side of the bars) weighing $1 / 4$ pound square feet. After 8 years of sea service the vessel required no maintenance. Unfortunately she was wrecked on the rocky coast of Sardinia during a storm in 1959.

Since about 1960, ferro-cement surface craft have been produced in Great Britain, Canada, New Zealand, Australia, China, and South Africa. In America the emphasis so far has been on ferro-cement floating marinas; this trend may expand to include small boats in view of the popularity of the 18 foot ferro-cement outboard speedboats currently being produced and some of which were exhibited at the recent Western National Boat and Marine Show held at Anaheim, California. $*$ The People's Republic of China probably uses more ferro-cement boats than do all other nations combined; thousands are used as sampans, and are usually 30 feet long (Jackson and Sutherland, 1969).

It is unlikely that ferro-cement construction will ever be practical for floating vessels longer than 100 feet, but there is no doubt that such construction will prove beneficial in the area of fishing boats and pleasure craft.

Gabellini built numerous reinforced concrete vessels and pontoons in Italy during the last decade of the 19th century. Included among these were a flat-bottom barge ( 90 gross tons) used by the Italian Navy and the Liguria (150 gross tons) which plied between Rome and Geona (Freeman, 1918).

A concrete vesse1, known as the Gretchen, was built in America during 1892, but details are unavailable. About the beginning of the 20 th centruy two German firms began building reinforced concrete barges for commercial use; several of these vessels were of 200 gross tons each. During the period 1914 to 1918 many ocean-going concrete barges were produced in Great Britain. These vessesl were used for transporting armament to France; some were of 1000-gross ton size. By 1919 the Britons were using a 2500 ton concrete ship, the Armistice, which was

\footnotetext{
"Anon. (1970). "Cement Boat Display," Los Angeles Times, Section D, p. 10 (15 March).
} 
205 feet long, 32 feet wide, and nearly 20 feet high; from 1929 to about 1949 she operated between Liverpool, England and Lagos, Nigeria, after which period, the ship was stripped of all machinery and used as a floating warehouse. In 1969 the Armistice was scuttled at sea because her hull was badly spalled (Morgan, 1970).

From 1914 to 1918 a small number of concrete ocean-going ships and barges were produced in France; each approximated 300 gross tons in size. During the years 1919 through 1921, the French built 15 concrete hulls of which 11 were designed by E. Freyssinet. The unit weight of concrete in these 180 foot long vessels was 140 pcf. Though heavier than steel ships, Freyssinet's ships utilized numerous strands of small diameter reinforcing steel so that the ratio of total deadweight to full load displacement was 0.61, which approached that of a steel ship of equal size.

The first large reinforced concrete ocean-roing ship produced in America was the Faith which was constructed at Redwood City, California in 1917. This vessel of 3,427 gross tons, hull thickness varying from 4 to 4-1/2 inches, was in operation from 1918 to 1921. Though the U. S. Shipping Board Emergency Fleet Corporation program called for constructing 38 concrete ships for World War I use, only 12 were built. Lengths ranged from 260 to 434 feet; beams, from 43 to 54 feet; and depths, from 26 to 36 feet. The hulls of these 12 ships (six of them were tankers) incorporated steel reinforcing bars ranging from $3 / 8$ to $1-3 / 8$ inch diameter. Hull thicknesses ranged from 4 to 6 inches. The average compressive strength of the concrete was 4,000 psi at age 28 days. The following tabulation, prepared for the U. S. Shipping Board;" shows the tonnage comparison among three types of hull:

\begin{tabular}{|c|c|c|c|}
\hline & Concrete & Wood & Steel \\
\hline $\mathrm{Hu} 11$ & 2,500 & 2,300 & 1,160 \\
\hline Fittings and Equipment & 191 & 191 & 180 \\
\hline Propelling Machinery & 206 & 206 & 200 \\
\hline Margin & 75 & 80 & 60 \\
\hline & 2,972 & 2,777 & 1,600 \\
\hline Reserve feed & 80 & 80 & 80 \\
\hline Ordnance & 23 & 23 & 23 \\
\hline Fue 1 & 300 & 300 & 300 \\
\hline Stores & 40 & 40 & 40 \\
\hline Cargo & 2,760 & 2,180 & 3,057 \\
\hline Total dead weight & 3,203 & 2,623 & 3,500 \\
\hline Full load displacement & 6,175 & 5,400 & 5,100 \\
\hline $\begin{array}{l}\text { Ratio of total dead weight } \\
\text { to full load displacement }\end{array}$ & 0.52 & 0.48 & 0.69 \\
\hline
\end{tabular}


Crushed lightweight (expanded clay) aggregate was utilized in the 120 pcf concrete of 11 of these 12 ships (Boyd, et. al., 1921). It is apropos to note that drill cores extracted about 1953 from the hull of the wrecked Selma, constructed of this lightweight concrete, revealed no corrosion of reinforcing steel after 35 years of exposure to seawater (Mather, 1969). In addition to the 12 concrete ships actually built in America during World War I, a total of 32 concrete barges (ranging from 500 to 1200 gross tons) were also built; 21 were used on the Erie Canal and Hudson River and 11 were used at New York Harbor. Most of these barges were too easily damaged by blows that would not have been severe enough to impair the serviceability of either wooden or steel vessels. Moreover, also constructed at that time were three 100 foot tankers and five lighters (each 500 gross tons). The greatest shortcoming of these various concrete ships and barges was the extreme brittleness of the concrete. The record of performance indicated some doubts that reinforced concrete ships and barges would ever become commercially popular. Despite such negative attitudes, the consensus regarding general characteristics disclosed that concrete ships served their intended purpose in World War I. In passing, it is of interest to note that concrete ship construction is more economical along the Pacific coast than elsewhere in the continental U. S. because of equable climate. The history of the American concrete ships has been described (Haviland, 1962) and summarized previously (Jackson and Suther1and, 1969).

In Great Britain, during 1943 and 1944, the construction of enormous concrete floating caissons known as "Phoenixes" ( a military code name) was accomplished as part of the invasion harbors known as "Mulberries" which were installed, after being towed across the English Channel, along the coast of Normandy. Mulberry A (the American harbor) was located off Omaha Beach; and Mulberry B (the British harbor), off Utah Beach. These 146 caissons were constructed as precast concrete units which necessitated 330,000 cubic yards of concrete and 31,000 tons of reinforcing stee 1 , and involved $1,500,000$ square yards of forms. The labor force approximated 20,000 men (Billig, 1955). The units ranged from 176 to 204 feet in length and were as high as 60 feet (Stanford, 1951). Other published data (Wood, 1948) indicated the use of 410,000 cubic yards of concrete for Phoneix units and an additional 132,000 cubic yards for supplementary caissons. The bridge-carrying precast concrete pontoons, known as "Beetles", were 50 feet long by 22 feet wide by 9 feet high (hull proper). For the Phoenix concrete, the aggregate/cement ratio was 4.5 , maximum size of crushed stone aggregate was $3 / 4$ inches and the designed compressive strength was 850 psi. For the Beetle concrete, maximum size of aggregate was $3 / 8$ inches and the designed compressive strength was $1500 \mathrm{psi}$. The intended 1 ife of these units was 90 days.

Meanwhile, America was constructing ships and barges as part of the U. S. Maritime Commission program that was underway in 1942 . These vessels were built at five concrete shipyards, namely, Savannah, 
Houston, Tampa, San Francisco, and National City, adjacent to San Diego (Tuthil1, 1945). During the period 1942 and 1945 a total of 104 concrete hulls were built; 24 of these were for self-propelled dry cargo ships (McLaughlin, 1944) each 350 feet long by 54 feet wide by 35 feet high; the remainder were for barges (Engineering News-Record, 1943) or lighters which were designed for towing and which ranged from 265 to 366 feet in length, 48 to 56 feet in width, and 18 to 38 feet in height. The concrete in all of these vessels incorporated lightweight aggregate (maximum size $1 / 2$ inch) modified portland cement (ASTM Type II), and in some cases a set-retarding admixture. Average slumps were seldom over 4 inches. Cement factor was 9 bags in most cases. Minimum compressive strength required at age 28 days was 5,000 psi. The average water/cement ratio ranged between 0.45 and 0.50 (by weight). Hull thickness of the concrete vessels was $6-1 / 2$ inches.

Among the 80 ship-shaped concrete barges, 26 were built at the Delair shipyard of Barret $\&$ Hilp, contractors, at San Francisco Bay under contract for the U. S. Maritime Commission. The first of these 366-foot barges was floated in its graving dock in June 1943. The barges were designed for loads of 2,368 pounds per square feet of ship bottom and 416 pounds per square feet of deck. The superstructure was designed so that vertical bulkheads would resist horizontal forces, due to waves arriving aft on the deck, as high as 950 pounds per square feet. Reinforcement was heaviest in the midsection where steel amounted to 35 pounds per cubic feet of concrete. Reinforcing bars were positioned carefully to specified clearances which, at certain locations, were within $1 / 2$ inch of the concrete surface. The bottom was 7 inches thick and the sides 6 inches thick. Each longitudinal reinforcing bar was welded into one piece 366 feet long, dragged into the formwork, and laid in proper position. Unit weight of freshly mixed concrete was 126 pounds per cubic feet initially, but was later reduced to 116 pounds per cubic feet. Wooden forms for the hulls were erected in 6 graving docks. The completed concrete hulls were floated into the Bay by flooding the graving docks.

Early in the U. S. Maritime Commission's concrete shipbuilding program, an investigation of concrete vessels built previously during World War I revealed that reinforcing steel rarely corroded or became exposed due to spalling wherever the concrete cover over steel was greated than $3 / 8$ inch.

In addition to the U. S. Maritime Commission's program during World War II, the Bureau of Yards and Docks in 1943 undertook the construction of 13 auxiliary reinforced concrete floating repair docks (ARDC), each of 2800 ton capacity (Anon., 1947). These were 389 feet long, 84 feet wide, and had an overal height of 40 feet which included 14 feet high bottom pontoons (compartmental); the 26 feet high wing walls tapered from 14 feet at the base to 10 feet at the top deck. Eight of these were built at Wilmington, North Carolina and five at San Pedro, California in dry basins. Each required 3300 cubic yards of concrete which was designed to have a 28 day compressive strength of 4000 psi, obtained 
by using a cement factor of over 8 bags per dubic yards and a water/ cement ration of 5 gallons per bag. Five of these 13 floating repair docks* were towed to advanced bases in the Pacific Ocean area. A11 proved water tight and required no maintenance during the war. The use of concrete for these ARDC's was based on the successful earlier performance of 400-ton capacity floating concrete docks, designed by the Bureau, for use in repairing small patrol craft.

Another concrete vessel designed at BuDocks, and constructed early in 1944, was the prototype of the concrete LCT (Landing Craft Tank). The overall dimensions and capacity were identical to the steel LCT's in use at that time. The prototype was 112 feet long, 32 feet wide, and weighed 224 tons (in air). The construction involved precast slabs, precast cells, shotcrete, and cast-in-place concrete (MacLeay, 1950). The cells were 4 by 7 by 5 feet in size and had wall thicknesses of $3 / 4$ inch (for the 4 foot sides) and 1-1/2 inches (for the 7 foot sides). Reinforcement was wire fabric. Compressive strength of the concrete in the cells was $8500 \mathrm{psi}$ at age 28 days; aggregate/cement ratio of the rather stiff mixture was about 2.5 for the cells and for the slabs which were $1-1 / 4$ inches thick and also reinforced by wire fabric. The completed prototype was tested for 6 weeks, during which the vessel outrode a hurricane and underwent full-speed landings on gravelly beaches, without damage to the concrete. The cost of such concrete LCT's was deemed comparable to that of steel LCT's built under wartime conditions, but apparently the USN need for such landing craft diminished the following year, and no production was initiated.

A11 of the concrete vessels constructed in America, Great Britain, and Europe during both World Wars I and II have been estimated to represent a total displacement of 500,000 tons (Jackson and Sutherland, 1969). These ocean going concrete ships and barges were structurally sound. Nevertheless, further development was apparently undesirable because conventionally reinforced thick concrete hulls are heavier than comparatively thin steel hulls. Assuming no shortage of steel plate in peacetime, the greater motive power requirements of a concrete ship preclude the comparatively economic operation that prevails among steel ships. This weight disadvantage might be overcome by resorting to prestressed concrete hulls, but such possible trend has not yet appeared among the steel-oriented ship designers.

The experienced gained in building concrete hulls during World War II subsequent1y led to improved methods of fabricating floating concrete platforms. A post-war example is the landing stage built in 1952 at Hamburg, Germany (Minetti, 1956). It consists of five compartmentalized reinforced concrete pontoons, each 390 feet long by 60 feet wide by 13 feet high, having wall 10 inches thick (Billig, 1960).

A floating highway, nearly $1-1 / 2$ mile long, and known as the Hood Canal Bridge crosses a portion of Puget Sound about 35 miles north of Seattle. The structure, completed in 1960, consists of 23 floating reinforced concrete pontoon bolted together (Andrew, 1959). Water depths at mean low tide range from 70 to 340 feet, tidal range is 18

\footnotetext{
* Designated ARDC during the war and in 1946 redesignated ARDL(C) which denotes Auxiliary Repair Drydock Little (Concrete).
} 
feet, and maximum observed tidal velocity is nearly 3 knots; when wind velocities reach 92 knots (the observed extreme) the choppy waters involve 5 feet high wave at 35 -foot wave lengths. The roadway is 20 feet above the waterline, or 14 feet above the pontoon decks, to protect automotive vehicles from seawater spray. Each concrete pontoon is 50 feet wide, divided into cells 15 feet long and 12 feet wide; pontoon lengths range up to 360 feet; bottoms and sides are 9 inches thick, decks are 7 inches thick and the walls of the interior cells are 6 inches thick. The draft of the typical pontoon is nearly 9 feet. Adjacent pontoons are joined by bolts spaced at 15-inch centers around the perimeters of the pontoons. The bolts pass through heavy concrete beams that are integral with the top and bottom slabs and the side walls of the pontoons. Two continuous floating structures were thus created, each being attached to a 600-foot draw span which is situated near the middle of the floating bridge in order to accommodate passage of aircraft carriers. The floating highway is anchored by means of wire cables that extend from the pontoons to concrete-filled anchorage blocks previously placed underwater; there are 42 of these gravity anchorages, each of which has a submerged weight of 550 tons. The pontoons were precast in a graving dock. Each pontoon was post-tensioned before the deck was cast; the tendons, composed of eight $3 / 8$ inch diameter strands of seven wires each, 1 ie in the bottom slab (at 2-foot centers) and in the lower portions of the walls (interior and exterior). The cost of construction was $\$ 20,000,000$ and required three years to complete; the pontoon work represented $\$ 14,000,000$. A severe storm early in 1960 , when ten of the 23 pontoons had been joined, damaged the joints between adjacent pontoons and cracked the decks and bottom slabs of seven pontoons (Engineering News-Record, 1961). Repairs and modifications during 1961 cost an additional $\$ 3,500,000$. The modified design involved joining the pontoons with bolts supplemented by epoxy resin bonds, and posttensioning the assembly (Nichols, 1964).

Also of interest, although never built, is the floating tunnel proposed 19 years ago to accommodate automotive traffic across Puget Sound. The nearly 14,000-foot long underwater concrete tube was designed to have a buoyancy nearly three times the maximum live load, to be situated 50 feet beneath the surface so as to not obstruct oceangoing ships, and to be anchored to the 800 foot deep floor of Puget Sound. The tube was to consist of 34 precast sections, each 400 feet long by 60 feet wide by 30 feet high. The cross-section was to be similar to the outer end of binoculars, a configuration adopted for the BART twin-tube described previously. Precasting was to be done in a graving dock, necessitating 400,000 cubic yards of concrete. The estimated cost of this floating concrete structure was about $\$ 55,000,000$ based on 1949 price levels (Andrew, 1951).

Hollow concrete pontoons have been used for marinas since the early 1960 's (Sellner, 1964). Customary sizes of the modular units range from 6 feet long by 3 feet wide by 1 foot high to 8 by $2-1 / 2$ feet; in this range the wall thickness varies from $1-1 / 2$ to 2 inches (Noble, 1964). 
More recent units are 30 feet long by 8 feet wide by nearly 3 feet high and have walls 3 inches thick. Though pontoons of normal weight concrete (145 pcf) possess the advantage of inertia, lightweight concrete (50 to 115 pcf) has been used. Compressive strengths range from 2,000 to 6,000 psi at age 28 days.

Apart from structures ashore, prestressed concrete is a promising material for use in pontoons and flat-bottom barges. Ferro-cementconstructed vessels, described previously, are generally thin curved hulls although a few prestressed ferro-cement flat-bottom hulls have been built in England and New Zealand. Prestressed concrete flat-bottom barges, prestressed as well as conventional, are known to have been built in the Philippines, China, and the Soviet Union. Prestressed concrete barges used in the Philippine Islands are 200 feet long by 55 feet wide by 14 feet high.

Twenty years ago Freyssinet (1950) stated, "A11 methods of assembly by prestress of units, whether themselves prestressed or not, into larger structures can be used for the assembly of floating units of dimensions dependent upon the available means of floatation. By further prestress it is simple to link such assemblies together once they are floating, thus enabling the building up of structures whose dimensions are independent of the means of floatation. This method is applicable to any floating works: docks, ships, quays, and breakwaters, whether floating or fixed; floating platforms monolithic over very large areas; power-stations utilizing energy derived from the sea (thermal, potential, or dynamic); as wel1 as floating structures with or without hollow interiors later anchored to the ground (locks, docks, etc.)."

Recently a British firm of consulting engineers prepared a report for Shell United Kingdom Ltd relative to concrete seadromes at London, New York, Chicago, Los Angeles, Tokyo, and Caracas in Venezuela (Civil Engineering and Public Works Review, 1970). They are proposing a floating cellular prestressed post-tensioned concrete raft to provide an aircraft runway length of 14,000 feet for acconmodating jumbo jet aircraft. The structure is designed to withstand aircraft exerting a take-off load of $1,000,000$ pounds. Precase prestressed concrete cells, each $100 \times 100$ $\mathrm{x} 31 / 2$ feet in size and filled with expanded polystyrene, would be floated into position and joined together by post-tensioning laterally and longitudinally. Protection against waves would be provided by a floating breakwater. More recently, another floating airport (FLAIR) concept of precast, prestressed concrete has been suggested (Weidlinger, 1970). Obviously, these concepts reflect the structures foreseen by Freyssinet 20 years ago.

\section{FRESHWATER STRUCTURES}

Notable exceptions, $i$. e., structures not in a marine enviornment per se, include Lake Pontchartrain Bridge (fixed) and the two Lake Washington Causeways (floating). 
The largest application of precast, pretensioned concrete construction in the world is exemplified by the twin-span Greater New Orleans causeway which extends north from metropolitan New Orleans for 24 miles across freshwater Lake Ponchartrain. This structure is the longest highway bridge in the world (Palmer, 1957). The first span was begun in 1955 and completed in 1956, at a cost of $\$ 30,000,000$ using a simplified design and assembly-line methods for fabricating the precast pretensioned parts of the bridge. The second and parallel span was opened in 1969. Except for two bascule spans and three humps for passage of water-borne traffic, there are no vertial or horizontal curves throughout its entire length. The following facts pertain to the first of the two spans (VanBuren, 1957). Production facilities for the bridge decks involved three pretensioning benches each of which was 490 feet long by 43 feet wide and capable of producing a line of eight bridge sections at one time. By casting sections on one of the three benches everyday, a daily production schedule of eight slabs or 448 feet of bridge deck was established. Nearly 5,000 hollow, centrifugally cast, prestressed, steam-cured cylindrical piles were made. Each pile has a wall thickness of 4 inches, an outside diameter of 54 inches, and average length of 88 feet. The bridge consists of 2,215 identical bents each of which compromises four precast elements; specifically, two piles each weighing 30 tons, one cap weighing 30 tons, and one prestressed slab weighing 185 tons. Each slab is 56 feet long by 33 feet wide. Precast caps were possible because the piles were hollow; solid piles would have necessitated cast-in-place caps. The compressive strength of the concrete constituting the bridge deck slabs was 3,000 psi before prestressing wires were released at a 36-hour age. Al1 components were precast in a specially built yard. Erection reached a peak of $1 / 2$ mile per week.

A significant floating concrete structure erected between World Wars I and II is the Lake Washington Floating Bridge situated at Seattle and completed in 1940. The bridge includes 25 cellular flat-bottom reinforced concrete pontoons, each 59 feet wide and varying from 117 to 378 feet in length (Andrew, 1940). Outside walls and bottom slabs are 8 inches thick and inner compartmental wall are 6 inches thick. Drafts of the pontoons range from 7 to 14 feet. Two graving docks were constructed on the Puget Sound waterfront were a tidal range of 10 to 17 feet afforded suitable means of launching the units; they were towed to Lake Washington through the existent ship canal and locks. The bridge is located where the freshwater lake depth varies between 100 and 220 feet. The assembly of pontoons is stabilized by means of steel cables attached to anchors set in the floor of the lake. Ocean-going ships pass through a 200foot wide opening created whenever a special pontoon section is retracted longitudina11y. The water level in the lake fluctuates a maximum of 3 feet and is controlled by the locks. The pontoons are not subjected to freezing. Pontoons are connected by means of shear keys ( $3 \times 3 \times 1$ foot) which fit into recesses and the connections are supplemented by 54 bolts (3-1/4-inch diameter) distributed around the outer margins of adjacent pontoons (Andrew, 1941). Water content of the 6-inch-slump concrete was 
5.5 gallons per bag of cement, maximum size of gravel was $11 / 2$ inch, cement factor was 6 bags per cubic yard of concrete, and the 28-day compressive strength of the concrete was 3,500 psi. Each pontoon was fabricated in two pours; the first included al1 but the deck and the second the deck only.

In 1963 the second floating bridge on Lake Washington was opened to automotive traffic. It is 3 nautical miles from the first floating bridge. The biggest of the 35 prestressed concrete pontoons in the second bridge is 360 feet long, 60 feet wide, and 15 feet high. The weights (in air) of the pontoons range from 4,700 to 6,700 tons. 



\section{PART THREE - SYNTHES IS OF CONCEPTS}

by D. A. Davis

\section{DESCRIPTION OF CONCEPTS}

In the ensuing discussion, various platform concepts are described. In this initial phase of concept definition, a concerted effort is made to include a wide spectrum of ideas and approaches. Concepts which appear weak now may develop later into promising approaches to satisfy unique requirements. Pros and cons of the various concepts as well as operational and constructional deficiencies are discussed.

Candidates were classified according to their buoyancy elements into the three basic types defined below.

\begin{tabular}{|c|c|}
\hline Platform & Definition \\
\hline Elevated & $\begin{array}{l}\text { single or multi-story decks sup- } \\
\text { ported on vertical, hollow } \\
\text { buoyant legs (also called columns } \\
\text { or piles. }\end{array}$ \\
\hline Barge & $\begin{array}{l}\text { single or multi-story decks sup- } \\
\text { ported on barge-type hulls. }\end{array}$ \\
\hline Semi-Submersible & $\begin{array}{l}\text { single or multi-story decks sup- } \\
\text { ported on vertical legs atop } \\
\text { submerged horizontal pontoons. }\end{array}$ \\
\hline
\end{tabular}

Al1 suggested configurations not falling into one of the above definitions were grouped into a separate section.

\section{Elevated Platforms}

The most obvious feature of this concept (Figure 3.1) is the many various vertical buoyant elements possible for supporting the deck. De-coupling from the sea is achieved by reduction of the water plane area relative to the mass of the platform. This idea is not new. In 1924 Armstrong patented a concept for a floating airdrome that he envisioned as a refueling station for trans-Atlantic aircraft (Engineering News-Record, 1946). His platform, constructed of steel, resembled that depicted in Figure 3.1. 


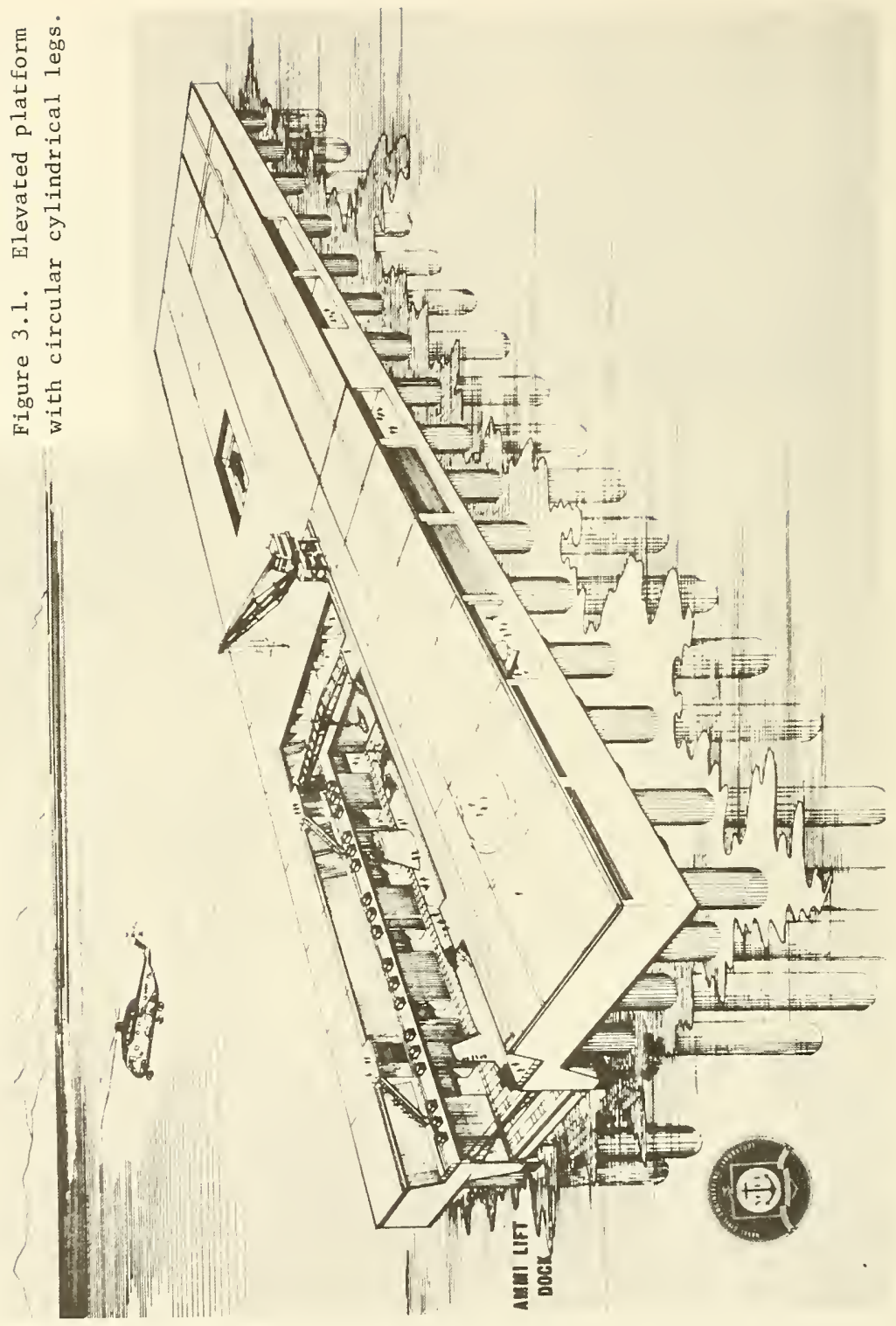


An elevated platform can be designed to have a minimum heave, pitch, and roll response for practically any sea condition. For a platform having cylindrical legs of constant diameter and length and uniform spacing in both plan dimensions, the natural heave period is:

$$
\mathrm{T}_{\mathrm{H}}=1.11 \sqrt{\mathrm{S}_{\mathrm{L}}}
$$

where $S_{L}$ is the wetted length of one of the legs. Thus, an elevated platform with a draft of 330-feet would have a natural heave period of 20 seconds, which insures that the platform will exhibit little heave motion in, say, a sea state 7 where the significant wave period is about 10 to 11 seconds.

Advantages. The advantages of a hydrodynamically stable elevated platform are manifold. Firstly, because of stability, aircraft takeoffs and landings are facilitated. This becomes an especially important consideration for handling large, heavily laden cargo aircraft, such as the $\mathrm{C}-130$, that are designed to operate from terrestrial air terminals.

Since elevated sections of modest plan dimensions are themselves stable, the assembly of much larger floating units from these sections will be a simpler procedure than will be the case with the dynamically less stable shallow-draft sections.

Assume a heavy-lift role for the $300 \times 300$ platform. The raising and lowering of large acoustic arrays or other heavy gear (weighing up to, say 400 - 600 tons) through a center-well is greatly simplified by elimination or reduction of dynamic loads induced by the oscillation of the platform. According to Davis and Wolfe (1969) this becomes an especially critical factor if cable is the suspension medium.

Habitation aboard the platform will be enhanced if it is hydrodynamically stable. The large platforms may require the presence of considerable number of support personnel, having little or no nautical experience, who may be susceptible to motion sickness. Certainly, life will be more pleasent for everyone aboard a stable platform.

Another advantage mentioned by proponents of elevated platforms, is the favorable station keeping properties of floating structures having minimal water plan and sail area. Pilot tests conducted in a wave tank tend to support the belief that an elevated platform with suitably shaped legs may actually remain stationary or advance into an incident train of regular waves. Additional tests are needed to support this finding, including tests with random seas which are more representative of actual sea conditions. It seems unlikely, however, that hydrodynamic form will ever be a suitable answer for some sea and wind conditions. For example, at locales were steady currents prevail, it will have no real effect. The platform will drift with the current. Steady winds of 20, 30 or more knots intensity can induce an appreciable thrust on floating structure having a large sail area. This latter effect suggests limiting the deck thickness and the diameter of the legs above the sea surface. 
The elevated platform could be designed so that damaged legs could be removed without recourse to dry-docking. Pumps could handle minor leaks which might develop from time-to-time, while water-tight compartments would isolate flooding due to localized failure in a leg.

Disadvantages. The principal disadvantage of an elevated platform is its inherent lack of static stability. A positive restoring moment can be assured only if enough ballast is added at the base of the legs (or if the length and breadth of the platform is increased, thereby increasing the water plane restoring moment). Depending on the platform size and the weight distribution of the structural and buoyant elements, the ballast can assume an appreciable percentage of the total weight.

Compared with the more conventional barge configurations, additional disadvantages of the elevated platform include (1) restriction to sites having a water depth greater than 300-400 feet because of the platform's large draft, and (2) high towing drag.

Candidate Leg Configurations. Figure 3.2 depicts five candidate leg configurations for a MOBS elevated platform. The simple geometry of the constant diameter circular cylindrical leg (a) lends itself to a variety of construction techniques including, for example, slip form casting and post tensioning of precast cylindrical segments. Cylinders could be capped with hemispherical end sections or left uncapped, the buoyancy of the latter would be adjusted by the addition or removal of compressed air. It has even been proposed that cylindrical legs be attached to deck sections by use of a gimbaled joint. Supposedly, this arrangement will result in, among other things, an elimination of moment transfer between the deck and the legs.

Legs (b) through (e) are typical examples of "bulbous" configurations. These legs are characterized by the following salient features (1) a low water plane area, which is desirable for minimizing the platform dynamic response, and (2) a bulbous shape which results in increased damping and induced added-mass, hence, a reduced platform response.

When used as buoyant support in a modestly dimensioned platform, say $300 \times 300$ feet in plan, any of the legs depicted in Figure 3.2 will require considerable ballasting if static stability is to be insured. Ballast in the form of dense concrete (addition of scap steel to the ballast mix), sand, scap iron or water could be used.

\section{Barge Platforms}

Advantages. Large concrete floating platforms have several inherent attributes which commend them for consideration in the MOBS program. It is apparent, for example, that there is a long and successful record established in the construction of ocean going concrete barges, ships and dry-docks. ${ }^{*}$ A $300 \times 300$-foot or even a $400 \times 1200$-foot barge platform is certainly not beyond today's state-of-the-art in floating concrete structures. 

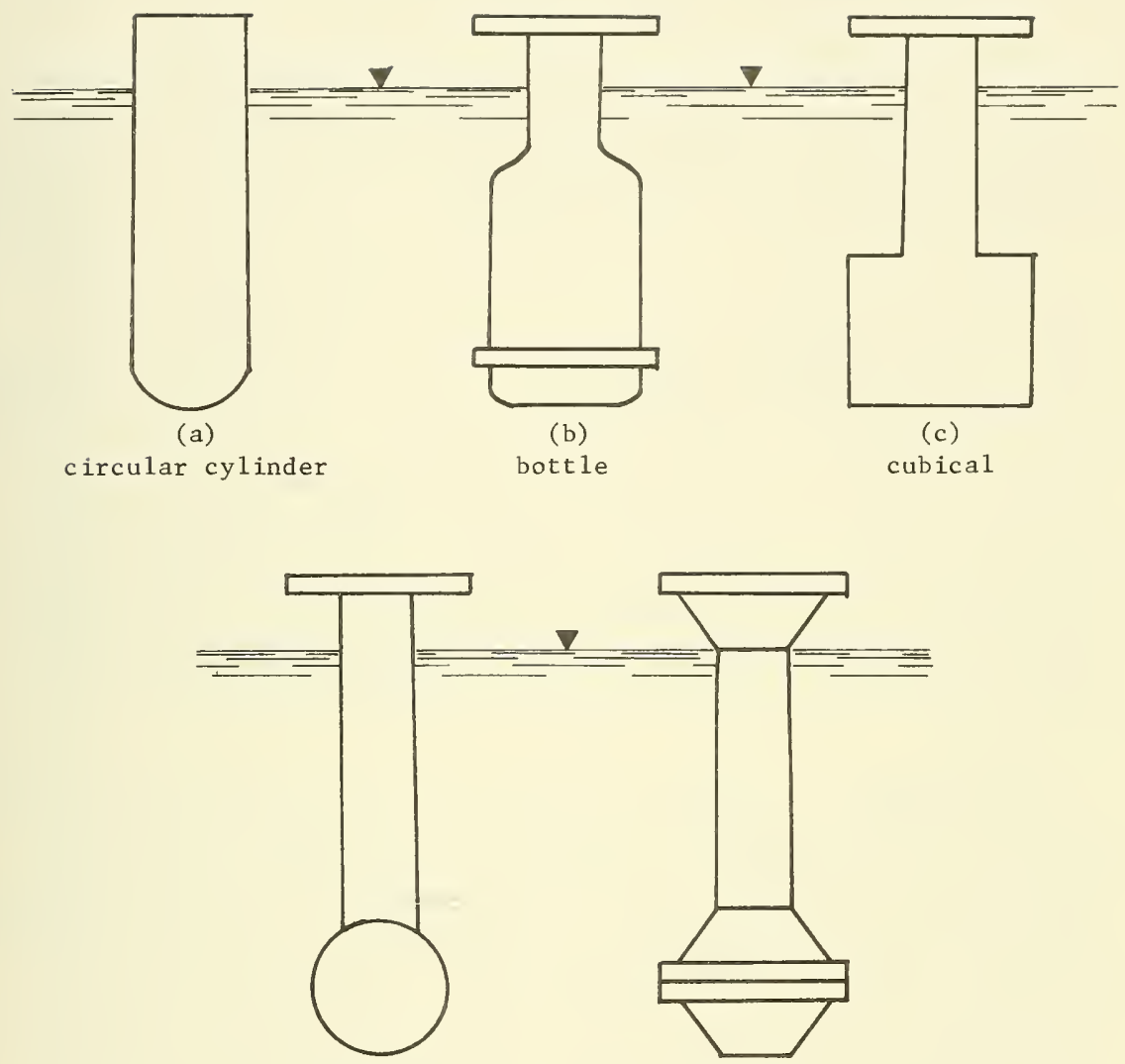

(d)

spherical

(e)

conical

Figure 3.2. Leg types proposed for MOBS elevated platform. 
A $300 \times 300$-foot barge MOBS can be constructed which has a considerable degree of positive static stability without the need of ballast, whereas the semi-submersible and elevated platforms must be ballasted to prevent capsizing.

The barge platform hull can be used for storing and housing personnel and equipment, including power plants and propulsion systems. The shallow draft of the barge, and the use of fairings fore and aft, will result in a comparatively low hydrodynamic drag. This becomes an important consideration if the platform must be moved rapidly, or for appreciable distances. The shallow draft will aiso allow operations at near-shore sites that are not possible with deeper draft configurations.

The barge may also be an effective breakwater. It has been demonstrated, both analytically and experimentally, that a large, floating slab is an effective wave attenuator. It has been reported (Bureau of Yards and Docks, 1963) that the transfer coefficient (ratio of transmitted wave height to incident wave height) for a rigid, floating slab, in deep water with zero draft, is about 0.2 for a ratio of slab length to incident wave length of 1.0 . Thus, by assuming that a flat bottom barge behaves as a rigid slab, a moored barge with plan dimensions of $1,200 \mathrm{x}$ 400 -feet could be expected to attenuate 1,200-foot by 400-foot long waves by $80 \%$, depending upon the alignment of the longitudinal axis of the barge. This is tantamount to a $96 \%$ reduction in the transmitted wave energy. One can conceive a sheltered area in the lee of the platform which could be used for docking all types of vessels, large and sma11. The relative motion between the barge-type platform and the vessels would be minimal and, as a result, cargo could be easily transfer red.

Disadvantages. Compared to a 300-foot x 300-foot elevated platform, a barge platform of the same size will tend to respond more readily to the seaway. Helicopters can tolerate some deck movement - operation from aircraft carriers are routine - and future VTOL aircraft may eventually achieve a similar tolerance to deck movement. It is questionable, therefore, whether the stability afforded by a semi-submersible or an elevated platform is really necessary for operations envolving these types of aircraft.

The barge platform is susceptible to two loading conditions which are of lesser importance for elevated and semi-submersible platforms. Firstly, hogging and sagging stresses must be considered due to the shallower height of the barge and greater water plane area. In all likelihood, the stresses induced by hogging and sagging can be accommodated by judicious use of longitudinal prestressed structural elements, especially at the barge mid-point.

Barge Configurations. Figure 3.3 illustrates three possible barge hulls. The first, the simplest configuration geometrically, is a flat sided, flat bottom hull having the distinction of offering the lowest draft to displacement ratio. Although catamaran and trimaran hulls will 
have a greater draft than a comparable flat hul1, they offer greater structural resistance to sagging and hogging stresses. In addition, the decreased water plane area of the twin and triple hull barges augers well for reducing the dynamic coupling between these barges and the seaway.

The barges depicted could be constructed as monoliths in dry docks (or in specially excavated shore sites), or assembled at sea from precast modules and/or sections (Part 5 discusses the construction alternatives). The modular approach could result in any one of the configurations shown in Figure 3.4 or the finished product shown in Figure 3.5 .

Semi-Submersible Platform

An early example of a semi-submersible platform was the steel structure designed (but never built) for use in Project MOHOLE. The MOHOLE platform was to consist of twin submersible hulls, measuring 350-feet in length, which were to support an elevated deck structure upon six large diameter, vertical cylinders. Today, there are many semibusmersibles serving the offshore oil industry as exploration, development and work platforms.

During tow (the platform could be self-propelled) the semi-submersible rides high out of the water in a shallow draft condition thus reducing hydrodynamic drag to a minimum. On station the platform is ballasted into a stable, deep-draft mode. Hydrodynamic stability on station results from (1) the relatively low water plane area of the vertical supports, (2) the large added-mass resulting from oscillation of the horizontal pontoons, and (3) fluid drag on the pontoons and connecting struts.

The semi-submersible shares some of the best features of the other two concepts. A properly designed semi-submersible has the dynamic stability of the elevated platform and the favorable drag characteristics of the barge. Conceivably, like the barge, a semi-submersible could be constructed with a propulsion system. It is difficult to imagine any type of elevated platform having this capability.

Figure 3.6 pictures a possible semi-submersible configuration. The platform has horizontal pontoons that support a multi-level deck. The vertical supports could be circular in cross-section as shown, or they could be streamlined for reducing the form and wave drag during tow or cruise. Several platforms like the one depicted could be joined to form large floating complexes.

If the ballast penalty for static stability is not considered excessive, if the design and assembly complexities involved in forming this type of platform from concrete can be resolved, and if a propulsion system is determined to be compatible with a submerged concrete hul1, then a semi-submersible platform can be considered a strong contender in the MOBS program. 

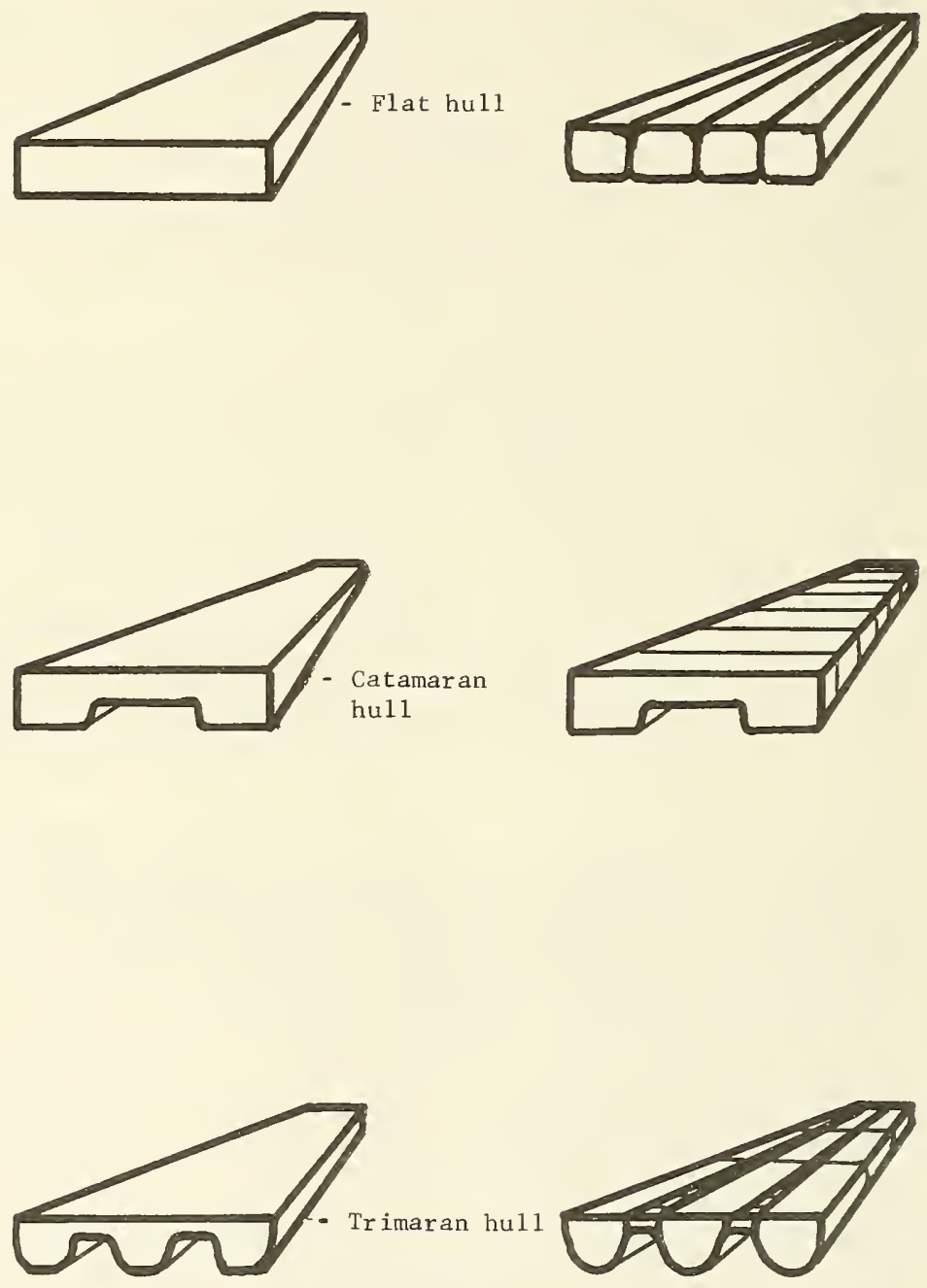

Figure 3.3. Alternative barge hulls.

Figure 3.4. Alternative modular barge hulls. 


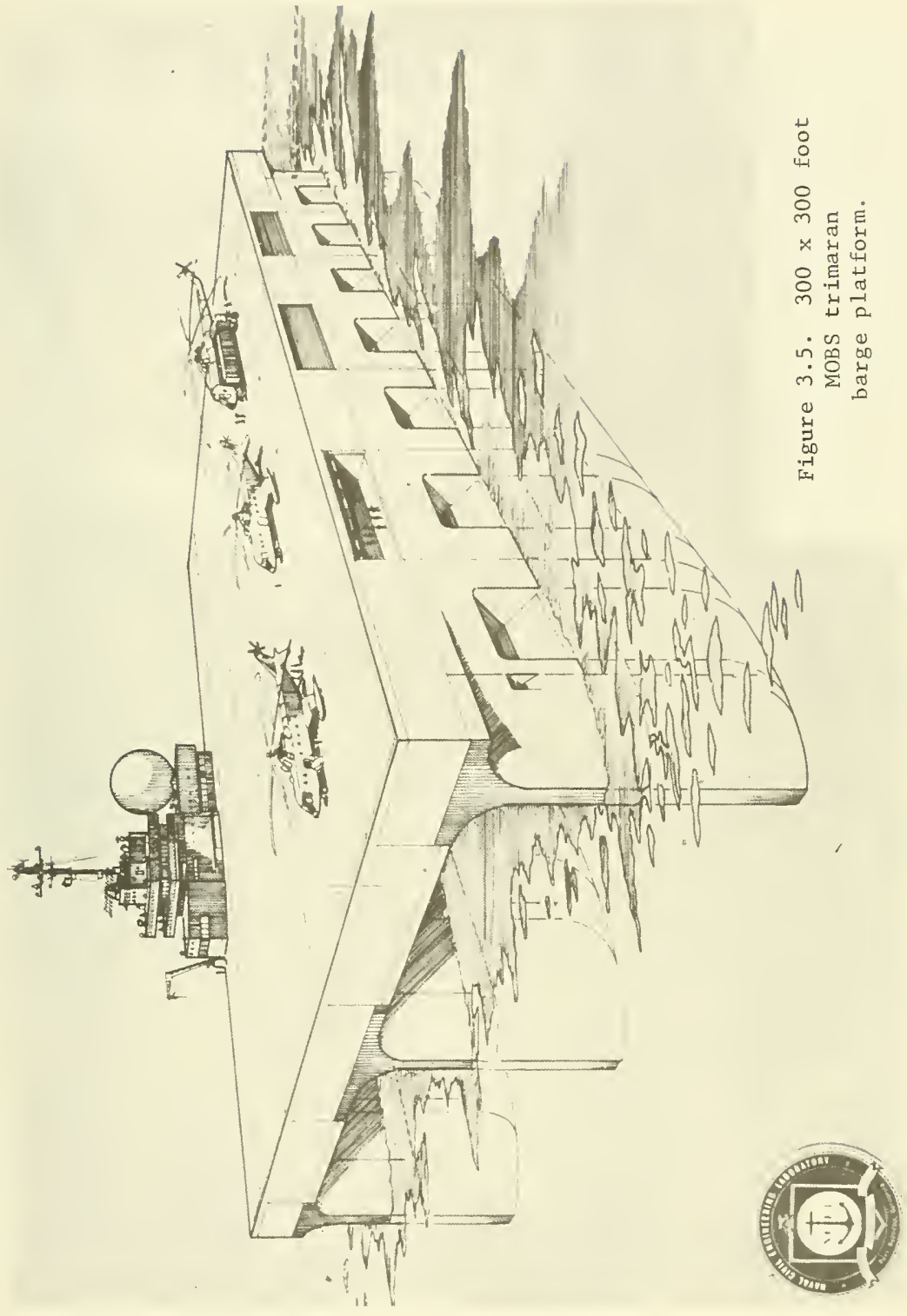




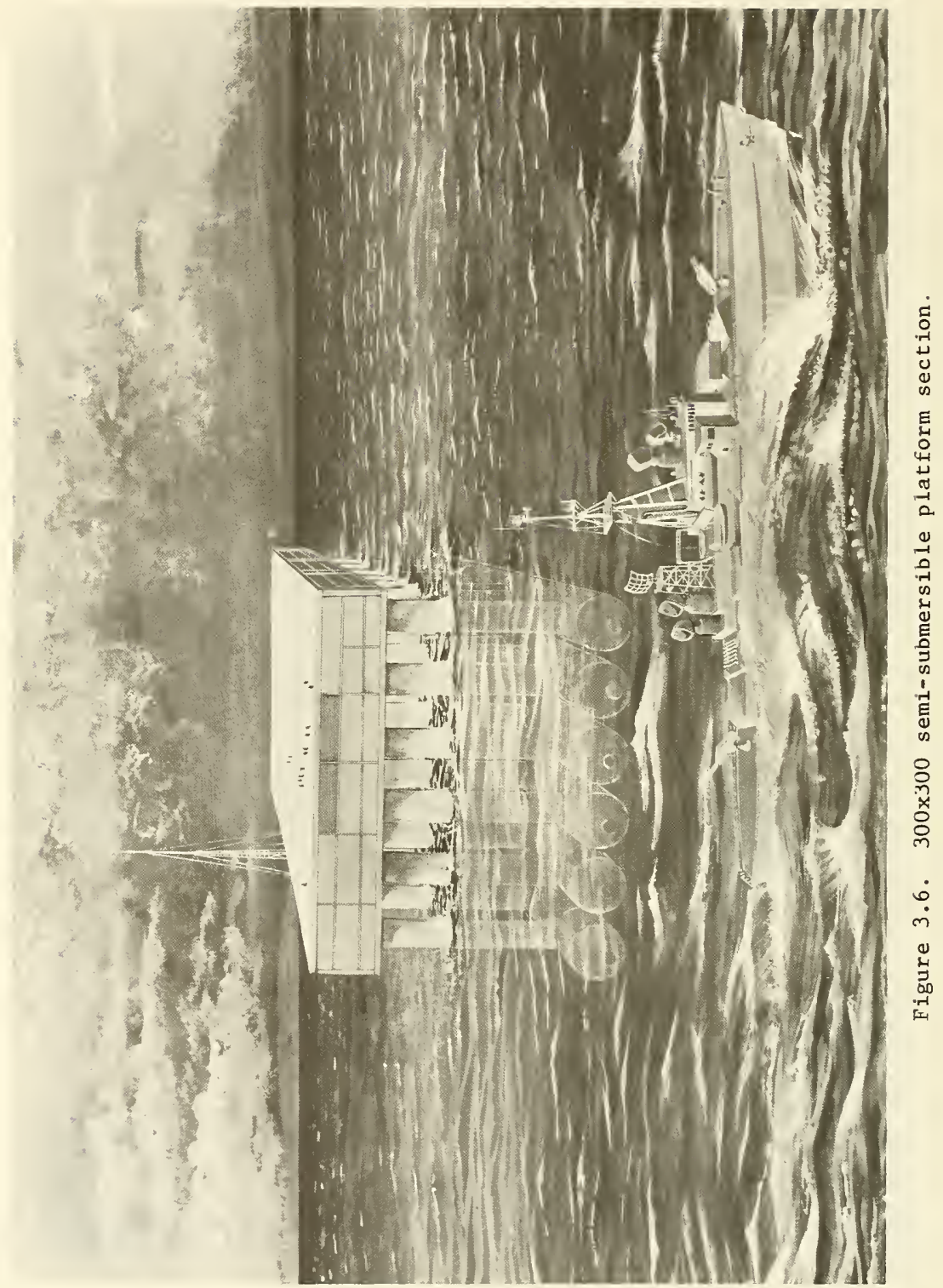


Other Concepts

Thin Slab. A thin floating concrete slab has some qualities which commend its consideration as a MOBS platform. Firstly, there is a considerable savings in materials as compared to deeper draft platforms. A typical slab platform might have a total section thickness of 10 feet or less. The slab would be composed of solid top and bottom panels, each on the order of inches of thickness, supported between by transverse and longitudinal interior bulkheads. The latter would form a cellular interior, the voids of which could be filled with low density foamed plastic to insure floatation in the event of a breach in the outer slab panels.

Full use would be made of pre-cast, prestressed panels in forming platform modules. The modules, formed in 100-foot $\times 100$-foot, 300-foot $x$ 300-foot or larger sections, could be constructed in a suitable dry dock, floated to the final assembly site and post-tensioned together to form a platform of practically any desired plan dimensions.

Lately, considerable interest has been expressed in using thin concrete floating slabs for constructing offshore airports. For example, Shel1 United Kingdom Limited (1969) commissioned a study on the use of floating concrete slabs for constructing a new airport for the city of London. They recommended that the runways, parking strips, terminals and hangers be supported on a floating reinforced concrete pavement, the interior cells of which would be filled with expaned polystyrene. A typical pavement section, 3 feet 4 inches thick overall, would consist of a "sandwich" of polystyrene between a 5-inch thick concrete top slab and a 3-inch bottom slab. Interior bulkheads would form cells approximately 6 feet square. Estimates are that a "seadrome" assembled from 100-foot $\times 100$-foot precast modules would support the loads imposed by the heaviest aircraft now operational or planned for the immediate future, up to and including the proposed commerical version of the C-5A military transport. Due to the runway's extremely low freeboard, the designers suggest using a floating breakwater and wave deflectors mounted around the runway perimeter to prevent washing of the flight deck.

In a study conducted at Rutgers University by the College of Engineering and the Center for Transportation Studies of the Eagleton Institute, a proposal was made for developing a floating V/STOL airport (Nawy, 1967). One possibility envisioned was a 1,000-foot diameter, 21-foot deep reinforced concrete, circular cylindrical platform having an interior deck for terminal facilities and aircraft storage. With a draft of 12feet, it is claimed that this platform could be employed in practically any water area such as rivers, lakes and tidal estuaries. The entire structure would be pre-cast in a basin and then towed to its permanent location.

As ecologic and aesthetic factors will undoubtedly play a more important role in the future planning of commerical airports; floating platforms such as the Shell and Rutgers concepts may yet prove to be more desirable alternatives to less costly terrestrial airports. There 
is a serious question, however, whether thin slabs are applicable to the MOBS mission requirements, which presumably will include the open sea. The low freeboard offers virtual1y no protection against deck washing, and it is extremely doubtful whether a floating breakwater can be developed which is effective in deep water against large ocean waves. The relatively low mass and large water plane area suggest that the thin slab will be closely coupled to the seaway and that platform motion, particularly heave, will be considerable.

Platform with Pre-Tensioned Mooring Lines. This concept is a variation of the semi-submersible platform. The platform (Figure 3.7) is first towed to the operational site in a shallow draft mode (to minimize drag resistance); then the anchor lines are deployed from each of the vertical buoyant support legs while water is added to the ballast tanks; and finally, the platform is emplaced with each gravity anchor resting on the seafloor. Hydrodynamic stability is due to several factors, the most important being:

1. low water plane area,

2. placement of the horizontal pontoons beneath the water surface where wave action is minimal, and

3. the anchor lines, which are always in tension, prevent vertical platform movement.

The platform depicted in Figure 3.7 is intended to serve as an oil exploration and development facility and, presumably, would be constructed from steel. There is no inherent reason, however, why concrete could not serve as the principle structural material. Recently, for example, Weidlinger (1970) described a composite steel/concrete floating airport which is anchored by taut mooring lines to the seafloor. Like the oil platform, most of the buoyant support is submerged to a depth sufficient to prevent excitation by the seaway.

The disadvantages of using this concept for MOBS are twofold: It would be difficult (and expensive) to deploy platforms in deep water, and (2) large platforms would require numerous anchors and mooring lines that will take time to emplace, as well as create a severe logistics burden. As a result, rapid re-deployment of the platform would be sacrified.

\section{CONCEPT OPTIMIZATION}

Crucial to any attempt at optimizing the base concepts for MOBS, viz. the elevated platform, semi-submersible platform and the barge platform, is a recognition of those parameters which characterize a candidate's performance. A complete listing of parameters would be long and an analysis of their effects time consuming and unwarranted due to the present uncertainty regarding the MOBS mission. Consequently, only a partial listing and discussion of the more important ones used in the preliminary design, will be attempted here. 


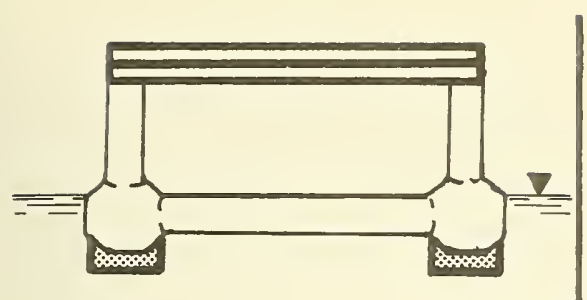

(A) Towing condition anchors retracted

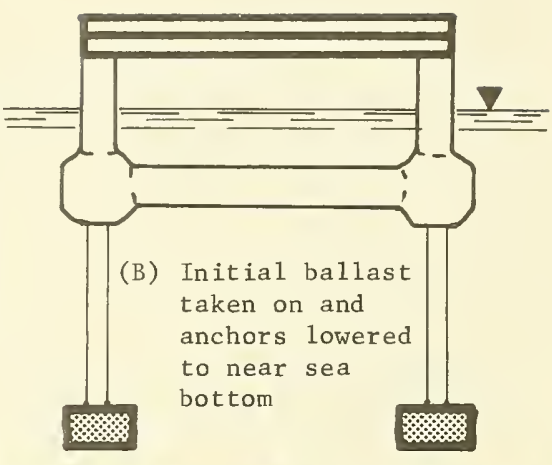

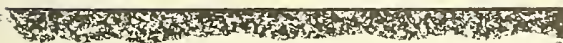

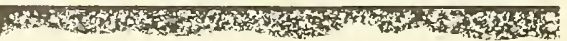

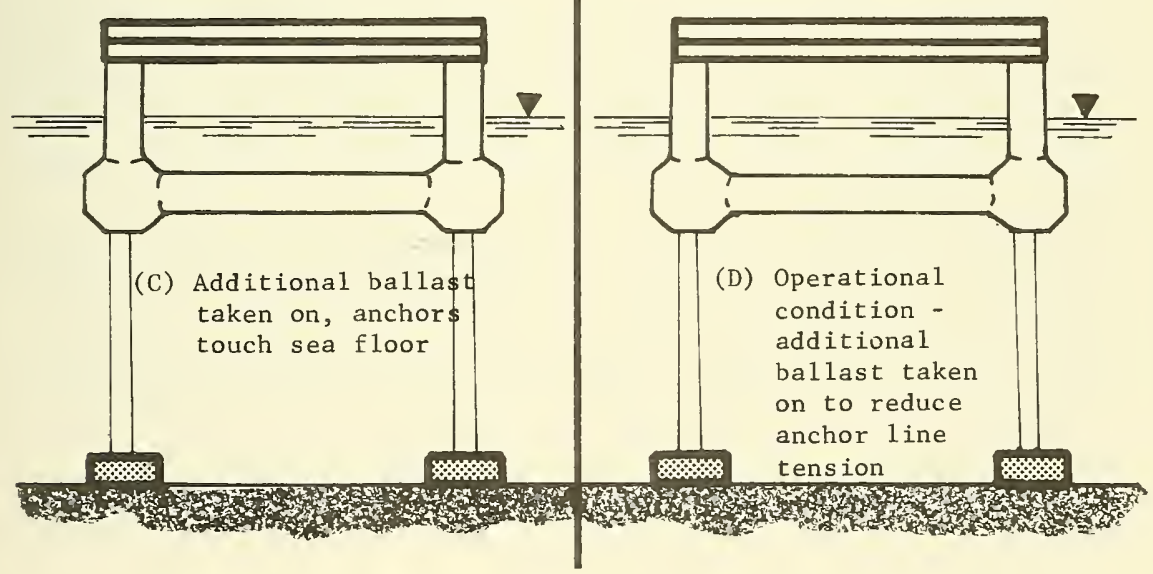

Figure 3.7. Tension leg platform anchoring sequence.

*Source: Corporate Brochure: Tension leg platforms for offshore petroleum operations. Deep 0il Technology Corporation. 
The following design/performance criteria are considered to be important for all elevated platform configurations:

Length of legs
Spacing of legs
Shape of legs
Static stability
Dynamic stability

Length of legs Spacing of legs

Static stability

Dynamic stability

\author{
Drag under tow \\ Total weight and distribution \\ of weight \\ Freeboard \\ Station keeping
}

Length of Legs. The length of the platform legs is an important consideration for several reasons. For example, lengthening circular, constant diameter legs results in an increase in the useable freeboard, an increase in the total mass of the platform and adversely affects the platform's static stability. If the legs are too long, the resulting draft will inhibit operations in shallow water, and the legs may be difficult to form, transport and attach to the platform. Obviously, by fixing the deck weight and freeboard and then lengthening the legs will result in reducing the number of legs required (i.e., increase the spacing) and/or reduce the required leg diameter (reduce the water plane area).

Spacing of Legs. This parameter is closely allied to the preceeding one. The relationship is especially obvious for platforms with uniform leg spacing in both deck plan dimensions. If, as before, the deck weight and freeboard are fixed, then increasing the spacing, i. e., reducing the total number of legs, must result in either longer legs or larger diameter legs (or both) in order to maintain buoyancy. The opposite is true if the spacing is decreased.

It may be desirable to reduce the total number of legs for several reasons. With fewer legs there will be less handling required during construction, although the legs will be correspondingly larger). Also it may be considered very desirable to include a center-well in some MOBS platforms for the purpose of raising and lowering heavy, outsized loads, e. g., acoustic arrays; and it will be necessary to insure that buoyant support members do not interfere with operations through the centerwell. If the leg spacing is large enough to allow, say, a fifty foot clearance between adjacent legs, it may be unnecessary to leave gaps in the spacing. A plausible argument can be made for including a lift-dock in MOBS and consideration must be given to the effect that this feature would have on leg spacing.

If the deck is envisioned as a single slab or a multi-level structure resting upon the vertical legs for support, then it is apparent that a large leg spacing will result in greater loading in the deck spans. Thus, increasing the leg spacing has the effect of requiring an increase in the deck thickness. The resulting increase in deck weight can only 
mean decreased static stability unless compensated for by additional ballast at the base of the legs.

Shape of Legs. The legs can assume any one of the configurations discussed earlier. Generally, legs are proposed which have either simple geometric shapes - e. g., circular, constant diameter cylinders which are relatively easy to design and analyze hydrodynamically - or exhibit one form or another of the bulbous type.

The circular cylindrical leg can change only by increasing length and/or diameter". The effects of these changes have been discussed previously. The bulbous leg can undergo certain transformations in shape which will improve the platform performance, and others which will detract from performance. For example, the size of the bulb at the base of each leg $c$ an be increased for the purpose of increasing the buoyancy. Increasing the buoyancy may result in a reduction of the total number of legs required. It may also mean that the narrow vertical support member between the deck and bulb can be reduced in diameter which results in a decrease of the water plane area per leg. However, increasing the buoyancy at the base of the legs will aggravate the problem of static stability and additional ballast must be added. clearly, then, for the bulbous leg platform a distinct trade-off exists between an increase in the bulb size, ballast requirement and acceptable degree of static stability.

Static Stability. Static stability is assured if a righting moment exists for al1 expected loading conditions and angles of platform 1 ist. Paradoxically, the elevated platforms which have good dynamic stability typically exhibit relatively poor static stability. As will be shown later, the ballast requirement for small platforms can amount to a significant portion of the total dead weight of the platform. Lateral and longitudinal stability can also be increased by enlarging the dimensions of the platform, i. e., increase the water plane restoring moment. A very large MOBS platform, say 1,000-feet x 4,000-feet is likely to have considerable stability, perhaps without the need for any ballast.

Dynamic Stability. Dynamic stability will be investigated in more detail in a later section of this report. Suffice it to say, this platform property is dependent on a number of factors including:

Water plane area: stability is increased by a small value for this factor.

Shape of legs: certain leg configurations lead to an increase in the added-mass and damping.

Mass :

the natural period of heave, pitch and roll increase as the mass increases. 
Hydrodynamic Drag. The force required to tow a platform in the ocean depends on the fluid drag of the buoyant support. Generally the drag will increase with an increase in leg length, diameter, or drag coefficient. The drag can be minimized by employing streamlined leg shapes, e. g., teardrop or "airfoil" shaped legs, and will be maximized for such non-streamline configurations as the cubical float leg of Figure 3.2. The addition of struts or other lateral support members between legs, which may be necessary for structural integrity and desirable for increasing the platform damping, will tend to increase the drag. Since the drag on a properly streamlined strut at certain Reynold's numbers may be as little as $1 / 10$ the drag on a circular cylinder with the same projected area, serious consideration should be given to employing streamlined components whenever possible (Shapiro, 1961).

Mass. The total mass and its distribution is important, of course, in studying the static and dynamic stability of candidate platforms. For elevated platforms with modest plan dimensions, e. g., the $300 \mathrm{x}$ 300-foot platforms, each added pound of dead weight in the deck must be compensated for by additional ballast in the legs if the same degree of static stability is to be preserved. It behooves the designer to maintain the deck weight at a minimum. The use of prestressed structural elements and lightweight concrete are two ways of achieving this.

Freeboard. The freeboard must be sufficiently high to prevent deck washing and wave uplift on the underside of the deck. Raising the freeboard will have the effect of increasing the displacement and reducing static stability. To preserve stability, ballast, once again, must be added to increase the restoring moment. An increase in the freeboard also effects the aerodynamic and hydrodynamic drag, since both the sail area and submerged leg length are increased. For an efficient design, then, it is imperative that the freeboard be kept to a minimum, commensurate with the operational requirements for the platform.

Station Keeping. One of the inherent advantages of an elevated platform is its apparently favorable drift response in a seaway. Pilot tests at NCEL (Naval Civil Engineering Laboratory) have shown (somewhat inconclusively) that certain leg cross-sectional shapes, e. g., a crescent section with cusps aligned in the direction of wave trave1, may actually result in the platform's drifting into the advancing sea. It should be emphasized, however, that keeping the platform "on station" is dependent on factors other than wave induced drift. If the platform is located at a site where steady currents and winds prevail, then no variety of exotically shaped leg is likely to prevent the platform from drifting. 
Most of the design/performance parameters of interest for the elevated platform apply equally as well to the semi-submersible concept. Thus, the reader is referred to the previous discussion on the elevated platform.

Especially noteworthy for the semi-submersible is the significant amount of added-mass induced by oscillation of the submerged horizontal pontoons. Increasing the girth of these buoyant elements results in an increase in the added-mass which is desirable from the standpoint of platform dynamic response.

\section{Barge Platform}

Optimization of a barge platform is dependent on the following design/performance criteria:

1. Configuration of buoyant support

2. Static and dynamic stability

3. Hydrodynamic drag

4. Freeboard

Type of Buoyant Support. As opposed to elevated and semi-submersible platforms, barge platforms have a shallow draft. Barge hulls can be continuous, extending the width and breadth of the deck, or they can assume a catamaran or trimaran configuration, etc. Compared to a ful1beam hu11, the catamaran or trimaran hull offers the advantage of increased static and dynamic stability. This advantage is offset, however, by an increase in the platform draft, the need to account for hydrodynamic loads transmitted to the cross structures (Bond, 1970) and the probable increase in the total mass of the platform. The latter is due largely to the need for structural members to support the deck span between pontoons.

Static and Dynamic Stability. Typically, barge or ship-like floating structures have adequate longitudinal static stability, and this need not be a major concern for larger size MOBS platforms. A small MOBS platform, however, will require a check of both transverse and longitudinal stability under all loading conditions. Generally, catamaran hulls are noted for their favorable transverse stability, and this is one more cogent reason for adopting this configuration for a barge type MOBS platform.

Shallow draft floating platforms, which typically have a relatively large water plane area, unquestionably will be more susceptible to wave induced motion than comparable elevated and semi-submersible platforms. Again, compared to the flat bottom hul1, the catamaran is a better performer, due largely to its greater draft and decreased water plane area. 
Hydrodynamic Drag. An analysis of the hydrodynamic drag acting on a barge platform must consider three components of drag: (1) form drag, (due to separation) (2) wave making drag, and (3) viscous friction drag. Accurate estimates of the drag on any but the simplest geometrically shaped objects are only possible through the classic procedure of towing tests in a suitable model basin.

Freeboard. An increase in the freeboard will be accomplished by an increase in the draft and static instability of the barge. Thus, as is generally true for all floating platforms, it is desirable to maintain the freeboard at a minimum height which is commensurate with the mission requirements.

\section{PREL IMINARY DES IGN}

Several candidate platform configurations have been described with particular emphasis placed on elevated, semi-submersible and barge platforms. Certain design trade-offs possible with each of the leading configurations was presented. From the latter, optimization was found to depend primarily on considerations of static and dynamic stability, material requirements, and design complexity.

In this section an estimate of candidate platform size, weight, and hydrodynamic response will be presented. Size and weight estimates will be particularly helpful in estimating the production plant and material handling requirements essential for an accurate accounting of feasibility and total concept cost. The prediction of hydrodynamic response, especially dynamic response in heave, pitch and roll, is an important indicator of a candidate's potential for meeting stated mission objectives.

It is emphasized that the platform specifications presented are preliminary estimates only. The design calculations were based on simplified geometries of each basic configuration as given in Table 3.1. Such approximations are sufficiently accurate for relative comparisons and determining the order of magnitude of concrete quantities involved.

Structural Design Assumptions and Criteria

In addition to the simplified geometric configurations, the following assumptions were applied:

1. Both the single slab and multi-level decks for the elevated and semi-submersible platforms were considered as separate structural components resting on buoyant support elements.

2. The vertical legs for both the elevated and semi-submersible platforms were considered to have sufficient lateral bracing to prevent failure due to buckling. 
3. All structural elements were designed according to ACI standards for reinforced concrete construction.

4. Design live load for the platforms were:

(a) with multiple decks

$$
\begin{aligned}
& \text { flight deck...... . . } 250 \text { psf } \\
& \text { aircraft storage deck. . . } 250 \text { psf } \\
& \text { personnel deck .... . . } 100 \text { psf }
\end{aligned}
$$

(b) with single slab deck

$$
\text { flight/storage deck . . . . } 400 \mathrm{psf}
$$

5. Design live load was considered distributed uniformly throughout; no allowance was made for partial loading.

6. Concrete having a density of $150 \mathrm{lb} / \mathrm{ft}^{3}$ and a compressive strength of 6,000 psi was used in a11 design estimates.

7. A11 elevated and semi-submersible platforms were held to a minimum clearance of 50 feet between the bottom deck slab and the mean water surface when the platform was loaded with the full design dead load plus live load. This specification insured that wave uplift on the deck will be prevented in all but exceptionally high sea states.

8. Al1 platforms were designed with a minimum freeboard of 60 feet to insure that deck washing does not impede aircraft landings/ takeoffs as well as cargo transfer and storage operations.

Selected geometries given in Table 3.1 are discussed in the paragraphs that follow.

\section{Structural Design Approach}

Spacing of Buoyant Support Elements. Since elevated and semi-submersible platforms in the $300 \times 300$-foot size range exhibit poor transverse and longitudinal stability, it behooves the designer to minimize the weight of the deck. A trade-off made early in the study showed that the weight for both the solid slab and multi-level decks could be minimized without unduly increaseing the weight of other components (primarily the vertical and/or horizontal buoyant support cylinders and solid ballast) if the decks were assumed to be uniformly supported at 50 and 43-foot centers respectively for the single and multi-level decks. 
Table 3.1. Typical Simplified Geometry Used in Preliminary Design Calculations

\begin{tabular}{|c|c|}
\hline Element & Description \\
\hline Single & $\begin{array}{l}\text { Solid, two way slab structurally adequate } \\
\text { to span spacing between supports. }\end{array}$ \\
\hline Multiple & $\begin{array}{l}\text { Three deck levels consisting of flight deck } \\
\text { plus two lower-level decks with } 20-\mathrm{ft} \text { clear- } \\
\text { ance for middle deck and } 8 \text {-ft clearance for } \\
\text { bottom deck. }\end{array}$ \\
\hline Barge-type hull & $\begin{array}{l}\text { 100-ft beam with } 50-f t \text { clear span between } \\
\text { hulls; U-shaped cross section. }\end{array}$ \\
\hline $\begin{array}{l}\text { Elevated platform } \\
\text { columns or legs }\end{array}$ & $\begin{array}{l}\text { 25-ft diameter, cylindrical, spaced at } \\
50-f t \text { and } 43-f t \text { centers each way respec- } \\
\text { tively for the single and multi-level } \\
\text { decks. }\end{array}$ \\
\hline $\begin{array}{l}\text { Semi-submersible with } \\
\text { 36-ft. diameter hulls } \\
\text { and column supports. }\end{array}$ & $\begin{array}{l}\text { 26-ft diameter, cylindrical columns, spaced } \\
\text { as for the elevated platform, atop horizon- } \\
\text { tal cylindrical hulls transversely spaced } \\
\text { to match } 50-\mathrm{ft} \text { or } 43-\mathrm{ft} \text { spacing of columns. }\end{array}$ \\
\hline
\end{tabular}

* Selected spacing was for purpose of maintaining same draft for the single and multi-level decked platforms.

Multi-Level Deck for Elevated and Semi-Submersible Platforms. three decks were designed as two-way slabs. Drop panels, column capitols and interior circular columns were designed to support dead and live loads between deck levels (the longitudinal axes of the deck columns were assumed coincidental with the axes of the vertical buoyant legs). The clearance between the flight deck and the first interior deck was fixed at 20 feet to meet the mission requirement for aircraft storage. An 8-foot ceiling height was provided for the lower interior deck. The peripheral deck columns (rectangular in cross-section) were covered by an outer wall, designed to resist the hydrostatic pressure that would be present if the deck were launched and floated to an atsea assembly site.

Single-Slab Deck for Elevated and Semi-Submersible Platforms. A much simpler design than the preceeding one, the deck was designed as a two-way slab supported at 50 -feet centers by the vertical buoyant legs. The weight totals determined included an estimate of the mass of the connection between the deck and legs. 
Vertical Legs for Elevated and Semi-Submersible Platforms. The vertical legs were designed to support the deck dead and live loads and to resist the imposed hydrostatic and hydrodynamic pressure. Adequate lateral support between legs to prevent buckling was assumed.

Horizontal Buoyant Members for Semi-Submersible Platforms. It was assumed that the critical loading condition for the horizontal cylinders is the surrounding hydrostatic pressure. The design of the connection between these members and the vertical legs was not attempted.

Barge Platforms. For all three sizes of the barge platform, the pontoons were considered to be spanned by a solid, two-way deck slab. Two interior deck levels were provided in each for internal storage of aircraft, equipment and personnel.

Hyddrodynamic Design - Assumptions and Procedure

Static Stability. All of the platforms summarized have at least neutral static stability* An acceptable standard for static stability has not been established for MOBS. More information is needed on the type and possible distribution of the live load and the effect of pitch and roll on aircraft operations and habitability. A platform which has low transverse static stability will inherently have a long natural roll period. Thus, a platform with roll period, say on the order of 100 seconds would be ideal for a floating airbase, but may be so near static instability as to be severely limited in its load carrying capacity.

Dynamic Stability. A floating platform has six possible modes of motion: linear displacement as heave, surge and sway and angular displacement as pitch, roll and yaw. For MOBS the most important modes will probably be heave, pitch, and rol1.*

An analytical scheme for predicting the elevated platform motion in heave was developed and proved to be a useful aide in selecting feasibile platform configurations (See Appendix A for details). A1though the equations have been linearalized, $i$. e., they are applicable to small amplitude motion only, the results are worthwhile when properly interpreted.

It is particularly important that the correct values for the damping and added-mass coefficients be used if response accuracy is desired at resonance. The damping and added-mass are dependent on the motion of the platform: on velocity for damping and acceleration for addedmass. Since the predicted results are relatively insensitive to a wide range of values for these coefficients outside of resonance, where the

\footnotetext{
"Several, such as the barge platforms and the elevated platforms with a deep draft, have considerable positive stability. $* *$.

Pilot tests recently conducted at NCEL of an elevated platform indicate that surge may also be important.
} 
platform velocities and acceleration are sma11, any "reasonable" choice of coefficient will suffice for predicting the response in that frequency domain. This is fortunate since it is difficult to predict the damping and added-mass effects by analytical means. Recourse is usually made to experimentation for the answer.

Results

Size and Weight. Preliminary design specifications for five types of MOBS platforms are presented in Table 3.2. The platform types summarized are:

1. Semi-submersible platform with single level deck.

2. Semi-submersible platform with multi-level deck.

3. Elevated platform with single level deck.

4. Elevated platform with multi-level deck.

5. Barge platform.

The tabulations for the elevated platform and the semi-submersible platform are given for both single and multiple decks. These values represent the extremes, since in all probability the optimized designs for specific missions will have combinations of single and multiple decks; the weights of such platforms will lie between these extremes. The barge-hull platform has interior decks; the single deck did not appear practical for structural reasons. Thus, only one tabluation for the barge is given.

It is apparent from Table 3.2 that considerable savings in concrete are possible with the barge platform. This can be seen clearly in Figure 3.8 which compares the weight of the multi-level deck, elevated and semi-submersible platforms with the barge platform. The platforms each have the same plan dimensions, i. e., $300 \times 300$-feet, and support the same live load. The weight advantage, and material savings, of the barge configuration is reflected also in the estimates for the $400 \mathrm{x}$ 1200-foot and $1000 \times 4000-$ foot size platforms.

Figure 3.9 illustrates the relative size of the three MOBS base concepts while the freeboard and plan dimensions are identical for each platform. The principal difference lies in the draft for each candidate, the elevated platform having a loaded draft more than five times that of the barge.

Dynamic Response. The natural heave periods for three selected $300 \times 300$ platforms are presented in Table 3.3. The estimates for the elevated and semi-submersible platforms were determined from the following expression:

$$
T_{H}=\frac{2 \pi}{\sqrt{\frac{k}{M}}}
$$

where $\mathrm{T}_{\mathrm{H}}$ is the natural period in heave, $\mathrm{k}$ is the restoring force per foot of ${ }^{H}$ submergence and $M$ is the total mass of the platform (including the mass of the live load and the added-mass). 
Table 3.2. Preliminary Design Specifications for MOBS Platforms

\begin{tabular}{|c|c|c|c|c|c|}
\hline \multirow[b]{2}{*}{ Platform Type } & \multirow{2}{*}{\multicolumn{2}{|c|}{$\begin{array}{l}\text { Platform } \\
\text { Property }\end{array}$}} & \multicolumn{3}{|c|}{ Platform Size } \\
\hline & & & M1: $300^{\prime} \times 300^{\prime}$ & M2: $\quad 400^{\prime} \times 1,200^{\prime}$ & $\mathrm{M} 3: \quad 1,000^{\prime} \times 4,000^{\prime}$ \\
\hline $\begin{array}{l}\text { (1) } \\
\text { Semi-Submersible/ } \\
\text { Single Level Deck }\end{array}$ & $\begin{array}{l}\text { Wgt, structural concrete } \\
\text { Wgt, ballast concrete } \\
\text { Wgt, water ballast } \\
\text { Wgt, total } \\
\text { Draft (heavy) } \\
\text { Freeboard (heavy) } \\
\text { Deck clearance }\end{array}$ & $\begin{array}{l}\text { (LT) } \\
(\mathrm{LT}) \\
(\mathrm{LT}) \\
\text { (LT) } \\
\text { (FT) } \\
\text { (FT) } \\
\text { (FT) }\end{array}$ & $\begin{array}{r}57,400 \\
13,300 \\
25,300 \\
96,000 \\
138 \\
60 \\
58 \\
\end{array}$ & $\begin{array}{r}306,000 \\
71,000 \\
135,000 \\
512,000 \\
138 \\
60 \\
58 \\
\end{array}$ & $\begin{array}{r}2,550,000 \\
592,000 \\
1,130,000 \\
4,270,000 \\
138 \\
60 \\
58 \\
\end{array}$ \\
\hline $\begin{array}{l}\text { Semi-Submersible/ } \\
\text { Multi-Level Deck }\end{array}$ & $\begin{array}{l}\text { Wgt, structural concrete } \\
\text { Wgt, ballast concrete } \\
\text { Wgt, water ballast } \\
\text { Wgt, total } \\
\text { Draft (heavy) } \\
\text { Freeboard (heavy) } \\
\text { Deck clearance }\end{array}$ & $\begin{array}{l}\text { (LT) } \\
(\mathrm{LT}) \\
(\mathrm{LT}) \\
(\mathrm{LT}) \\
(\mathrm{FT}) \\
(\mathrm{FT}) \\
(\mathrm{FT})\end{array}$ & $\begin{array}{r}84,400 \\
8,500 \\
32,100 \\
125,000 \\
138 \\
88 \\
50 \\
\end{array}$ & $\begin{array}{r}450,000 \\
45,000 \\
171,000 \\
666,000 \\
138 \\
88 \\
50\end{array}$ & $\begin{array}{r}3,760,000 \\
378,000 \\
1,420,000 \\
5,560,000 \\
138 \\
88 \\
50\end{array}$ \\
\hline $\begin{array}{l}\text { Elevated/Single } \\
\text { Level Deck }\end{array}$ & $\begin{array}{l}\text { Wgt, structural concrete } \\
\text { Wgt, ballast concrete } \\
\text { Wgt, water ballast } \\
\text { Wgt, total } \\
\text { Draft (heavy) } \\
\text { Freeboard (heavy) } \\
\text { Deck clearance }\end{array}$ & $\begin{array}{l}\text { (LT) } \\
(\mathrm{LT}) \\
(\mathrm{LT}) \\
(\mathrm{LT}) \\
(\mathrm{FT}) \\
(\mathrm{FT}) \\
(\mathrm{FT}) \\
\end{array}$ & $\begin{array}{r}73,100 \\
22,600 \\
54,300 \\
150,000 \\
330 \\
60 \\
58 \\
\end{array}$ & $\begin{array}{r}390,000 \\
121,000 \\
289,000 \\
800,000 \\
330 \\
60 \\
58 \\
\end{array}$ & $\begin{array}{r}3,250,000 \\
1,010,000 \\
2,400,000 \\
6,660,000 \\
330 \\
60 \\
58 \\
\end{array}$ \\
\hline $\begin{array}{l}\text { (4) } \\
\text { Elevated/Multi- } \\
\text { Level Deck }\end{array}$ & $\begin{array}{l}\text { Wgt, structural concrete } \\
\text { Wgt, ballast concrete } \\
\text { Wgt, water ballast } \\
\text { Wgt, total } \\
\text { Draft (heavy) } \\
\text { Freeboard (heavy) } \\
\text { Deck clearance }\end{array}$ & $\begin{array}{l}\text { (LT) } \\
\text { (LT) } \\
\text { (LT) } \\
\text { (LT) } \\
\text { (FT) } \\
\text { (FT) } \\
\text { (FT) }\end{array}$ & $\begin{array}{r}113,600 \\
33,000 \\
64,400 \\
211,000 \\
330 \\
88 \\
50 \\
\end{array}$ & $\begin{array}{r}605,000 \\
176,000 \\
344,000 \\
1,125,000 \\
330 \\
88 \\
50 \\
\end{array}$ & $\begin{array}{r}5,060,000 \\
1,470,000 \\
2,860,000 \\
9,390,000 \\
330 \\
88 \\
50 \\
\end{array}$ \\
\hline Barge (5) & $\begin{array}{l}\text { Wgt, structural concrete } \\
\text { Wgt, ballast concrete } \\
\text { Wgt, water ballast } \\
\text { Wgt, total } \\
\text { Draft (heavy) } \\
\text { Freeboard (heavy) } \\
\text { Deck clearance }\end{array}$ & $\begin{array}{l}\text { (LT) } \\
\text { (LT) } \\
\text { (LT) } \\
\text { (FT) } \\
\text { (FT) } \\
\text { (FT) }\end{array}$ & $\begin{array}{r}60,400 \\
0 \\
0 \\
60,400 \\
63 \\
62 \\
60 \\
\end{array}$ & $\begin{array}{r}321,932 \\
0 \\
0 \\
321,932 \\
63 \\
62 \\
60 \\
\end{array}$ & $\begin{array}{r}2,687,800 \\
0 \\
0 \\
2,687,000 \\
63 \\
62 \\
60 \\
\end{array}$ \\
\hline
\end{tabular}

1. All weights given in long tons.

2. Tabulations for draft, freeboard and deck clearance are for conditions of full uniform live load throughout. 



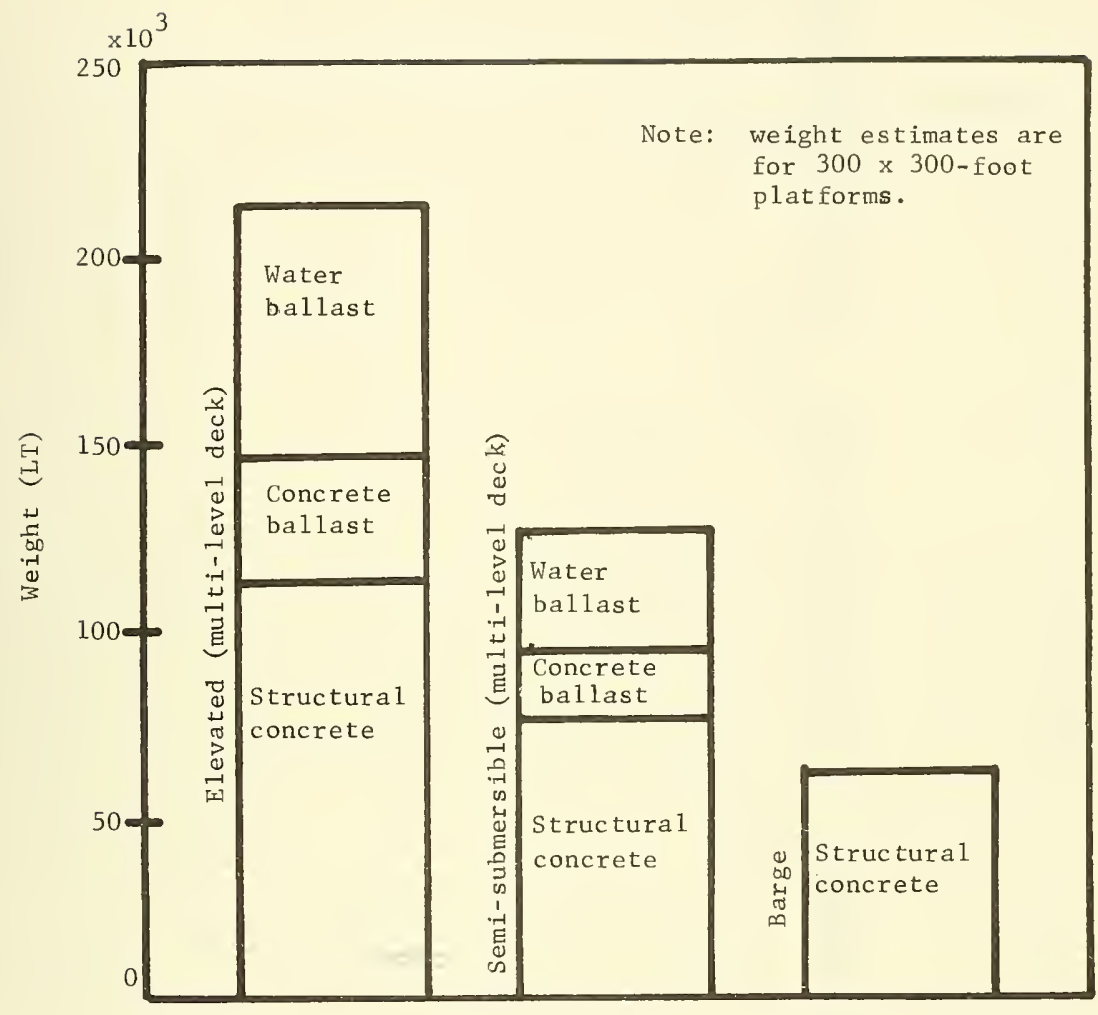

Figure 3.8. Weight comparison for three candidate MOBS platforms. 


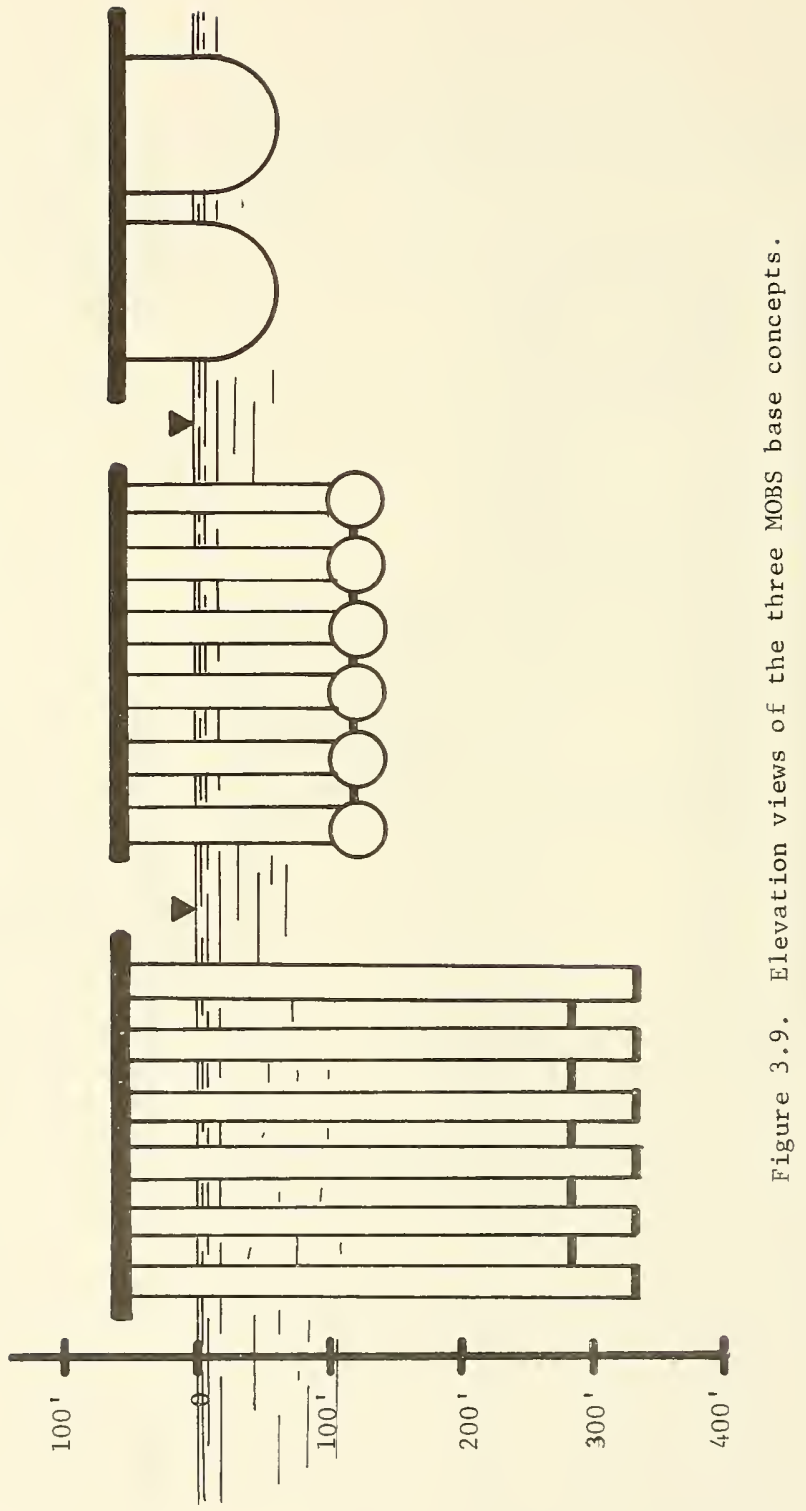


Table 3.3. Estimated Heave Periods for

Selected MOBS Candidates

\begin{tabular}{|c|c|}
\hline Platform Type & $\begin{array}{r}\text { Natural Period in Heave } \\
\text { (Sec) }\end{array}$ \\
\hline $\begin{array}{l}\text { (1) } \begin{array}{l}\text { Elevated (330 ft-draft, } \\
\text { multi-deck) }\end{array} \\
\text { (2) Semi-submersible } \\
\text { (multi-deck) }\end{array}$ & 20 \\
(3) Barge & $10-12$ \\
\hline
\end{tabular}

The added-mass for the elevated platform was assumed to be negligible and was neglected in arriving at the estimates in Table 3.3. This assumption makes sense only if the legs are slender, constant diameter cylinders without inter-connecting structural support. The addition of supports between legs and the inclusion, especially, of damping plates at the base of the legs will add considerably to the vitural mass of the elevated platform. The heave period, in this case, would be greater than that shown in the Table.* The added mass for the semisubmersible platform was assumed equal to the mass of the water displaced by the horizontal floats. The barge natural heave period is a gross estimate based upon the response of conventional ships with comparable displacement.

For a platform to be considered "stable" in heave, it should have a natural heave period of at least 20 seconds. A natural period of this magnitude is insurance against high platform response for all but extreme storm wave and swell conditions.

An analysis, programmed to run on a computer and described in Appendix A, predicts the heave response for elevated platforms in regular seas. The heave response for various assumed irregular seas is also determined. Figure 3.10 represents a typical output from the program. In this case it is the heave response of the $300 \times 300$, single deck elevated platform with a heavy draft of 330-feet. Several values have been assumed for the damping coefficient. The principal effect of changing this coefficient is to alter the response at resonance. For all practical purposes the three curves concide to the left and to the

* The estimate given by the equation compares favorably with the results of the analysis described in Appendix A. Since the latter accounts for the added-mass, there is further justification for concluding that this effect is small compared to the platform mass. 
right of resonance. Thus, even without the precise value for the damping coefficient, it is possible to estimate with confidence the heave response for this particular platform to incident waves with periods up to, say, 15 seconds.

Figures 3.11 through 3.12 depict the heave response for the same platform for three assumed irregular sea states using the Neumann windwave spectrum. Each of these plots shows the heave response of the subject platform in both a "light" and a "heavy" load condition for a single assumed Neumann wind velocity (30 and 40 knots). Even at the highese sea state investigated, the platform exhibits a small motion relative to the height of the incident sea.

One is cautioned about extending this approach to higher sea states for at least two reasons:

1. The equations of motion have been linearlized and, thus, should not be applied too far beyond the domain of "small amplitude" waves.

2. The platform heave response curve, i. e., the platform response to regular waves, is at present, imprecisely known around resonance. This fact begins to have importance at higher sea states since the energy contained in the wave spectrum tends to shift towards lower frequencies and to concide with the heave response curve at resonance. Since the heave spectrum is obtained by forming the product of the square of the heave response curve and the ordinate of the wave amplitude spectrum at the same frequency, the uncertain value of the platform heave response near and at resonance tends to create uncertainty as well as in the heave spectrum.

The total vertical movement at any point on the platform is a superposition of the pure heave response and the vertical movement due to pitch and rol1. The investigation into the effects of the latter are not complete and therefore are not included in this report.

An elevated platform having constant diameter cylindrical legs for buoyant support is perhaps the easiest configuration for analysis. Other platform types, e. g., elevated platforms with bulbous legs, semisubmersibles and barges, are also amenable to analysis. The principal difficulty lies in determining the damping and added-mass coefficients by analysis or experiment. 


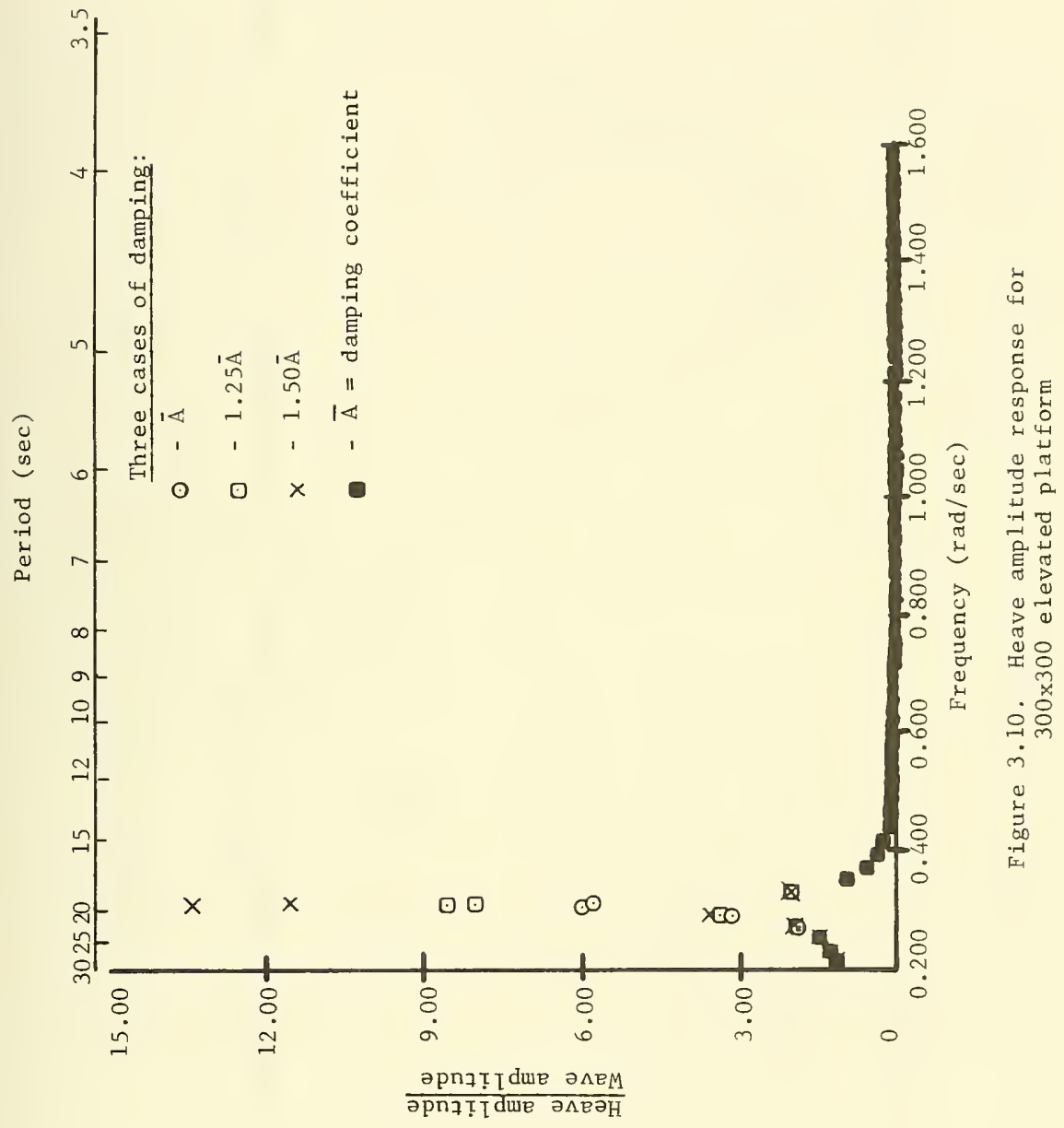









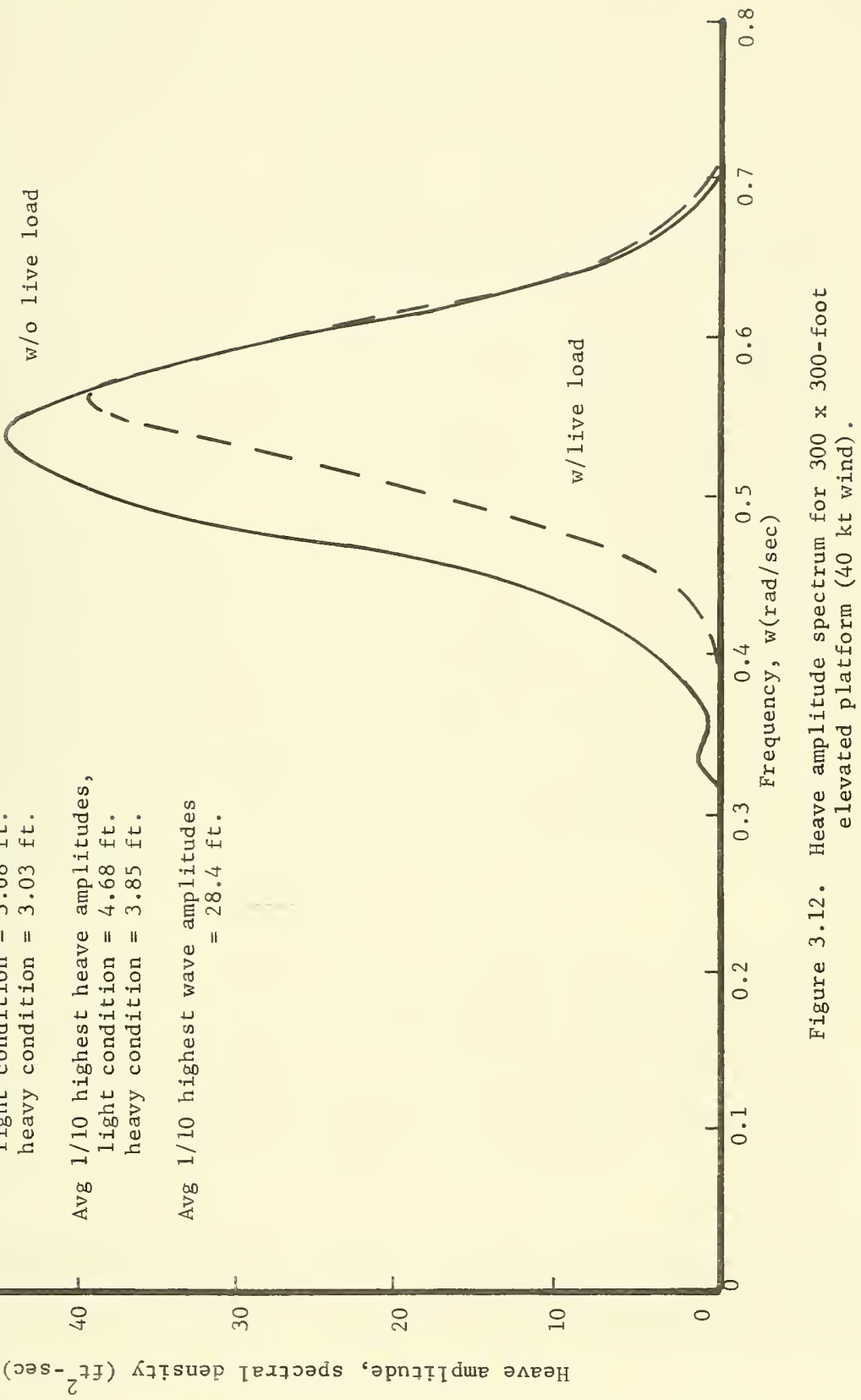



PART FOUR - CONCRETE PRODUCTION

by D. F. Griffin

RESOURCES

The size and scope of facilities required to produce portland cement concrete for mobile ocean based platforms will depend upon (a) size and number of platforms to be constructed as well as (b) the location selected for construction.

The production and placing of concrete requires a spectrum of operations including (a) mining, crushing, and processing of sand and gravel (or crushed rock) to produce aggregate of suitable quality, gradation, and quantity, (b) mining of raw materials for the production of cement clinker subsequently to be ground into portland cement, (c) the location of a suitable and adequate scurce of water, and (d) the combining of sand, gravel, cement, and water into freshly mixed concrete ready for emplacement.

Depending upon the quantity of concrete to be produced and upon the location most feasible for its production, new facilities may have to be established if not, for all, at least for a part of the operations.

A floating platform of the scale envisaged will obviously be a high cost item. Therefore, it must be assumed that fabrication processes and materials will be of the highest quality attainable on a practical working basis. The buoyant components must be of dense, well compacted, concrete of low water-cement ratio and high cement content in order to be impermeable to water, and to provide utmost protection to embedded reinforcing metal or metal fasteners. In fact, the metal required might wel1 be made of corrosion-free titanium. Its higher cost could be offset to some degree by savings in concrete cover that might be as low as 1.5 inches.

Construction Site

It is believed at this time that the first decision should be to select two or three alternate feasible construction sites from the point of view of launching the completed platform. Each site should then be considered in relation to availability and economy of labor, aggregates, cement, and water.

Initial consideration of construction sites on the Pacific Coast of the U. S. might well include areas close to San Diego, Los Angeles, San Francisco, Portland, and Seattle.

Materials of Construction

Aggregates. High quality aggregates are not to be found everywhere, nor generally in great abundance. For each specific possible construction site, the location and supply of acceptable aggregates should be considered 
very carefully. Acceptability of aggregates should be based on standard tests of the American Society for Testing and Materials. An investigation of a source for aggregates should be thorough and make certain any supply of acceptable aggregates is adequate for the amount of concrete required. It is quite probable that some existing source of aggregates already processed and ready for use will be found. On the other hand the exigency of the situation may require development of an entirely new source of raw materials. In this case, a custom-built mining and processing plant will be required. A plant of this nature would be quite costly. It could be justified on the basis that there is no other alternative or that enough aggregates will be required to make the price of the product competitive with other sources of materials.

To the best of the author's knowledge, data concerning amounts and locations of deposits of suitable concrete aggregates are not available. The following table showing sand and gravel production in the Pacific Coastal states provides an indication of the availability of aggregates; however, these are not necessarily all suitable for use in portland concrete.

Sand and Gravel Production - Pacific Coast States

\begin{tabular}{|c|r|c|}
\hline Location & 1967 & \multicolumn{1}{c|}{1968} \\
\hline California, short tons & $116,125,000$ & $124,655,000$ \\
Washington, short tons & $28,164,000$ & $31,432,000$ \\
Oregon, short tons & $19,630,000$ & $18,260,000$ \\
\hline
\end{tabular}

Source: Separate Reprints from the 1968 U. S. Department of the Interior, Bureau of Mines Minerals Yearbook. The Mineral Industry of California. (Washington), (Oregon). Includes names and addresses of principal producers of sand, grave1, and cement.

The Pit and Quarry publications issues annually a Directory of Nonmeta11ic Minerals Industries. (Pit and Quarry, 1970). Producers are listed alphabetically with a geographical cross-reference section of plants so all existent sources of production are known.

Manufactured 1ightweight aggregates are available and weight savings are sometimes very advantageous compared to conventional mined aggregates. A schematic diagram of a lightweight aggregate manufacturing plant is contained in the Rocklite Lightweight Concrete Reference Manual (Lightweight Processing Company Publication). Many technica1 details about lightweight aggregate and concrete made with this aggregate are also included. 
The number of lightweight aggregate producing plants per state for both natural and manufactured aggregates is shown on the map of Figure 4-1. Approximately 60 percent of the plants are in coastal states; of, these, about 50 plants are near coastal waters. All 1 ightweight aggregate plants known to be in existence are listed on the Lightweight Aggregate Map issued by Pit and Quarry Publications (1969). Each plant's address, the type or types of lightweight aggregate it produces, and the brand name or names of the products are shown.

Cement. The below tabulated information shows the amount of portland cement shipped from mills, and the manufacturing capacity for the U. S., the Pacific Coast States and Texas. The latter is the largest producer on the southern and eastern seaboards.

Portland Cement, Thousands of 376-1b Barrels

\begin{tabular}{|l|r|r||r|r|r|r|}
\hline \multirow{2}{*}{ Location } & \multicolumn{2}{|c||}{ Shipment From Mills } & \multicolumn{3}{|c|}{ Manufacturing Capacity } \\
\cline { 2 - 7 } & 1967 & 1968 & 1967 & 1968 & \multicolumn{1}{c|}{ utilized } \\
\hline U. S. & 374,017 & 397,448 & 508,952 & 509,058 & 72.6 & 77.6 \\
Washington & 5,614 & 6,328 & 9,575 & 8,200 & 61.5 & 77.2 \\
Oregon-Nevada & 3,518 & 3,812 & 6,400 & 5,700 & 53.0 & 63.5 \\
California & 42,034 & 47,595 & 62,300 & 64,300 & 67.5 & 73.1 \\
Texas & 31,944 & 34,499 & 46,199 & 47,793 & 69.9 & 71.5 \\
\hline
\end{tabular}

Source: Tables 2 and 7 of U. S. Department of the Interior. Reprints from the 1968 Bureau of Mines Yearbook, Cement. Worldwide production of cement by countries is given in Table 22, p. 24 of this reference.

It may be observed that in the U. S. as a whole there is a reserve manufacturing capacity of about $23 \%$, and in California, the reserve capacity amounted to about $27 \%$ in 1968 .

In a location such as California, where the production of cement in 1968 amounted to 12. percent of the entire U. S. production, it is unlikely that a new cement plant would be required. Even if a constrution site were to be selected in Oregon or Washington, a new cement plant may not be justified for MOBS. But this would have to be determined on the basis of a trade off with cost of shipping cement from other areas. The number of U. S. portland cement distributing plants is shown on the map of Figure 4.2. The origina1 "Portland Cement Map," lists each producing plant by city and state as well as the grinding and distributing plants. (Pit and Quarry Publications, 1969) 

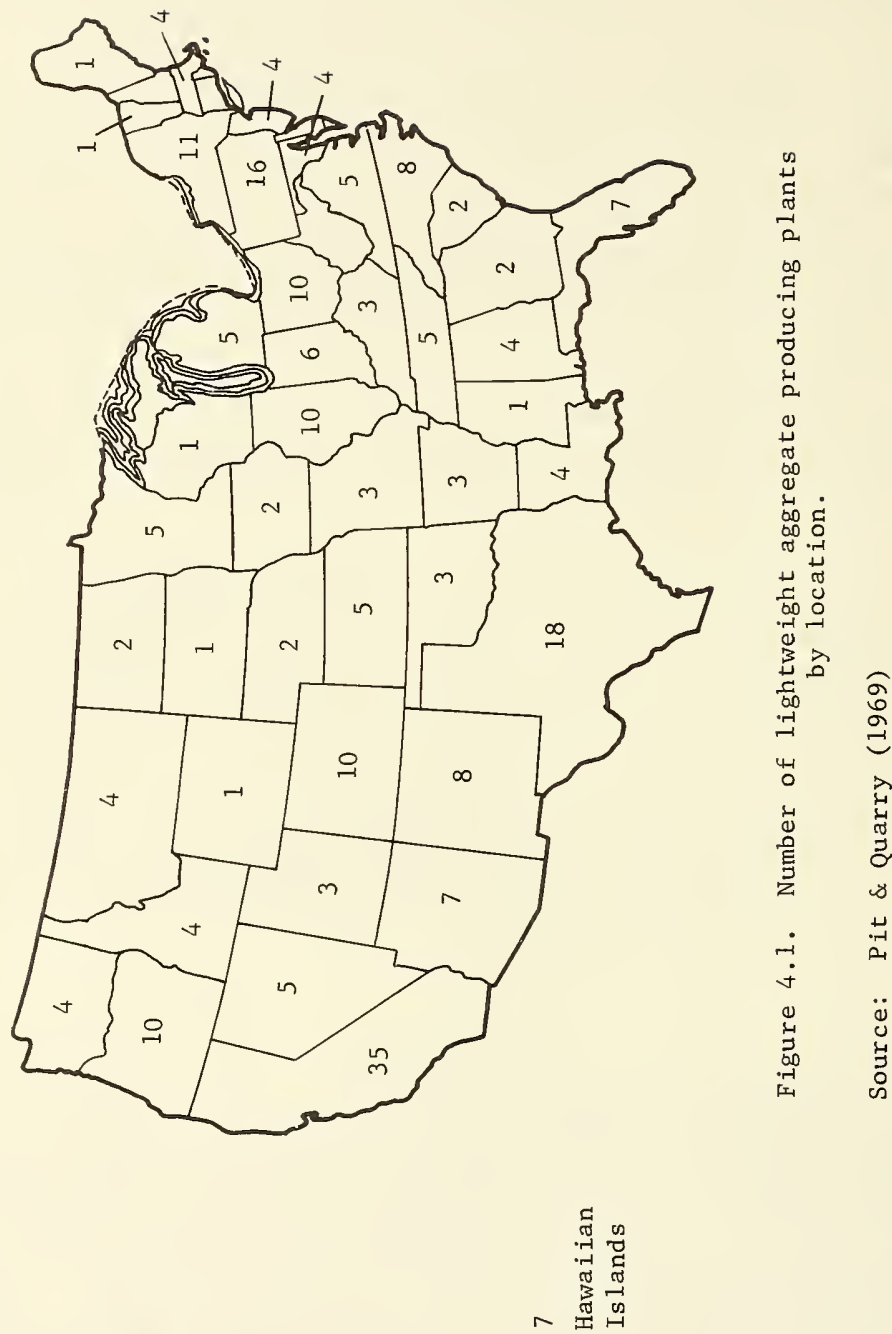


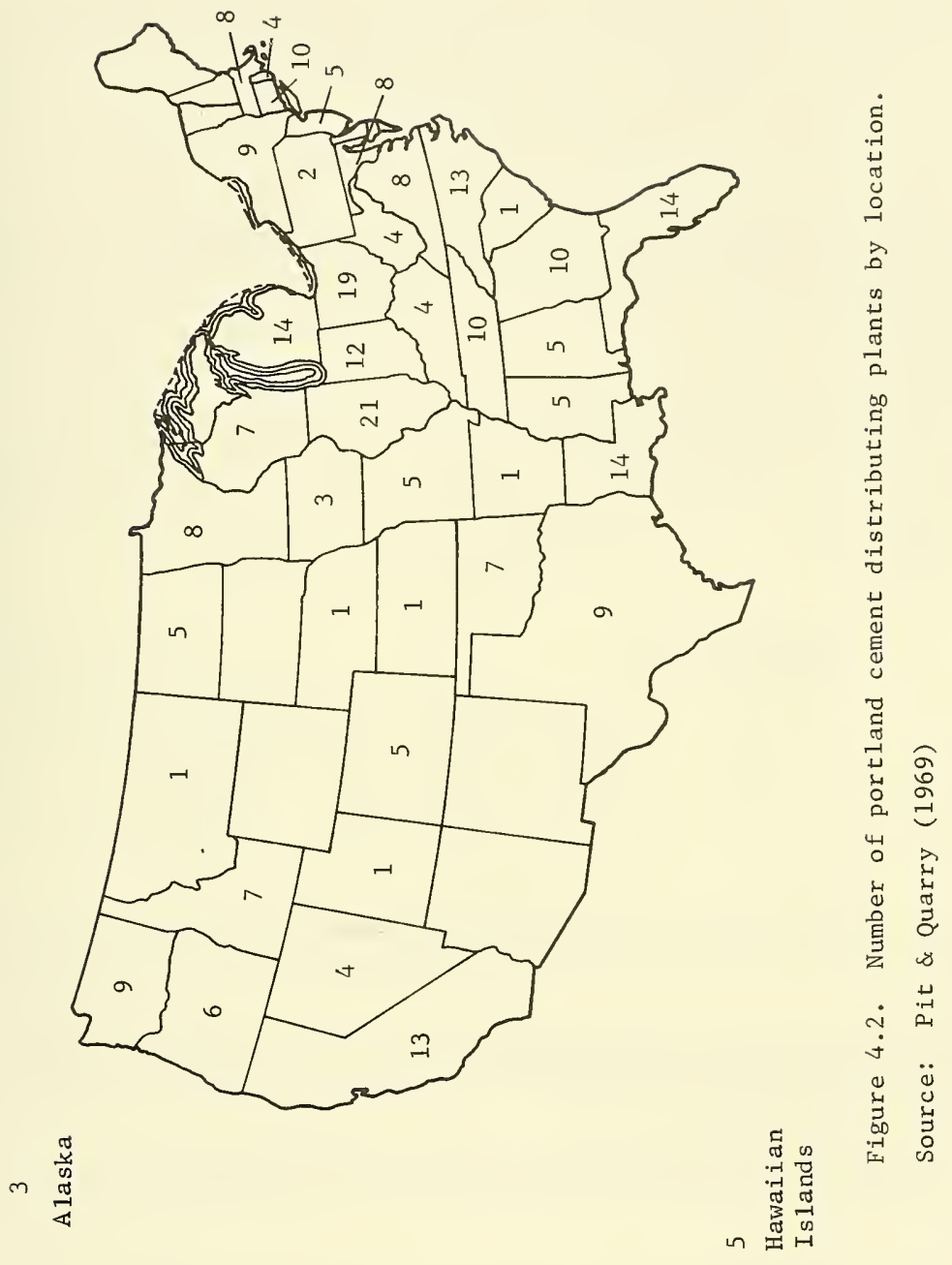


Water. Concrete for MOBS should be of high quality, i. e., low slump, low water requirement, and high cement content. Assuming not less than 8 sacks of cement per cubic yard of concrete, and a water to cement ratio by weight of 0.4 , the water required for each 1,000 cubic yards of concrete would be: 36,100 gallons. In addition, considerable water would be required for washing tools and mixers. In general, water for concrete should be of the same quality as drinking water.

Ready-Mixed Concrete. Depending upon the potentially feasibile construction site locations, it may or may not be economical to construct a new concrete batching plant. In California, as of 1967, there were 62 companies operating 274 plants producing 8.8 million cubic yards of ready-mixed concrete; Oregon had 17 companies operating 22 plants producing 0.5 million cubic yards; and Washington had 21 companies operating 50 plants producing 1.2 million cubic yards.

Collectively, the southern coastal and eastern seaboard states produce concrete vastly in excess of that produced in the three western coastal states; however, California produced 2.75 times more ready-mixed concrete than Texas, the second highest producing seaboard state.

Within the U. S. as a whole, the number of plants producing annual quantities in excess of a specified level are indicated below.

$\frac{\text { No. of Ready-Mix Plants }}{\text { Producing }}$

134

65

34

25

17

\section{Quantities in Excess of}

$100,000 \mathrm{cu}$. yds.

200,000

300,000

400,000

500,000

Based on a 5-day, 40-hour week, each company that produced 500,000 cubic yards per year, averaged at least 1,900 cubic yards per day, or 240 per hour.

Transit mixed (truck mounted mixer) concrete accounted for 76 percent of the total reported production during 1967. Central mixing (pre-mixed at plant, agitated in truck enroute), accounted for about 24 percent.

In the event that ready-mixed concrete were to be used, the disposal of truck mixer wash water and unused concrete may become a problem. A solution to this problem is offered by the National Ready-Mixed Concrete Association (1964).

Ready-Mix Concrete Costs. Published data as to costs of various motions involved in the production of concrete are not to be found in the open literature. In lieu of information of this type which would be variable for different types of plant set-ups as well as dependent 
upon methods of accounting, it is believed that the published prices of ready-mixed concrete would provide an adequate cost index. These prices reflect all costs associated with the production of the final product, that is, production of sand, gravel, cement, water and the appropriate combination of these materials to formulate plastic concrete ready to be placed in molds.

Table 4.1 shows prices per cubic yard of concrete for the period 1965 through 1969 for eight major cities of the U. S. The price of concrete during this period has held remarkably steady for the U. S. as a whole. The national average (based on 22 major cities) increased from $\$ 14.27$ in 1965 to $\$ 15.62$ per cubic yard in 1969. In 1969 the lowest price per cubic yard was reported for Atlanta at $\$ 12.75$; the highest, in New York at $\$ 21.65$.

The cost of concrete in place is another story, and includes all costs of planning, design, formwork, reinforcing metals, rental for land use, labor, and form removal. Until a specific structural concept has been adopter and designed, such costs are impossible to esimate with accuracy.

\section{PRODUCTION}

\section{Production Plants}

Generally speaking, it is believed the probabilities of utilizing existent production plants for aggregate, cement, and concrete at a CONUS site are very good. Regardless of where the MOBS construction site is likely to be - CoNUS or remote - existent cement plants have ample capacity to supply required amounts of cement. About the only reason for considering a new cement plant would be the discovery of a prime source of raw materials in proximity to the construction site. In this event, nearly any one of the existent large cement producers would literally jump at the chance to establish a new cement plant.

Aggregate Plants. Aggregate producing plants are generally custom designed. The type of equipment generally needed includes mining and excavating machinery, rock crushers, elevated storage bins, aggregate size separators, belt conveyors, bucket conveyors, and facilities for washing aggregate. Specific equipment needed is well illustrated and specified in the Handbook and Purchasing Guide for the Nonmetallic Minerals Industries (Rick, 1969), issued annually.

\section{Concrete Plants. Concrete plants are of two general types.} One type includes concrete mixers set up in such a way that freshly mixed concrete is delivered bymeans of a large dump bucket on a cable supporting system direct from the mixer to the actual point of emplacement. The construction of Hoover Dam exemplified this system. Such a system is economical only where large quantities of concrete are to be fabricated and delivered to a site close to the plant. Establishing such a plant might be economical for MOBS. 


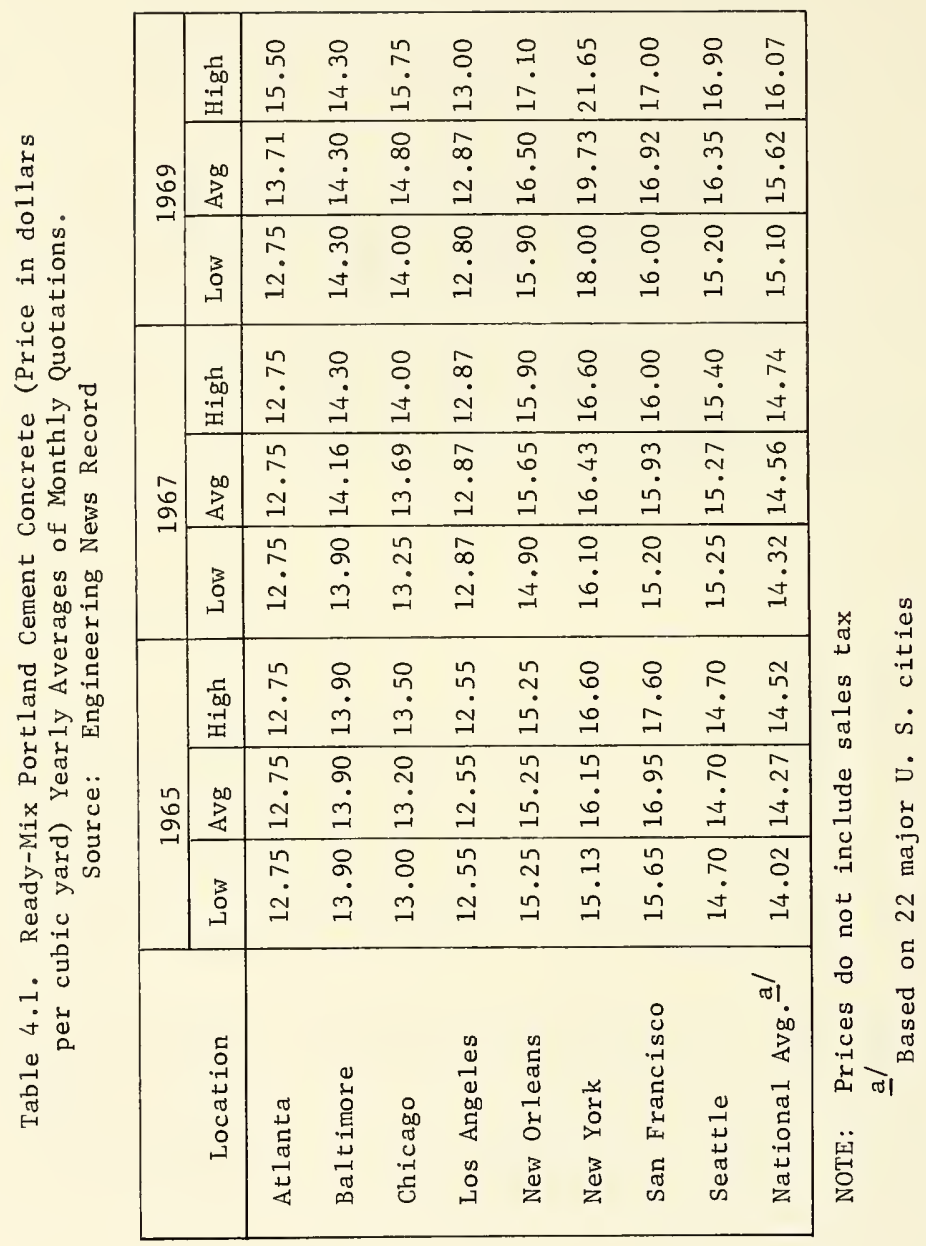


By far the greatest amount of concrete produced in the U. S. is known as ready-mixed concrete. The term ready-mixed concrete means any portland cement concrete mixture which is ready to use on arrival at the job site. Ready-mixed concrete includes: (1) transit-mixing, or concrete produced from a central-batching plant, where the materials are proportioned and placed in truck-mixers for mixing enroute to the job or after arrival there, and (2) central-mixing, or concrete proportioned and mixed at a central-mixing plant and hauled in agitatortype trucks to the job.

The major items, or classes, or equipment required in setting up a ready mixed concrete plant may be enumerated as follows:

1. Means for delivering, unloading, storing, and handling fine and coarse aggregates.

(a) Delivering - Railroad gondola cars (and railroad accessories) and/or dump trucks.

(b) Storing - Open field stockpiling, elevated closed

bins.

(c) Handling - Pit dumps equipped with conveyor belts (or bucket belt system) to move material either to stockpiles or to elevated bin storage. If aggregate has to be classified into specific particle sizes, washing and screening plants are also required.

2. Provision for delivering, unloading, storing and handling cement: (a) in sacks, (b) in bulk.

(a) Delivering - Sacked cement should be delivered in closed railroad cars or closed trucks to avoid effects of adverse weather. Open vehicles may be used for short hauls in dry weather. Bulk cement requires delivery by special bulk delivery railroad cars or trucks were the cement is completely enclosed from the weather.

(b) Unloading - Sacked cement requires forklifts for unloading palletized sacks. Bulk delivery requires unloading cement into elevated bins by pneumatic pumps.

(c) Storing - Bulk cement is stored in elevated closed weather-tight bins, sacked cement is stored inside weather-tight warehouses.

3. Equipment for elevating the aggregates and cement. Either aggregate or cement can be transported on conveyor belts if the slope is not too steep. For steep slopes bucket conveyors are used.

4. Overhead compartment bins for storage of various sizes of fine and coarse aggregates; also for one or more types or brands of cement when bulk cement is used.

5. Weighing batchers for measuring the quantities of aggregate, cement, and water. Batching systems range from completely manual 
operations to fully automatic. An example of the latter is the ABC Count-Way System: This is a fully transistorized digital system of solid state design, which uses computer logic and a photo-electric scale reader. Logic blocks are grouped on cards for control function, and field maintenance is reduced to plugging in replacement cards. There are no relays or other moving parts in the logic circuitry, except for the switches and push buttons. Functioning of this system is based on pulse-generating unit which derives an illuminated sensor arm on face of scales dial. Number of pulses generated is determined by preset digital dials, punched tape or cards, or other input means. A floormounted console houses the electronic equipment.

6. Stationary mixers for the central mixing plant.

7. Collecting hopper and chute for truck - mixer operations.

8. Two-way chute and flop-gate arrangement for combination central-mixing and transit-mixing plants.

9. Boiler and accessories for cold-weather operation for heating water, thawing aggregates and heating the operating platform enclosure.

10. Recording instruments, temperature, relative humidity, weights of ingredients for each batch, etc.

11. Office and quality control testing facilities. Most, if not a11, of the above items are detailed in the Handbook and Purchasing Guide, (Rick, 1969) and Concrete Industries Yearbook, (Peck, 1969).

An example of a specialized concrete products plant is the Bayshore Concrete Products Corporation plant at Cape Charles, Virginia, in which Raymond Concrete Pile Company has a partial ownership. This plant represents an investment of approximately $\$ 3,500,000$. It is situated on 50 arces of land. A single shift operation can produce about $\$ 5,000,000$ worth of miscellaneous concrete products per year. On a $40-$ hour week basis, this plant can produce about 3,000 lineal feet of cylinder piles per week in size up to 60 inches outside diameter. It can also handle precast concrete units up to 300 tons each.

Cost of Concrete in Place. The San Francisco Bay Tube project (Western Construction, 1967), known as BART (Bay Area Rapid Transit), might well be used as an example of current history of a large concrete construction project - and as a means for estimating the cost of a Mobile Ocean Basing System. For a total contract price of $\$ 89,000,000$, the building, launching, outfitting, sinking and joining of twin tube sections for a length of 3.6 miles were accomplished. Included were:

*/ Additional information on BART construction is contained in Part 2 of this report. 
(a) 15,600,000 cubic yards of material to be displaced to form a trench on the bottom of the Bay to receive the tube sections. The "binocular-shapred" cross-section of a tube is about 24 feet by 48 feet and contains two 17-foot diameter cores.

(b) Fabrication and placement of a ventilation structure on the San Francisco end. This structure is 68 feet wide, 122 feet 1ong, and 108 feet high. It will contain 10,000 tons of structural steel and 27,800 tons of concrete.

(c) 80,000 cubic yards of rock dike at the eastern end of the tube.

(d) Temporary electrical far:ilities.

(e) Imbedded electricail facilities.

(f) 300,000 cubic yards of concrete (the tube consists of $3 / 8$ inch thick steel plate skin and 27 inches of reinforced concrete).

Not included in the above is finish construction, track laying, and 2.8 miles of approaches costing about $\$ 90,000,000$.

If all costs of items (a) through (f) were charged to the concrete, the cost per cubic yard would approach $\$ 300$. On the other hand, the fabrication cost of an average BART tube section, including the stee 1 shell, reinforcing steel, and all associated work, was approximately $\$ 120$ per cubic yard.

Lack of space for setting up a plant to furnish the 300,000 cubic yards of concrete for BART, led the contractor to buy the concrete from Rhodes \& Jamieson, Ltd., a major supplier in the Bay area. Rhodes and Jamieson set up a special batch plant, for the project, one of the largest in Northern California, and delivered the concrete a distance of 1.5 miles in transit trucks. The plant had a $11 \frac{1}{2}$-yard Rex mixer, a capacity of 250 cubic yards per hour, and was equipped with an electronic console with 24 pre-set mix designs.

The plant mixed 5 cubic yards of cement and aggregates, while at the same time held another 5 cubic yards on the scales. The plant had 400 tons of overhead aggregated storage in eight compartments and two overhead cement silos with 500 bbls each (376 lbs per bbl). Concrete placement was estimated to reach 3,000 cubic yards per week.

Quality Control in Production

Quality control in the production of portland cement concrete not only requires a sound set of specifications, but also, it requires the active participation of knwoledgeable inspectors. The inspectors must be capable of sampling aggregates, cements, and fresh concrete and performing necessary tests to assure that the final product meets all specifications. 
Aggregates. Any producer of aggregate for use in portland cement concrete must be prepared to demonstrate that his product is suitable for use in portland cement concrete. Speifications must include reference to accepted standard tests such as those promulgated by the American Society for Testing and Materials (1969).

Cement. Most cement mills maintain their own testing laboratories to remain assured of good quality control of this highly competitive product. Specifications for portland cement are available (ibid).

Concrete. Most of the concrete in the U. S. is produced as readymixed concrete. Ninety percent of the total volume is produced by companies that are members of the National Ready Mixed Concrete Association. As one means of assuring the consumer of high quality concrete delivered to the job site, the NRMCA and the Associated General Contractors of America have adopted and published a statement of separate and joint responsibilities (NRMCA, 1965). NRMCA has also published a statement entitled, What Quality Guarantee Should the Customer Expect from the Ready-Mixed Concrete Producer (Walker, 1961), and standard specifications for ready-mixed concrete, NRMCA Pub. No. 124.

In an effort to assure adequate standard for concrete plants the NRMCA and the Concrete Plant Manufacturers Bureau have published a statement entitled, Concrete Plant Standards of the Concrete Plant Manufactureres Bureau (NRMCA, 1967). NRMCA also provides instructions and check 1ists for certification fo Ready Mixed Concrete Production Facilities (NRMCA, 1967). In order to assure that concrete delivered in trucks is acceptable, NRMCA and the Truck Mixer Manufacturers Bureau have published a statement entitled, Truck Mixer and Agitator Standards of the Truck Mixer Manufacturers Bureau (NRMCA, 1966). Each member company is expected to abide by these standards.

The referenced documents are excellent guides* however, they must be enforced and reinforced by inspectors on the job.

Requirements in CONUS or Remote

Fundamentally, there is no difference in requirements for production of ingredients and their blending into portland cement concrete whether the job site is in conUS or remote. The same plant items and equipment are required in either case. A coNUS site may make it possible to use existent concrete production facilities whereas a remote site may require the whole spectrum of operations to be new.

\footnotetext{
"Various additional NRMCA publications are included in the reference 1ist.
} 


\section{PART FIVE - CONSTRUCTION METHODOLOGY}

by M. J. Wolfe

CONSTRUCTION PROCEDURES

As with most other facets of MOBS, a detailed analysis of construction procedures will require a specific, well-defined example platform. Because of the varying configurations of the three basic types of platforms, no one technique, procedure, or solution can be suitably applied to all of the platforms under consideration without some changes. Similar remarks apply to the choice of construction sites. It is important to note, however, that enough descriptive detail exists to make general, yet valid, conclusions on the overall suitability of utilizing conventional concrete construction practices for fabricating a particular type of MOBS platform.

The construction and subsequent assembly procedures can be conveniently divided into three distinctive categories based on platform type:

1. Elevated

-- Launch deck fully assembled as a module; add and connect buoyant support columns at sea; deballast.

2. Semi-Submersible -- Launch buoyant elements fully assembled as a module; add and secure deck elements at sea; adjust ballast.

3. Barge

-- Launch fully assembled platform; or launch buoyant elements fully assembled as modules as for the semi-submersible, adding deck at sea.

Various techniques and/or possible options applicable to the above schemes for fabrication and assembly are discussed in the following sections.

Location of Construction

Dike and Polder. Figure 5.1 illustrates a type of construction site for large floating structures which has been successfully used in the past. A large pit (polder) is excavated behind a dike or, perhaps, a dredge can excavate enough material to form a dike. The units are constructed on the polder using conventional construction techniques and equipment. After the units are completed the polder can be flooded and part of the dike dredged away. The unit can then be floated out and towed to the site of operations. 


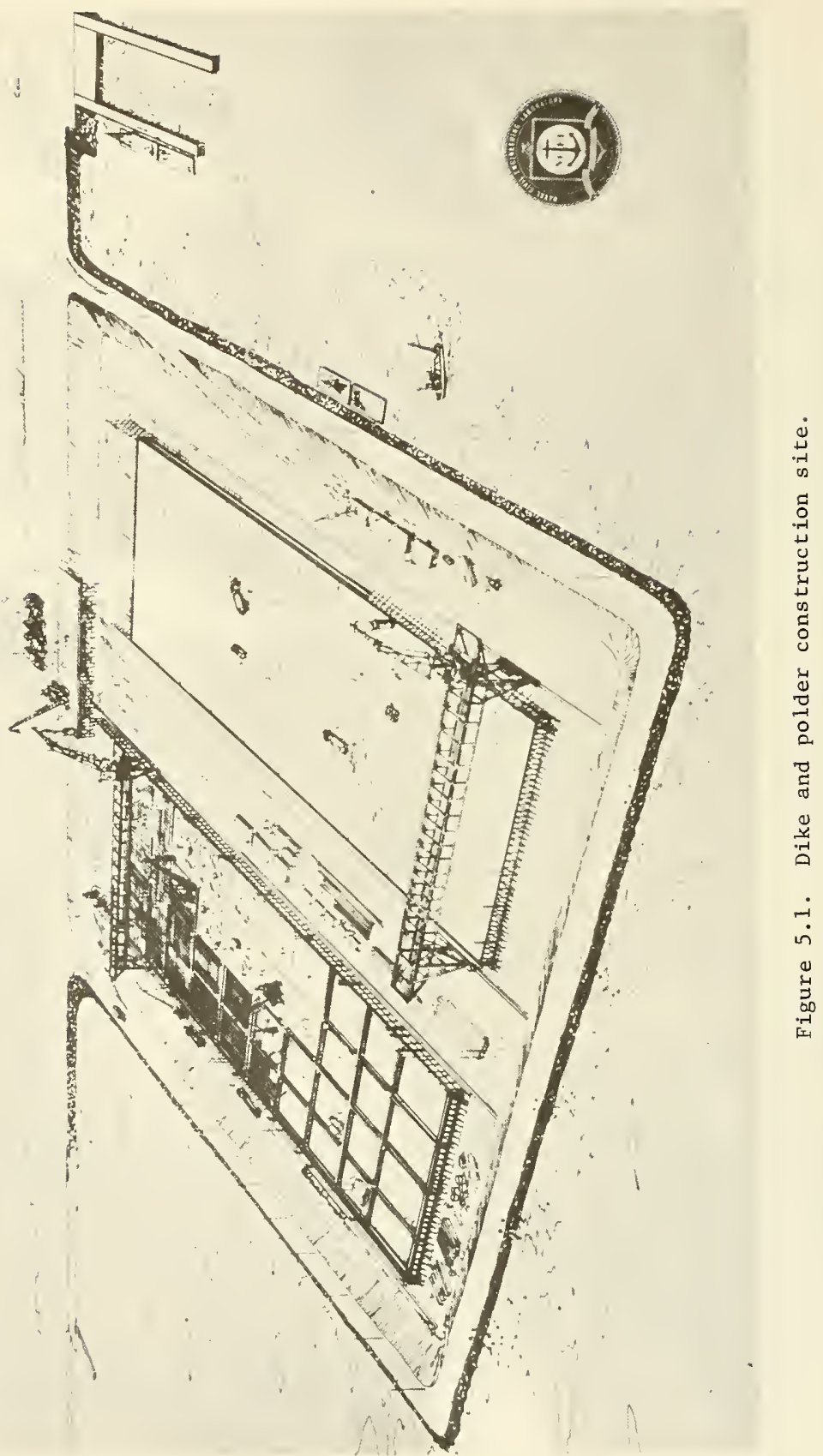


Figure 5.2 is a cross-section view of a typical dike. The core is made of a substance more impervious than the surrounding material. The armor stone provides protection from incoming waves and the possible effects of currents. A properly designed and constructed dike of this type will last a very long time with little need of repair.

There is a considerable amount of information available on the design and construction of a dike. Most dikes have been designed conservatitvely to avoid disaster due to wave attack, storm surges, leakage, and similar phenomena. For a polder to be used as the MOBS construction site, it appears highly likely that a less conservative design may be acceptable because the useful life of the MOBS dike is many times shorter than that of a dike built for long-term protection. Settlement and/or shrinkage of the dike may be tolerated and leakage can be combated by installing pumps. Also, it may not be necessary to use armor stone if there is little wave action in the waters surrounding the construction site.

There appear to be a large number of estuaries, lagoons, and similar bodies of water near the ocean which, with little effort, could be used as a construction site. If a suitable location of this type can be found, it may be possible to decrease site preparation costs considerably. A small dike could be built to block-off the sea, the area pumped dry and, if necessary, expanded employing conventional earthmoving equipment.

An obvious advantage of the dike and polder approach is the possibility of using standard concrete mixing and placing equipment in their design environment. Also, there will most likely be sufficient space for equipment and material storage. Another important advantage is the lack of constraints on the size of the module in plan; even fullscale, shallow-draft platforms could be fabricated and launched. But, the constraint of most concern for the dike and polder is depth: platforms with excessive draft might make this approach economically impractical.

A number of concrete structures have been successfully fabricated behind dikes. The designers of the La Fontaine Tunnel in Canada used a polder excavated in the St. Lawrence River to construction prestressed concrete sections 120 feet wide, 15 feet high, and appproximately 300 feet long." The dike extended over a half mile into the waterway. A11 of the tunnel sections were constructed before a portion of the dike was broken and the construction area flooded. The sections were then towed to the tunnel site and lowered into a trench in the river bottom.

Another example of a project employing this construction technique is the large oil tank fabricated in a shallow pit on a beach in the Arabian Gulf (Ocean Industry, Sept 1969). Shaped like an inverted funnel, the tank is 207 feet in diameter at its widest section. It weighs 15,000 tons, had an 8-foot draft when floating, and required two tugboats for towing to its final resting place 58 miles offshore.

"PCI Journal, August 1965 and Engineering News Record, 1 July 1965. 


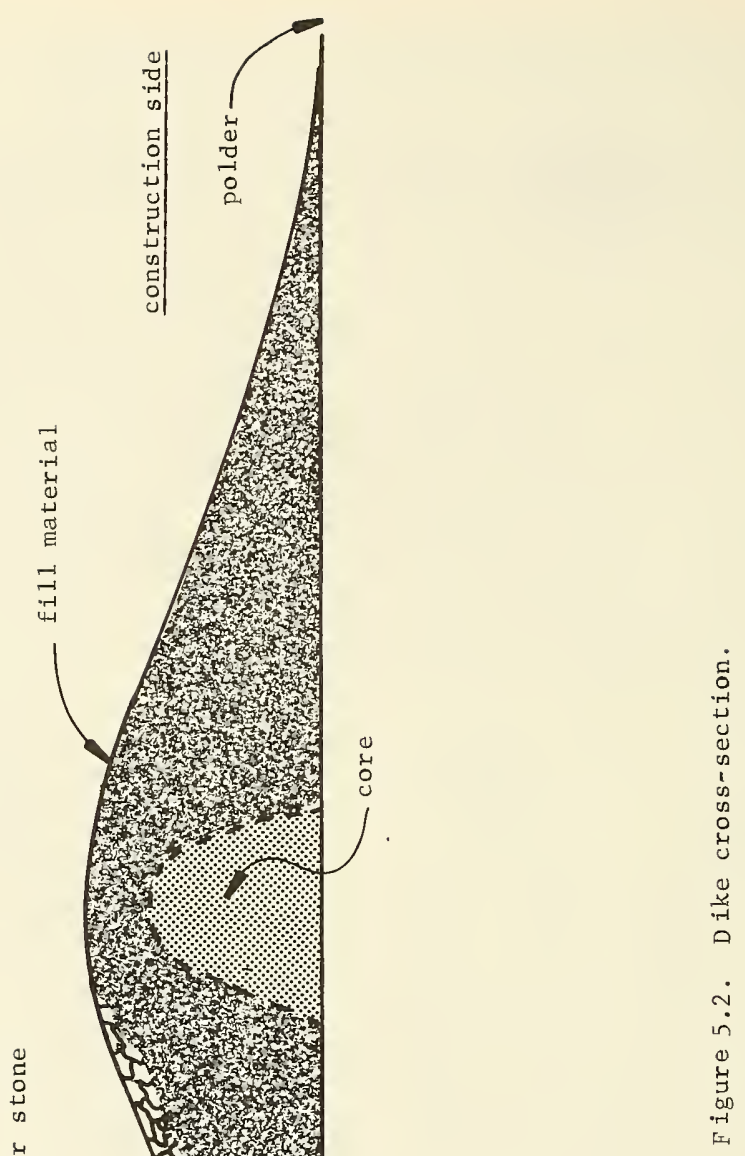


Figure 5.3 illustrates the approximate relationship between the cost per mile of the dike and dike height (Ralph M. Parsons Co., 1969). These costs include the polder and all necessary items, such as drainage channels and sealer. Assuming a 40-foot high dike, the approximate cost would be $\$ 7 \frac{1}{2}$ million per mile of dike; the cost for each size of platform, based on the assumption the polder has water on three sides, is given in Table 5.1. Since a 40-foot high dike is somewhat higher than most platforms need to have adequate draft clearance, the totals in Table 5.1 can be considered to be on the safe side.

Table 5.1. Estimated Costs of Polder Dike

\begin{tabular}{|c|c|c|}
\hline $\begin{array}{c}\text { Platform } \\
\text { Size (ft) }\end{array}$ & $\begin{array}{c}\text { Assumed Polder } \\
\text { Size (ft) }\end{array}$ & $\begin{array}{c}\text { Cost of Polder Dike } \\
(40-\mathrm{ft} \text { dike) }\end{array}$ \\
\hline $300 \times 300$ & $400 \times 500$ & $\$ 1,840,000$ \\
$400 \times 1200$ & $500 \times 1400$ & $3,400,000$ \\
$1000 \times 4000$ & $1200 \times 4400$ & $9,600,000$ \\
\hline
\end{tabular}

As is true of a11 large construction projects, the costs of moving and placing large amounts of material to construct a polder can vary between wide extremes because of differences in location. Thus, any cost estimates for the dike and polder arrangement must be viewed as indicators of orders of magnitudes rather than actual values.

Drydock. As noted in Part 2 of the report, drydocks have been used successfully as construction sites for floating concrete vessels. While feasible for this type of construction, it is doubtful that a full-scale platform could be built in an existing drydock because of limitations on width. There are very few drydocks big enough to build a 300-foot by 300-foot structure. According to Kohler (1970), the largest shipbuilding dock in the world is over a third of a mile long and 100 yards wide. Located in Belfast, this dock is capable of accommodating ships of up to one million tons dead weight. As a practica1 alternative to using such a large dock or something similar, it seems best to design the modules to be more ship-like in plan -- perhaps 100 feet by 300 feet or even 100 feet by 1,000.

There are some noteworthy advantages resulting from fabricating modules in a drydock. Foremost is the ready-made work site near the water's edge. Also, there is ready access to the large capacity cranes which are standard equipment at any shipyard; but, since it is routine to establish complete concrete-mixing plants, including heavy-1ift cranes, in virtually any location, it would seem best to consider the availability of heavy construction equipment of secondary importance. 


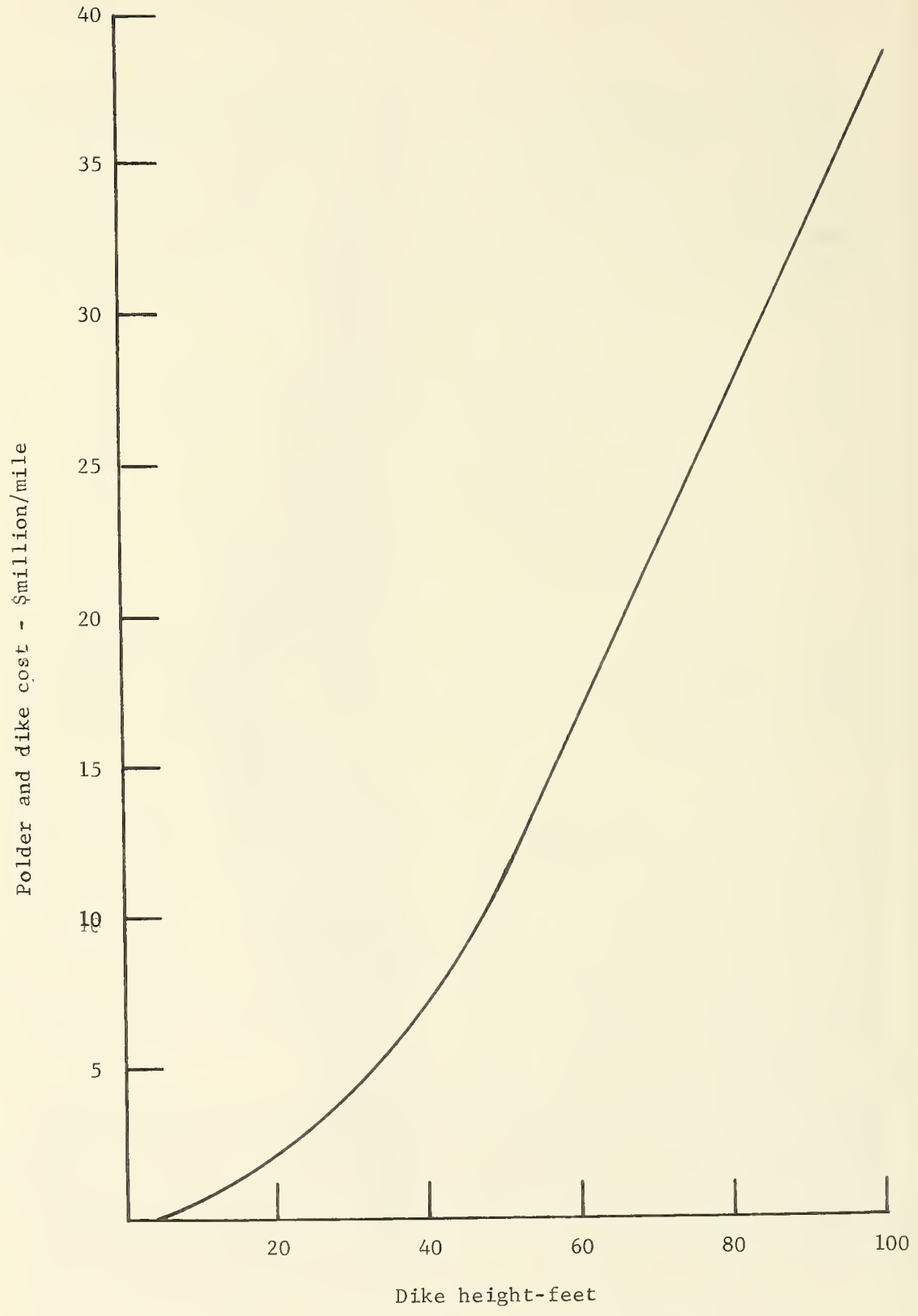

Figure 5.3. Polder and dike costs. 
Slipways. In a slipway the vessel is built on a plateau somewhat above the high water mark. Upon completion of construction, the hull is slid down rails which continue under water. Slipways are oriented so the longest axis of the hull is perpendicular to the water's edge; in this way, valuable waterfront space is conserved. A variation of the slipway is the "side-launch" type of facility, in which the hull is built parallel to the water's edge.

The slipway suffers from the same limitations as a drydock with respect to the maximum outside dimensions permitted for a module. On the positive side, such a facility appears to be suited as a dry assembly point for long sections composed of prefabricated elements -- in particular the cylindrical buoyancy chambers of the semi-submerisble platform.

At Sea. A fourth possibility for a construction site is the ocean itself. For some processes, such as the slip form process (discussed later in the text), this is a necessity. For others, the possibilities of using the ocean as a work site need further careful study. Particularly advantageous is the unlimited space and the possibility of harnessing tremendous buoyant forces for supporting heavy loads.

Concrete Construction Practice

In general, the MOBS platforms under study entail nothing unusual in the way of concrete construction practices. The various types of concrete fabrication, such as cast-in-place and precast, have been practiced in enough different situations and projects that all but the most unlikely problems have been encountered and solved. Trial-anderror experience alone has improved the practices and techniques of concrete measuring, mixing, handling, transporting, and placing to the stage where these operations are essentially routine. Initially, then, it is justified in assuming that everything through the placing of concrete is virtually independent of the type of construction site; and, further, there appears to be no unsolvable problems posed by any of those sites previously discussed or reasonably imagined.

Cast-in-Place Construction. Cast-in-place construction is by far the most common approach to building a large concrete structure. The basic steps in the procedure include (1) installation of the forms, (2) mixing and placing of the concrete, (3) allowing the concrete to cure, and (4) removal of the forms. The great bulk of the buildings, irrigation channels, dams and similar structures are built in this manner. A "cast-in-place" MOBS platform or module would be built the same way, resulting in the same kind of monolithic structure.

It is interesting to note that prestressing reinforcement can be incorporated into the design of cast-in-place concrete structures. Usually post-tensioning is used. All of the advantages of prestressing are achieved yet the great dead-load weights of comparable precast units are avoided. Ordinary forms and pouring methods are used. The technique has been used for all types of structures, including multi-span bridges. 
Precast Construction. Precasting is the fabrication of a member in a location other than its final position in a structure. Usually precasting is done at a specialized factory from which the pieces are shipped to the assembly site. However, job-site precasting is not unusual; tilt-up slabs used for constructing buildings is an example of the latter.

A majority of the precast items are mass-produced with each manufacturer supplying well-defined specifications. Piles, girders, roof members, and other standard products form the great bulk of the products fabricated at the factories. The acceptance of off-the-shelf precast items by engineers has increased the quality and decreased the unit costs of the end product. This is due primarily to the cyclic nature of the precast technique, which can be performed daily, thereby increasing the efficiency of the labor. Another added cost-reducing factor is the manufacturers' willingness to invest in better quality equipment to produce the standardized items, knowing that they can amotorize the initial investment over a longer period of time. In short, all the benefits which accrue in mass production in general can be had in a precast concrete operation.

The equipment used in a precasting operation does not differ from that found in any concrete project. Conventional mixers, vibrators, and associated equipment are suitable for mixing and placing the concrete into reusable forms. Transporting and handling of precast concrete items are carefully controlled operations. Pickup points are designated and used to lift and place the units. Indiscriminate attachment of lifting lines will likely overstress the member, as will tilting or placing in a way other than the position designated. None of these provisions and restrictions on handling is unduly troublesome, as the widespread use of precast concrete elements indicates.

In addition to providing items of high quality, precasting also offers the advantage of easy prestressing. Either pretensioning or posttensioning can be done quickly and economically, under the best of conditions, at the casting site.

A disadvantage of precasting, particularly with respect to MOBS, is the limitation on the size of the units that can be cast. The size constraints are not inherent in the technique itself, but are imposed by the availability and capacities of heavy-1ift equipment. Heavy and large concrete sections are not practical to transport and difficult to place and position. Consequently, the weight of a precast section is foremost in the design. For MOBS elements, or in a platform of moderate size, this is not a drawback. But if a large platform were to be assembled from easily-managed components, it appears certain there would be too many elements and connections to be practical.

The cost of a precast concrete item is usually determined on the basis of area or length. Precast concrete panels 7 inches thick and 300 to 500 square feet in area wi11 cost about $\$ 1.80$ per square foot, including erection and alignment. This j.s approximately $\$ 60$ per cubic yard (using 3,000 psi concrete). Standard precast bridge beams ( 3 feet 
wide) for highway loading cost $\$ 25$ to $\$ 33$ per lineal foot, depending on the span. This cost includes all labor and materials necessary for final positioning and securing of the span. On the basis of cost per cubic yard, it appears that precast reinforced concrete is roughly twothirds that of cast-in-place for simple and small structures. Prestressed, precast concrete costs roughly twice that of reinforce concrete.

Fabrication of Cylindrical Elements

Standard Technique. A successful and efficient technique for fabricating large prestressed concrete pipe is presently being used in the California State Water Project. Pipe sections 20 feet in outside diameter with walls 20 inches thick are fabricated at a temporary plant located on a 45-acre site near the Castaic Dam, fifty miles north of Los Angeles.

The fabrication technique consists of two basic steps. First, concrete is placed into vertical, cylindrical steel forms and vibrated. A relatively thin steel membrane is imbedded in the resulting concrete "core" to give the final product complete impermeability to seepage in either direction.

After a short period of curing, the core has gained sufficient strength to be transported and placed vertically on a large turn-table where it is rotated rapidly while prestressing wire is wrapped around the circumference. The prestressing tension in the wire can be as high as 170,000 pounds per square inch. After the first layer of wire is finished, a layer of concrete is applied, allowed to dry, and a second layer of wire is wrapped. A final coating of concrete follows. Up to 16 miles of prestressing wire have been installed in a single pipe section.

The pipe sections are made in 20-foot lengths and weigh 150 tons. To handle and position these large objects, two special pieces of equipment were designed and built. One, called the "Liftmobile" is a large traveling frame, towed by a standard rubber-tired caterpiller tractor, which can 1ift, transport, and accurately position the sections onto the prestress and cement mortar coating turn-tables. When the pipe is ready for installation, the Liftmobile tips it on its side where it can be picked up by a second vehicle, the "Pipemobile." The Pipemobile is a 63-foot long, 20-foot high rubber-tired machine which can be backed through a pipe section, lift it, and move at 12 miles per hour to the final installation point (Figure 5.4). The Pipemobile operator can position the $150-$ ton sections to within the 1/8-inch tolerance specified for the project.

High quality concrete is used for the pipe section. Depending on the location of the section, compressive strengths vary from 4,500 to $6,000 \mathrm{psi}$. The production rate varies from about 350 to 700 cubic yards per day. The entire batching system is automated and no difficulties in quality control have been encountered.

With two eight-hour shifts and a total payroll of 60 , the factory comfortably produces eight 20-foot sections per day. Construction costs 
are somewhere in the range of $\$ 50$ to $\$ 60$ per ton (or $\$ 100$ to $\$ 120$ per cubic yard of concrete). At this rate, a 20-foot 0 . D. pipe would cost from $\$ 7,500$ to $\$ 9,000$ per 20 feet of length. These sections are conservatively designed to withstand an internal pressure of approximately 175 psi.

High quality concrete pipe sections from 30 inches to 25 feet in diameter can be constructed routinely using equipment of the above description. Larger diameters are feasible, but most equipment used in the process would have to be strengthened and enlarged; this is not a problem. Since the cylindrical sections for the MOBS platforms are on the order of 30 feet, this process is nearly capable of immediately supplying the required construction elements.

If desired, such things as longitudinal holes for post-tensioning cable, an internal reinforcing net, or access holes can be made a part of a section. These and other reasonable design requirements pose no problems for the technique.

Vertical Slip Form Casting. Vertical slip form casting is a patented method of fabricating long cylindrical sections in deep water. Developed in Europe, the process involves a floating work platform which is furnished with all the equipment needed to mix and place concrete, store and transport materials and provide living quarters for the crew.

The method is we11-suited for mass production. As shown in Figure $5.5(a)$, the casting begins with a precast end piece (in this case a hemispherical section) which can be made locally, perhaps on a nearby floating dry dock, or shipped to the scene of the slip-forming operation. If necessary, water ballast can be added to the casting for stability.

The casting is done in a floating form, as shown in Figure 5.5(b). The unit can be trimmed by periodically adding water to the completed portion below the waterline. Using this procedure, it is possible to maintain the top of the form at a constant height. Usually this height is about 20 feet, so at a pour rate of 8 inches per hour, the concrete will be 30 hours old when it reaches the waterline. Concrete at this age will be strong enough to survive the water pressure. Curing will continue under water.

When sections are completed, the open end can be capped, perhaps with another concrete end-piece. By pumping the water out, the section will slowly rotate until it is in a horizontal position, Figure 5.5(c), ready for towing. If desirable, the completed section can be maintained vertically for final positioning under the deck of an elevated platform.

The vertical orientation of slide form casting is favorable to longitudinal prestressing. Good quality concrete, combined with prestressing will ensure water tightness. Prestressing also markedly increases the capability of the section to resist longitudinal bending moments. 


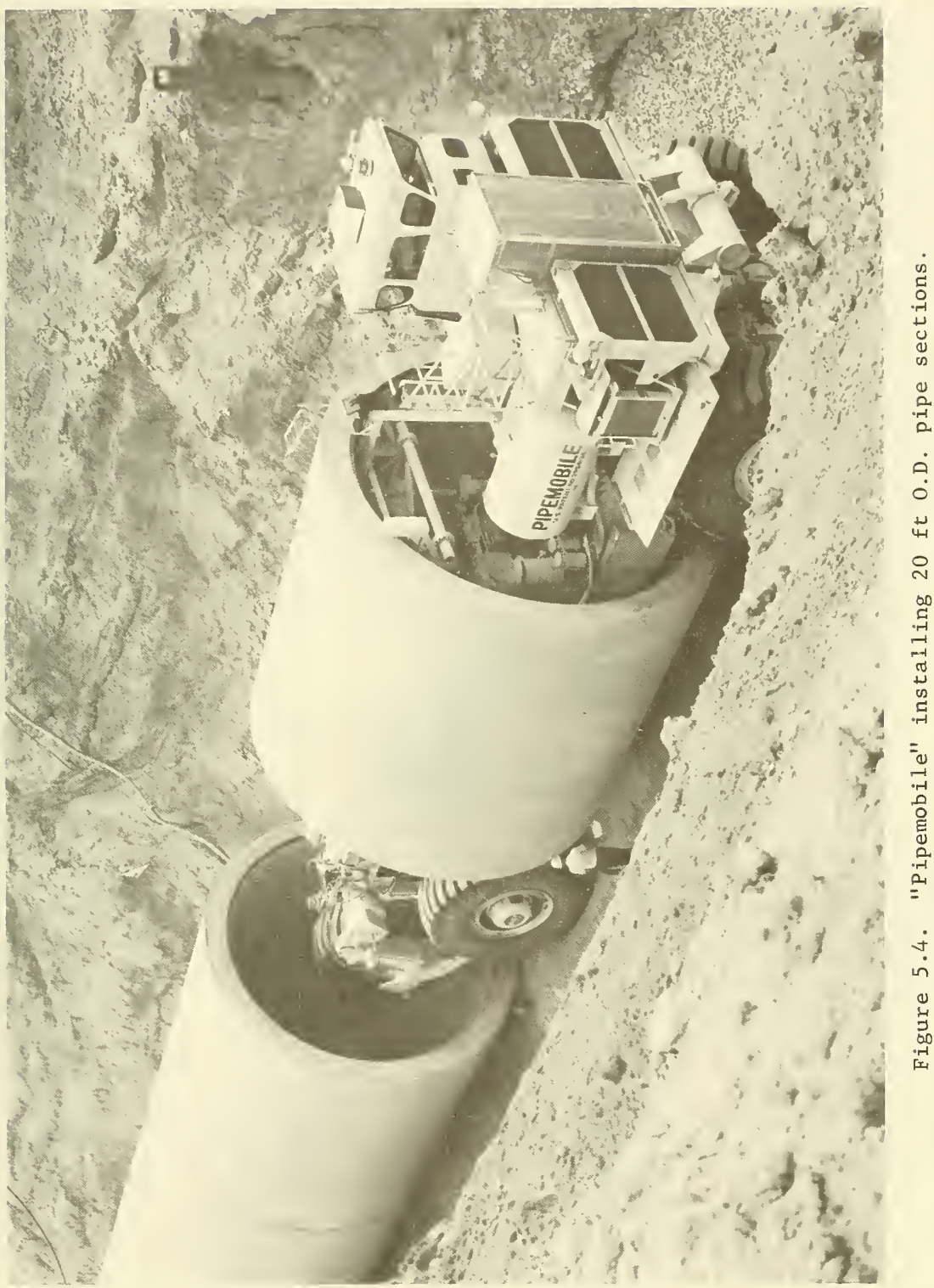




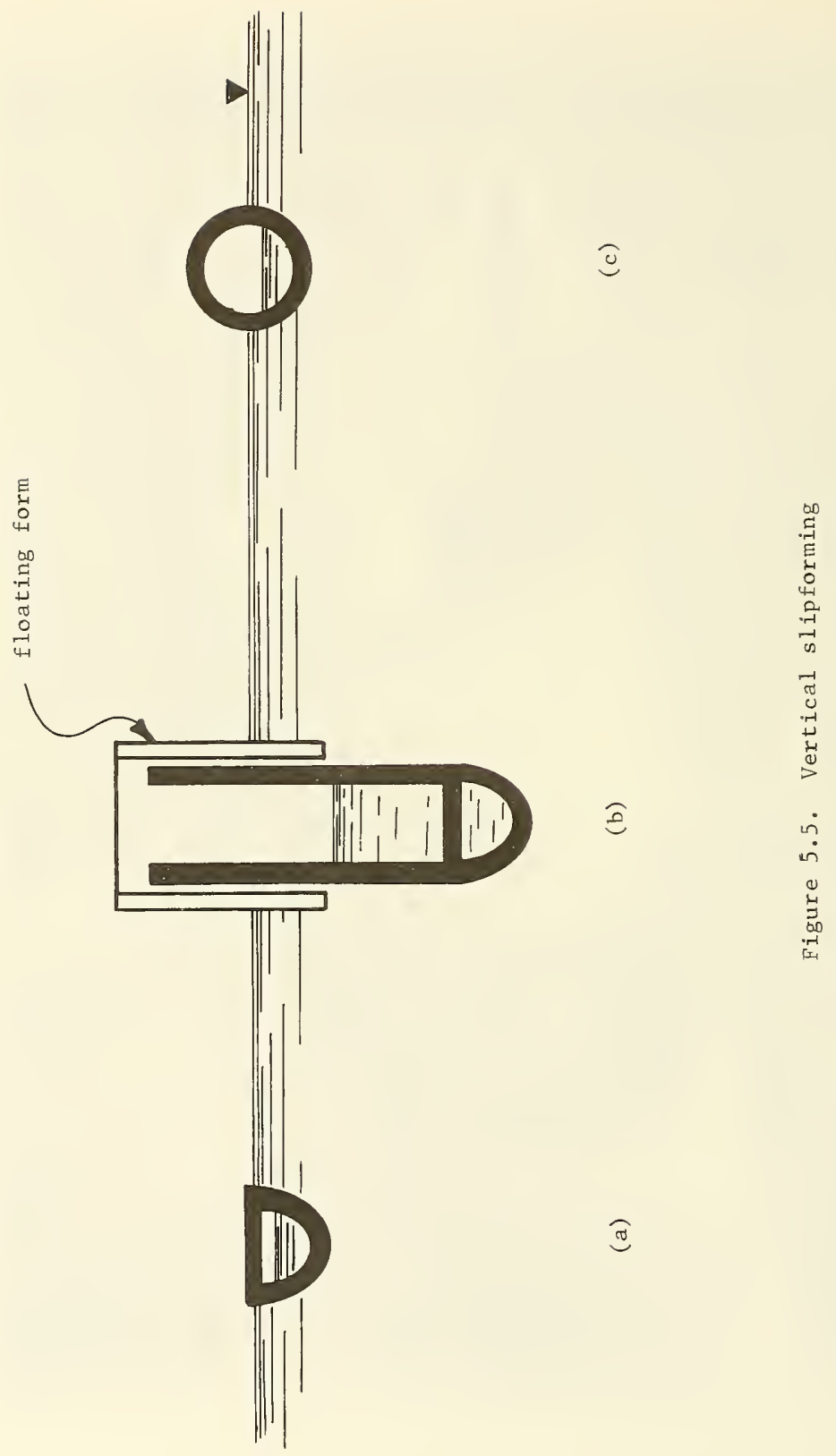


An advantage of this method is the ease with which construction may begin. There is no need for dry docks or polders; instead, construction can begin at any time in any quiet water of sufficient depth. The construction rate is estimated to be about 500 feet of section per month per form. Any number of forms may be used, and the area required is considerably less than if the sections were constructed horizontally on 1 and.

The process is a continuous manufacturing technique which results in a homogeneous concrete structure with no joints. Like al1 repetitious casting techniques, it is efficient and economical, particularly because there is very little equipment needed. The latter is particularly advantageous from an investment standpoint, since the major items of equipment can and should be conventional items presently available on the market. The forms are the only unusual elements, but they should be relatively inexpensive to build.

As far as is known, no large sections have been constructed using slip form casting. Some preliminary cost estimates have been derived for at least two large vessels which have been proposed as likely candidates for the technique. One, a 1,400 foot long supertanker, is estimated to cost 250-300 kronors per ton of concrete weight. * At the current exchange rate of 5.2 kronors per dollar, this is about $\$ 50$ to $\$ 60$ per ton or about $\$ 100$ to $\$ 120$ per cubic yard. A much smaller vesse1 of 1,000 tons displacement was estimated to cost $\$ 200$ per cubic yard. The cost of the equipment for construction of the supertanker is estimated not to exceed $\$ 4,000,000 .{ }^{*}$ These cost figures are within $10 \%$ of the cost estimates given for more conventional methods of concrete construction practiced in the continental United States.

Fabrication of Deck and Hull Elements

Deck. Deck elements for the elevated or the semi-submersible platform are seen as precast, prestressed concrete "box" elements, posttensioned in final assembly to obtain an integral deck and for connecting to the support elements. The box elements could be sized and tiered to meet multiple deck requirements. Solid slab construction appears un 1 ikely for the smaller platforms, but probably would be employed in the larger platforms in combinations with multiple decks. In optimizing the design, the box element could emerge as a likely candidate even for the single deck; the depth would satisfy structural requirements while the box feature would minimize weight and provide buoyancy.

$*$

*Hydro Concrete System, Aktiebolaget Hydro Betong, Stockholm, Sweden, 1965 , p. 4 of section PM No. 3. $* *$

Ibid., page 2 of Section PM No. 4 **:

Ibid., page 4 of Section PM No. 4 
The deck for the barge platform will probably be a combination of slabs, boxes and monolithic construction with the hull. Post-tensioning will be utilized were applicable.

The aircraft landing strip, a relatively thick section, could be precast integrally with the deck boxes, but more probably would be cast in place after the deck was fully assembled. The deck itself would serve as forms for casting the strip. The option of whether the strip will be cast before launching or after launching, at sea, is a designer's choice.

Construction techniques in practice for building systems will provide the necessary guidance to engineer the deck systems.

Hulls. For deep hull sections, it appears likely that cylindrical or curved sections will be the only efficient configurations. Cylindrical sections can be fabricated using any of the techniques discussed earlier. Curved sections can be constructed using forms or prefabricated sections. Both of the latter approaches have been successful in building large diameter tunnels and water pipes. Curved hull sections need not be unusually large, but some of the unique design requirements will impose modifications on conventional construction practices. Monolithic construction employed in building concrete ships will be an attractive option for hull construction.

Requirements for a Baseline Batching and Mixing Plant

A structure as large as MOBS will be composed of as much concrete as is used to construct a medium-size dam. It is anticipated that something on the order of $2,000,000$ or more cubic yards of mass concrete will be required for a large MOBS platform. The experiences and methods of construction firms engaged in mixing and placing large volumes of concrete, particularly dam construction, are excellent guides for evaluating the type and size of the batch plant needed for MOBS.

For the purposes of illustration, it is assumed that the plant is to be designed to mix and place 1,000,000 cubic yards of concrete per year. A plant of this size would be somewhat as follows:

Baseline Plant

Production . . . . . . . 1,000,000 cu yd/year Operation ........ two 10-hour shifts

Quantities handled per year

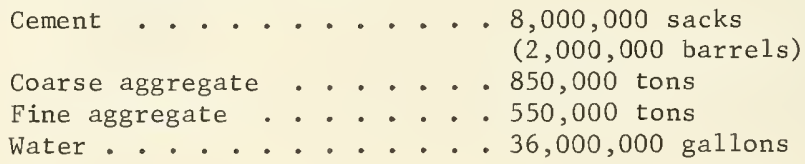


As noted in Part 4, there are currently 17 plants routinely producing in excess of 500,000 cubic yards per year. Any number of these can be assembled at the construction site to obtain virtually any production rate. It is reasonable to assume that any multiple or fraction of the above can be achieved by a system composed of equipment whose outputs have been scaled up or down the appropriate amount. The only limitation appears to be the problems of finding adequate manpower (both in skill and numbers) for exceptionally rapid construction.

There are a large number of feasible and practical alternatives for establishing a concrete-mixing plant, thus making it relatively safe to reason that the problem can be solved in all but the most remote locations. While it is difficult to estimate the total cost of equipment, it was determined from various sources on heavy construction that a one million-cubic-yard per year plant, newly purchased, would be slightly less than $\$ 4$ million. This dollar figure includes purchase price, installation cost and dismantling cost, and zero salvage value.

Materials

The technical 1iterature includes much information on mix design, laboratory investigations, and production of concrete for waterfront structures and ships. The extent of information is too great to report here. Comments on material specifications applicable to MOBS are offered in Appendix B, together with a selected reference listing.

\section{CONSTRUCTION TIME AND COST}

At a production rate of one million cubic yards per year, the time necessary to construct any of the platforms is indicated in Table 5.2. The maximum time noted is approximately $3 \frac{1}{2}$ years for the elevated platform with multiple decks. As was discussed in Part 3, the table values represent the extremes, the final platform will probably be a combination of single and multiple decks. On the other hand, the shortest time is only 0.03 years, which suggests that a baseline plant producing considerably less than one million cubic years per year would suffice.

Cost

Table 5.3 presents the estimated construction costs of the platform exclusive of power systems, machinery and personnel support facilities. The costs of mixing and placing the concrete, fabricating and installing the forms, and purchasing and installing the reinforcement are included in the figures. 
Table 5.2. Concrete - Q Quantities (in million cu yds) for Type of Platform Indicated.

\begin{tabular}{|c|c|c|c|c|c|}
\hline \multirow{2}{*}{$\begin{array}{c}\text { Platform } \\
\text { Size (ft) }\end{array}$} & $\begin{array}{c}|c| \\
\text { Single } \\
\text { deck }\end{array}$ & $\begin{array}{c}\text { Multiple } \\
\text { deck }\end{array}$ & $\begin{array}{c}\text { Single } \\
\text { deck }\end{array}$ & $\begin{array}{c}\text { Multiple } \\
\text { deck }\end{array}$ & Barge \\
\hline $300 \times 300$ & 0.05 & 0.08 & 0.04 & 0.05 & 0.03 \\
$400 \times 1200$ & 0.28 & 0.42 & 0.21 & 0.27 & 0.18 \\
$1000 \times 4000$ & 2.34 & 3.59 & 1.73 & 2.28 & 1.48 \\
\hline
\end{tabular}

a/

Includes both structural and ballast concrete from Table 3.2 . The table values also represent time in years, when production rate is one million cubic yards per year.

Table 5.3. Estimated a/ Construction Costs (in millions of dollars)

\begin{tabular}{|l|c|c|c|}
\hline \multicolumn{1}{|c|}{ Platform Type } & $300^{\prime} \times 300^{\prime}$ & $400^{\prime} \times 1200^{\prime}$ & $1000^{\prime} \times 4000^{\prime}$ \\
\hline $\begin{array}{l}\text { Semi-submersible, single } \\
\text { level deck }\end{array}$ & 5.3 & 28.3 & 236 \\
$\begin{array}{l}\text { Semi-submersible, multi- } \\
\text { level deck }\end{array}$ & 7.4 & 39.2 & 328 \\
$\begin{array}{l}\text { Elevated, single leve1 } \\
\text { deck }\end{array}$ & 7.0 & 37.4 & 312 \\
$\begin{array}{l}\text { Elevated, multi-level } \\
\text { deck }\end{array}$ & 10.7 & 57.5 & 481 \\
Barge & 5.0 & 26.7 & 223 \\
\hline
\end{tabular}

a/ Based on $\$ 150$ per cubic yard for structural concrete and $\$ 75$ per cubic yard for ballast concrete for the quantities given in Table 3.2. Costs include prices of concrete, forms, reinforcing and placing equipment. 
The estimates in Table 5.3 are based on the cost per cubic yard of concrete required for construction. Conservative estimates of $\$ 150 /$ cubic yard for structural concrete and $\$ 75 /$ cubic yard for ballast concrete were used in the calculations. In Table 5.4 unit cost figures for concrete construction are given for purposes of comparison. The $\$ 150$ per cubic yard chosen for MOBS is about 50\% greater than the national average for buildings and $25 \%$ greater than the prevalent estimate of $\$ 120 /$ cubic yard for floating concrete airports.

Table 5.4. Comparative Cost of Cast-in-Place Concrete

Dollars/Cu Yd.

National average for concrete framed building

including forms, hoisting equipment, but not

including finishing.

$\$ 92.50$

National average for concrete footings.

FLAIR: c/ (a) Reinforced concrete for anchors and buoyancy units

120.00

(b) Prestressed, precast deck panels, $14^{\prime \prime}$ thick (about 16 feet on a side (calculated cost))

105.00

Bay Area Rapid Transit, tunnel sections

(estimated cost; also see Part 4)

120.00

MOBS: (a) Structura1 concrete (estimated)

150.00

(b) Ballast concrete (estimated)

75.00

Sources:

a/

Building Construction Cost Data 1970, Robert Snow Means Company, Inc., Doxbury, Mass., p. 36 . b/

Ibid., p. 37

c/

Weidlinger, 1970

Table 5.5 presents some data on the unit area costs of single level floating platforms. The Lake Washington Floating Bridge was completed 
in 1963. The remaining structures are only proposals for which cost estimates have been made. The costs for the Toronto Floating Airport varied from $\$ 35$ per square foot to " . a pessimistic $\$ 4,356,000$ per acre. . ." (100 dollars per square foot) by the Canadian Department of Transport; the differences arise over the estimated costs of solving difficult anchorage and structural problems peculiar to the chosen site. The comparatively high cost of MOBS is due to the more severe design loads imposed by the ocean environment, combined with the more conservative unit cost of structural concrete.

Table 5.5. Selected Unit Area Costs of Single-Level Floating Concrete Structures

FLAIR: a/ (a) Large area

(b) Smal1 area

Rutgers Aquadrome $\underline{b}$ / (Parsons' estimate)

Lake Washington Floating Bridge $e^{\text {/ }}$

Parsons' Floating Pontoon Airport

Toronto Floating Airport: /

(a) Originator's estimate

(b) Canadian Department of Transport estimate

MOBS, single-deck semi-submersible, $\left(300^{\prime} \times 300^{\prime}\right)$
Dollars/sq ft

$\$ 29.40$

33.40

100.00

25.70

30.10

35.40

100.00

59.00

a/

Weidlinger, 1970

b/

Ralph M. Parsons Co., 1969

c/

Ibid., p. 102

d]

Ibid.

e/

Ibid., p. 103

City cost indexes are commonly applied to construction cost estimates to account for variations between locations. From recently published figures* it does not appear likely the total costs given in Tables 5.3 * Building Construction Cost Data 1970, 28th Annual Edition, R. S. Means, Co., Doxbury, Mass. 
and 5.4 would differ significantly among coastal cities considered as possible construction sites. However, prices quoted are for metropolitan and adjacent areas. For remote sites the costs could vary enough to warrant special consideration.

\section{ASSEMBLY TECHNIQUES}

The techniques described in these sections are in accordance with the philosophy expressed earlier in the text (section on Construction Procedure Summary). Some of the more prominient assembly methods for these platforms are discussed below.

\section{Elevated Platforms}

The assembling of large elevated platform will be a difficult task because of the tremendous mass and size of most of the components. The primary problem is that of moving and accurately positioning the supporting columns: their long length and varying buoyancy are seldom encountered in present-day construction at sea. The proposed assembly techniques are based on the availability of a floating deck, which is essentially a large pontoon designed to accept the columns that project downward. The proposed techniques have not been studied in depth.

Cable Guided Technique. Figure 5.6 schematically illustrates the essential steps for this technique. In step (a) the cylinder and deck are brought to the construction site. The cylinder is then flooded until it is resting vertically and fairly low in the water. A cable is attached to the cylinder and the other end is passed through the floating deck, as shown in step (b), to a winch of moderate size. The cylinder is then flooded further (minimum negative buoyancy) until it is low enough to pass under the deck and be pulled via the cable into position, and subsequently attached. The connected column would then be deballasted to neutral buoyancy. Step (c) illustrates how the flooded columns and deck would be resting in the water after all columns were attached. Finally, the columns would be dewatered in the appropriate sequence until the entire unit rises the required distance out of the water, as shown in step (d).

It may be possible to install only some of the column and then dewater so that the platform would be partially elevated (the deck would have to be designed accordingly). If this were possible it would be unnecessary to flood the remaining columns to the point where they are completely submerged, thereby simplifying attachment of remaining columns.

Segmented Column Technique. Another suggested assembly technique is illustrated in Figure 5.7. In this technique easy-to-handle, watertight sections are lowered through openings in the floating deck. The techniques requires a water-tight seal between sections and connecting 
the sections together with longitudinal cables or rods. The maximum practical length for such an assemblage is subject for further study. Water ballast can be used in the columns for buoyancy control. When al1 legs are assembled, the interiors can be pumped dry. The same variations discussed in the previous technique apply to this concept.

In this technique the segments may be towed to the assembly site or shipped via barge. In either case, heavy-duty handling equipment will be involved; the need for hoisting heavy loads in the open sea is a distinct disadvantage.

Slip Form Technique. The use of a slip form (discussed earlier in the section on construction procedures) offers a different $k$ ind of assembly procedure. In this technique the floating deck has circular forms built or installed into the deck openings. A cement mixing plant can be installed on the deck, or equipment which can receive concrete from a nearby floating plant can be installed. As in other assembly techniques, the requirements for sufficient buoyancy and structural adequacy of the deck will require investigating.

Semi-Submersible Platform

As with the elevated platforms, the semi-submersible can be considered to consist of two major sub-assemblies: (1) the superstructure or deck and (2) the supporting buoyant sub-structure. The deck of the semi-submersible differs 1ittle from that of the other types of platforms and can be constructed in the same way, most likely as modular units post-tensioned together to form the complete deck. Assembling the pontoons and vertical supports are unique problems.

If the cylindrical buoyancy pontoons are cast monolithically, no associated assembly problem exists. The alternate method of fabricating short sections with assembly by post-tensioning does require some thought. The most promising approach appears to be assembly on a polder, behind a dike. The sections could be positioned end-to-end and post-tensioned. Vertical support elements and necessary framing would be added and posttensioned. After completion of the assembly, the basin would be flooded and the sub-structure floated out. Deck elements could be cast at an adjacent site and placed onto the sub-structure at sea.

\section{Barge Platforms}

Monolithically cast barge modules would be built and launched without need for assembly. The same would apply to a barge module composed of prefabricated elements. The latter would probably be connected together by post-tensioning. As in ship construction, it may be desirable to fabricate the hull on land, launch it, and then outfit it while floating. Where araft is a problem, deck elements could be added at sea. 


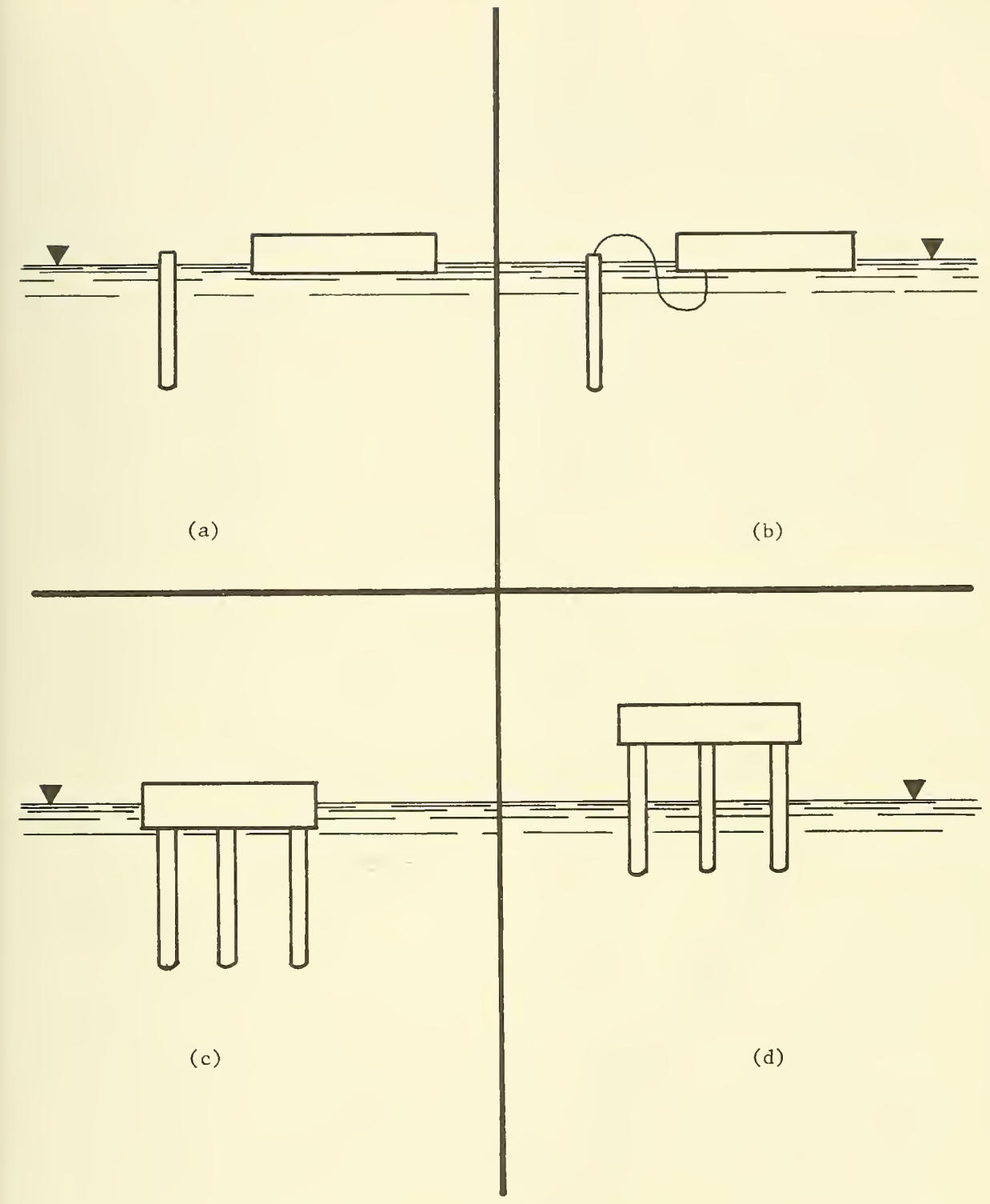

Figure 5.6. Cable-guided assembly technique 


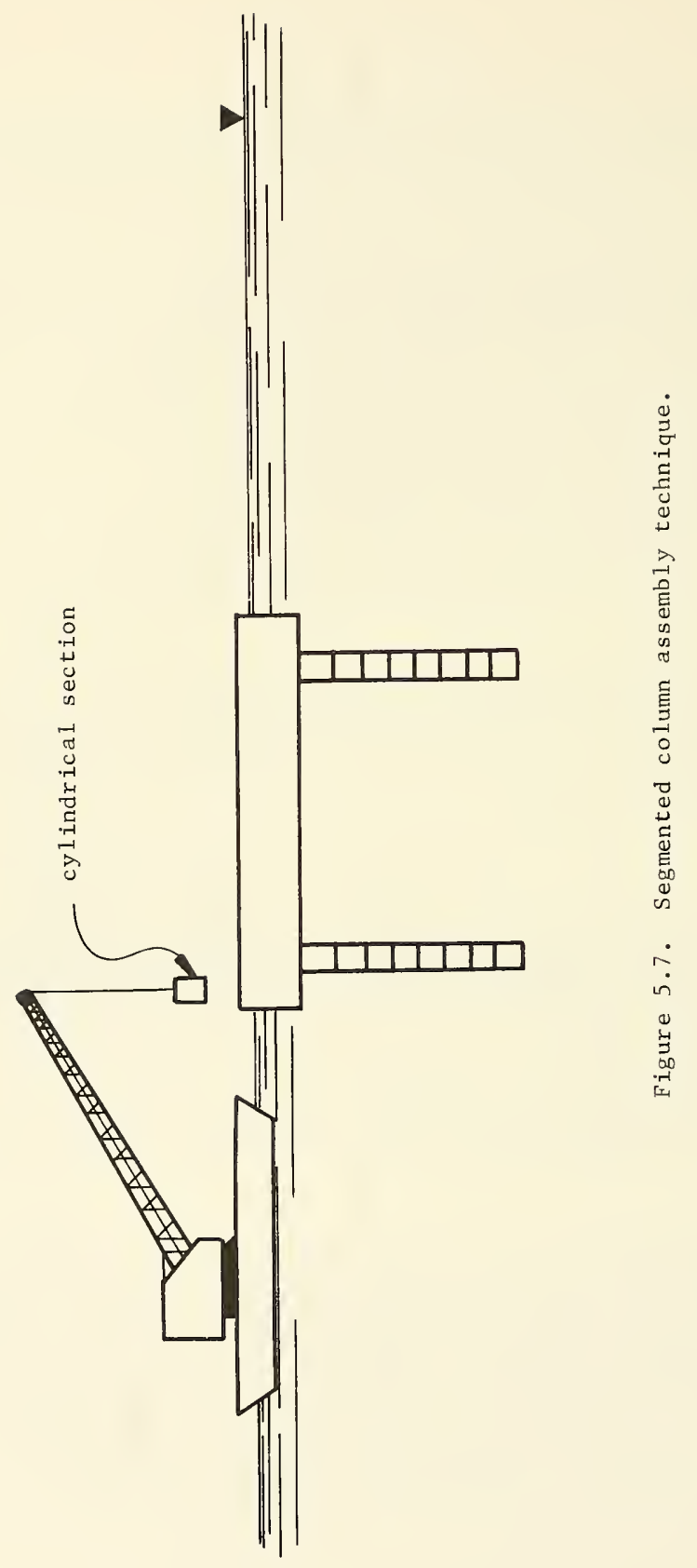




\section{PLATFORM TRANSPORT}

There are two basic modes of transport for CONUS-fabricated * elements: (1) transported as cargo or (2) assembled into sections and transported on the surface by tow or self-propulsion. Some facets of these transport modes are discussed in this section.

\section{Elements Transported as Cargo}

If prefabricated elements are to be transported to the assembly site, the limitations on cargo dimensions imposed by the sizes of hatches, holds, etc., suggest means other than standard cargo ships. Ocean-going barges and some of the Navy's unusual supply ships offer deck and hold space considerably larger than standard cargo vessels. Table 5.6 presents some data on the maximum practical dimensions of items which can be carried in a selected group of vessels. It can be seen that the maximum permissible dimensions of a load, coupled with handling at the remote site, make it highly impractical to transport many of the large prefabricated elements. The only attractive alternative appears to be the surface transport.

Table 5.6. Dimensions for Large Loads.

$\begin{array}{llr}\text { Vesse1 } & \begin{array}{c}\text { Length } \\ \text { (ft) }\end{array} & \begin{array}{c}\text { Width } \\ \text { (ft) }\end{array} \\ \text { McDermott 非16 (barge) } & 400 & 100 \\ \text { McDermott 非11 (barge) } & 300 & 90 \\ \text { AFDB Drydock } & 255 & 80 \\ \text { LSD 2 } & 250 & 45 \\ \text { INAGAUA (LST) } & 180 & 50\end{array}$

Surface Transport - Towing

It is assumed that the smallest unit to be transported will be a section at least 300 feet by 300 feet. As reported later in the text, two conditions for tow were investigated, (1) fully-assembled sections

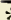

For modules fabricated at a remote site standard cargo ships can be used to transport any needed raw materials. Not only are these vessels wel1-suited for transporting cement, aggregates, and similar materials, they are also available in large numbers at virtually any time. Since there may be no permanent port facilities at the site of operations, means for establishing temporary port facilities will require investigating . 
with partial live load, and (2) partial sections with $80 \%$ of the deck removed. For the latter, only the buoyant sub-structure, completely assembled with necessary framing and partial deck, would be towed; the deck elements would be shipped separately for final assembly on station. While dynamic loads on the structure underway must be investigated, it appears unlikely that these will be a major problem since the structures will necessarily be designed to withstand the continuous dynamic loading encountered in the operational mode. This in itself will likely satisfy surface transport requirements.

When speed is not a factor, the size of sections that can be transported via towing is virtually unlimited. Perhaps the only constraint of any consequence is the limited water depths which are encountered in ports, canals, and channels throughout the world. If it is anticipated the structures will be transported through any of these depthlimited areas, a maximum draft of 35 feet is the most that can be to1erated. Although some shallow ports and facilities are being deepened and enlarged to accommodate large supertankers, it appears necessary to tow units smaller than sections, with a minimum draft, if they are to be towed through these areas.

Towing speed. $*$ It appears unnecessary and undesirable to limit the discussion of towing to any one speed. The possible missions for a MOBS platform could encompass a wide range of requirements from fast deployment, maybe on the order of an aircraft carrier, to something less rapid, where the time between the decision to deploy and the installation of a complete base could be as much as a year.

Whether the platform is self-propelled or towed, the most important characteristic with respect to propulsion requirements in the hydrodynamic drag. Unfortunately, estimates of the hydrodynamic drag acting on the relatively complex hull forms are problematical at best. In the calculations which follow, wave drag acting on the buoyant elements of the elevated and semi-submersible platforms and the barge hull will be disregarded. This drag component, for barge hulls at least, is negligible for Froude numbers less than about 0.2. A basic expression for calculating drag is

$$
\mathrm{D}=\frac{1}{2} \rho \mathrm{V}^{2} \mathrm{C}_{\mathrm{D}} \mathrm{A}
$$

where $\rho$ is the mass density of the fluid medium, $V$ is the relative velocity between the submerged object and the fluid, $C_{D}$ is the drag coefficient, and $\mathrm{A}$ is the projected area of the object normal to the direction of relative motion. The principle difficulty in applying the equation is selection of the appropriate value for the drag coefficient, $C_{D}$. For simple geometric shapes, e. g., spheres and circular cylinders, the drag coefficients are well defined, at least for Reynolds numbers less than $10 \%$.

*The section on towing speed was contributed by D. A. Davis 
The initial step in determining $C_{D}$ for the three different 300-foot $x$ 300-foot concepts is to consider the configuration for the buoyant support elements noted. In each case, the listed drafts are for (1) total dead load plus $25 \%$ live load, but with al1 unnecessary water ballast removed and (2) partial sections with $80 \%$ of the deck removed and no live load. Furthermore, it is assumed that the barge hull does not have highly streamlined "ship-like" prow and aft sections, and that the cylindrical elements employed in the semi-submersible and elevated platform have not been made more hydrodynamically efficient by enveloping them in streamlined fairings.

Hoerner (1965) presents drag coefficient data for barge-like hulls. Hulls with squared-off ends and length to beam ratios of 4 to 1 have drag coefficients on the order of 0.9 (for this type of vessel pressure drag dominates drag due to fluid friction) while hulls with flat bottoms and rounded ends have much lower values of $C_{D}, 0.30$ being typical. On the other hand, highly efficient hull forms in high speed displacement craft can have $C_{D}$ values considerably less than 0.30 . For the purposes of the present comparison, the MOBS barge-type hull will be assumed to have a drag coefficient of 0.30 .

For Reynolds numbers greater than $10^{6}$, the drag coefficient for a single, circular cylinder with its axis aligned normal to the incident flow is around 0.3. A matrix of cylinders, however, will be subject to interference effects which will probably result in a net lowering of the drag coefficient, especially for those cylinders in the matrix interior. However, since the effects of interference are difficult (if not impossible) to predict analytically it will be assumed herein that the drag coefficient for all vertical buoyant elements for both the elevated and semi-submersible platforms is equal to the value for a single, isolated cylindrical element, $i$. e., $C_{D}=0.30$. The horizontal cylindrical hulls, characteristic of the semi-submersible platform, are assumed to have a drag coefficient of 0.20 (See Hoerner (1965), Figure 21, p. 3-12).

Accordingly, Table 5.7 and 5.8 present the results of the drag estimates for the three candidates. In Table 5.8, $\mathrm{V}$ is the towing speed in knots, D is the drag force in pounds and $\mathrm{P}$ is the horsepower required to tow or propel each of the candidates. A comparison of conditions (1) and (2) reflect favorably on the latter to warrant further consideration. As a basis for towing comparison, it is noted that very large oceangoing tugs have about 10,000 horsepower.

Future studies should be based on more accurate determination of the drag coefficients (much will depend on selection of final hull configurations) by experimentation with models in a towing tank. In addition, wave-making drag and aerodynamic drag should be considered in final trade-off studies of competing systems. 
Table 5.7. Input Data for Drag Estimates

\begin{tabular}{|c|c|c|c|}
\hline Platform & Buoyant Support Elements & $\begin{array}{l}\text { Surface } \\
\text { Draft } \\
1\end{array}$ & $\begin{array}{l}\text { Transport } \\
(\mathrm{ft}) \frac{\mathrm{a}}{2}\end{array}$ \\
\hline Elevated & $\begin{array}{l}49 \text { vertical circular cylinders, } \\
25 \mathrm{ft} \text { in diameter (a } 43 \mathrm{ft} \\
\text { centers in a } 7 \times 7 \text { array }\end{array}$ & 324 & NA \\
\hline Semi-Submersible & $\begin{array}{l}49 \text { vertical circular cylinders, } \\
26 \text { ft in diameter @ } 43 \text { ft } \\
\text { centers in a } 7 \times 7 \text { array atop } \\
\text { seven } 36 \mathrm{ft} \text { diameter horizontal } \\
\text { pontoons capped with hemi- } \\
\text { spheres }\end{array}$ & 78 & 44 \\
\hline Barge & $\begin{array}{l}\text { Twin hulls } 100 \times 300 \mathrm{ft} \text { in plan } \\
\text { separated by a } 50 \mathrm{ft} \text { gap. Each } \\
\text { hull has a cylindrical trans- } \\
\text { verse cross-section and is } \\
\text { capped with spherical end } \\
\text { sections }\end{array}$ & 58 & 32 \\
\hline
\end{tabular}

a/

1. Dead load plus $25 \%$ of live load

2. $80 \%$ of deck structure removed 


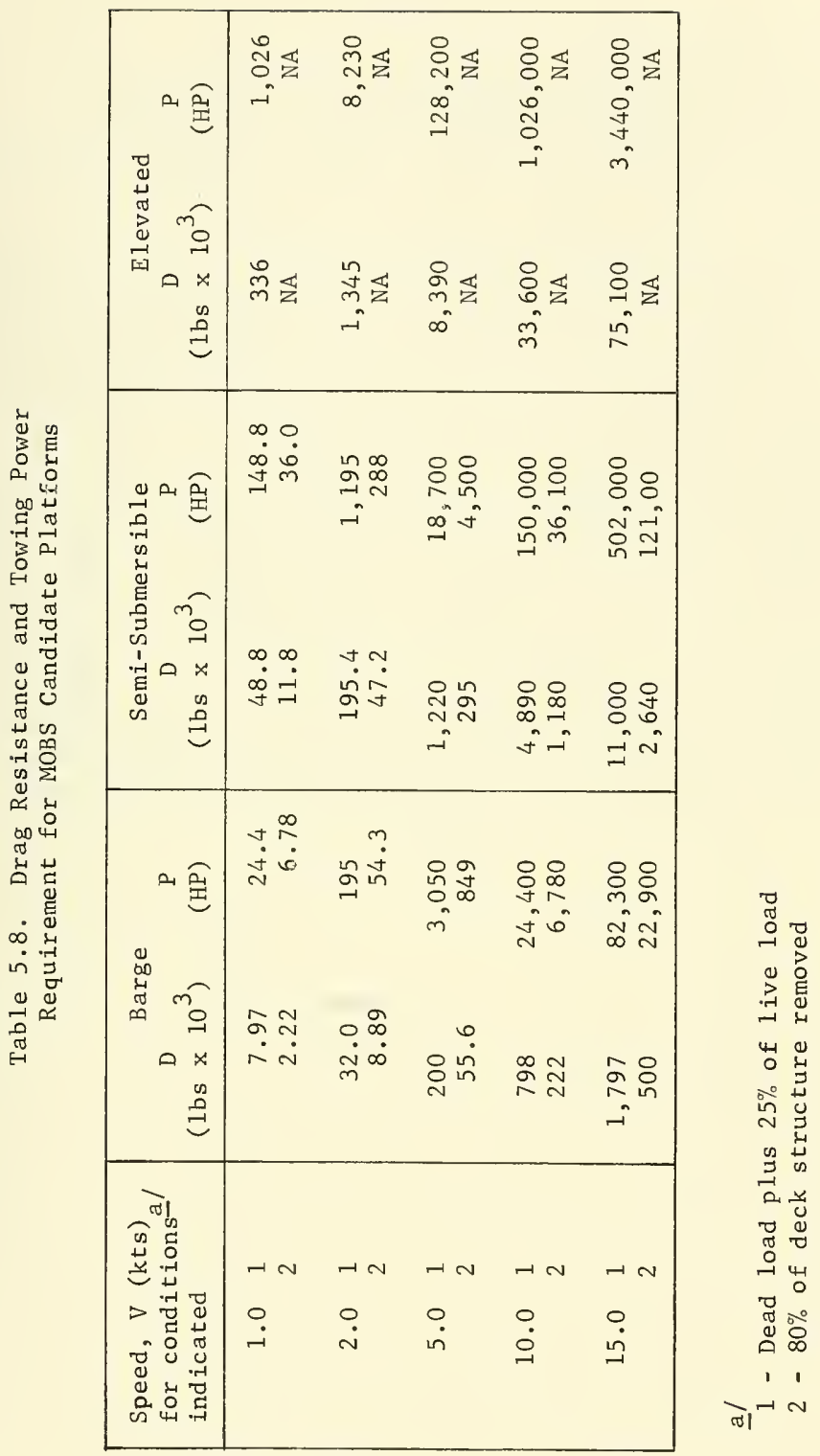


It is of some interest to briefly consider towing floating structures as large as MOBS. Table 5.9 presents some data on tow boat requirements for objects of various displacements. It is assumed that the towed vessel is equipped with a fairing and is essentially shiplike in shape.

During World War II a large number of dry docks were towed considerable distances. These dry docks varied in displacement for 1,000 to 7,600 long tons. The overal1 average towing speed was 6.2 knots. For: the large (7,600 long tons) dry docks, a 3,000 horsepower tug capable of towing at an average speed of 4.6 knots (slightly less than 8 feet/ second) was used. Table 5.10 presents some data on a few of these tows.

The large columns which are used for buoyancy in the elevated platform concepts displace less than 2,000 long tons, so it is feasible to tow them (in the horizontal position) with relatively small tow boats. The larger, barge-1ike floating decks can displace greater than 30,000 long tons. While the floating barges of this size can be towed, it is probably more practical to make the units considerably smaller so they could be towed by the smaller, readily available tug boats of the ATA class.

If the sizes of the components or modules are in the neighborhood of 2,000 long tons, a towing speed of six knots is possible. If the modules are 5,000 long tons or more, a towing speed of four knots is probably all that is practical. As a consequence, it does not appear that speed on the order of that of a cargo ship is possible if the modules are to be towed by conventional means. 


\begin{tabular}{|c|c|c|c|c|c|}
\hline 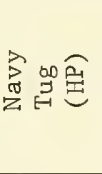 & 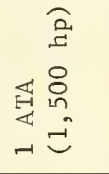 & 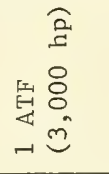 & 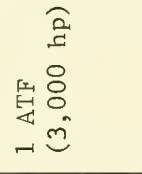 & & 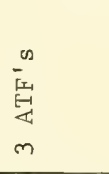 \\
\hline 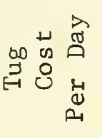 & $\begin{array}{l}8 \\
\infty \\
-1 \\
-\infty\end{array}$ & $\begin{array}{l}8 \\
\text { nิ } \\
m \\
\text { m. }\end{array}$ & $\begin{array}{l}8 \\
\text { n } \\
\text { m } \\
\text { m. }\end{array}$ & $\begin{array}{l}8.8 \\
80 \\
\text { in } \\
n=0\end{array}$ & $\begin{array}{l}8 \\
0 \\
0 \\
0 \\
\infty\end{array}$ \\
\hline 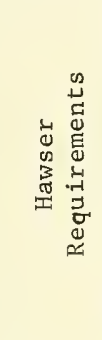 & 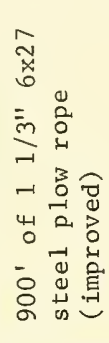 & 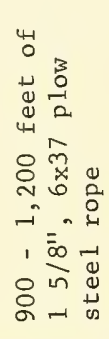 & 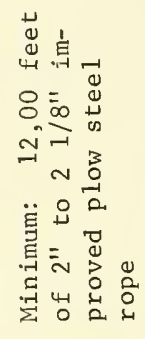 & 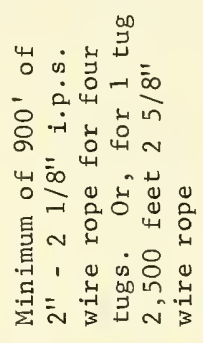 & 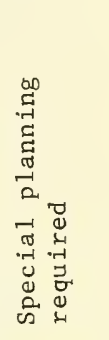 \\
\hline 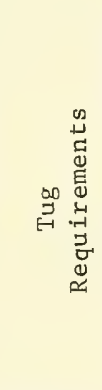 & 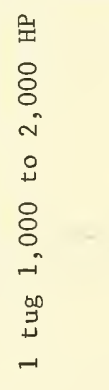 & $\begin{array}{l}\text { 旺 } \\
8 \\
0 \\
0 \\
-1 \\
0 \\
0 \\
8 \\
0 \\
0 \\
-1 \\
-1 \\
30 \\
3 \\
-1\end{array}$ & 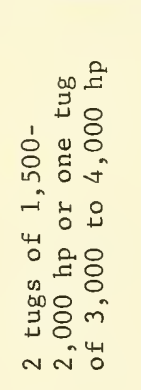 & 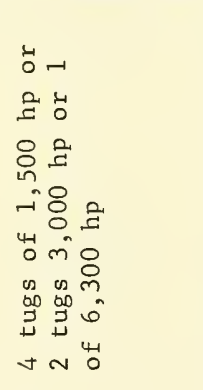 & 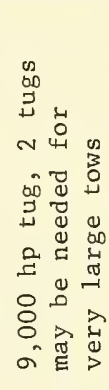 \\
\hline 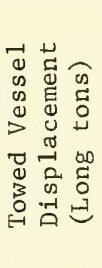 & $\begin{array}{l}8 \\
0 \\
\text { in }\end{array}$ & $\begin{array}{l}8 \\
8 \\
0 \\
0 \\
\dot{0} \\
8 \\
\text { in }\end{array}$ & $\begin{array}{l}8 \\
8 \\
\circ \\
\stackrel{0}{ } \\
\circ \\
\dot{0} \\
8 \\
\circ \\
0\end{array}$ & 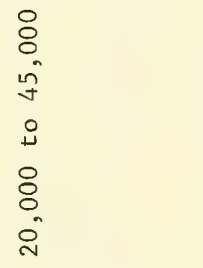 & 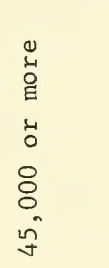 \\
\hline
\end{tabular}




\begin{tabular}{|c|c|c|c|c|c|c|c|c|}
\hline 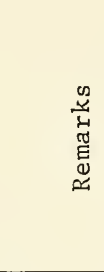 & 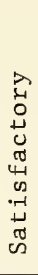 & 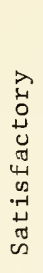 & 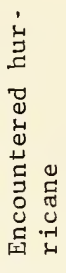 & 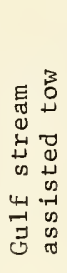 & 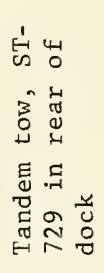 & 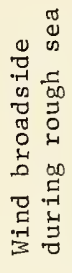 & 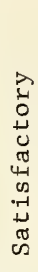 & 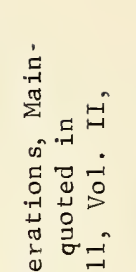 \\
\hline 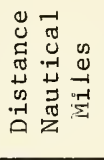 & 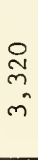 & \begin{tabular}{l} 
유 \\
$\stackrel{+}{+}$ \\
\multirow{f}{*}{}
\end{tabular} & $\begin{array}{l}\stackrel{0}{1} \\
\text { N } \\
\sim\end{array}$ & $\begin{array}{l}\text { ᄋ } \\
\text { ำ } \\
-1\end{array}$ & $\begin{array}{l}\stackrel{8}{\circ} \\
\end{array}$ & $\begin{array}{l}\text { ñ } \\
\text { ô } \\
\text { N }\end{array}$ & $\begin{array}{l}\text { mे } \\
\text { m}\end{array}$ & 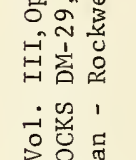 \\
\hline 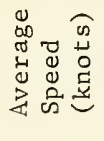 & ๙ & : & $\begin{array}{l}\infty \\
\dot{n}\end{array}$ & $\stackrel{-1}{\therefore}$ & $\begin{array}{l}\infty \\
\dot{m}\end{array}$ & $\ddot{0}$ & $\ddot{\sigma}$ & 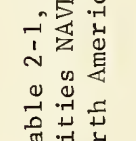 \\
\hline 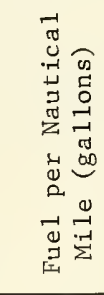 & $\stackrel{\infty}{\dot{m}}$ & $\underset{\sim}{\sim}$ & $\stackrel{\longrightarrow}{\mathscr{\infty}}$ & $\begin{array}{l}\mathscr{0} \\
\stackrel{\sim}{ }\end{array}$ & $\stackrel{\circ}{m}$ & $\stackrel{\llcorner}{\sim}$ & $\stackrel{\sim}{\sim}$ & 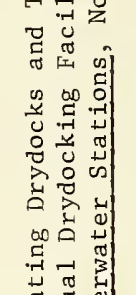 \\
\hline 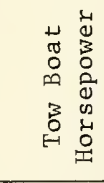 & $\begin{array}{l}8 \\
8 \\
\text { m. }\end{array}$ & $\begin{array}{l}\text { 오 } \\
\text { in } \\
\text {-1 }\end{array}$ & $\begin{array}{l}8 \\
8 \\
\text { m }\end{array}$ & 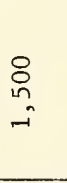 & $\begin{array}{l}8 \\
8 \\
\text { m. }\end{array}$ & $\begin{array}{l}8 \\
8 \\
\text { m }\end{array}$ & $\begin{array}{l}8 \\
8 \\
\text { n }\end{array}$ & 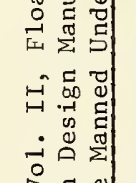 \\
\hline 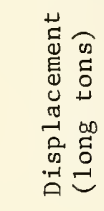 & $\begin{array}{l}8 \\
8 \\
-1\end{array}$ & $\begin{array}{l}\text { 尺 } \\
\text { r } \\
-\end{array}$ & $\begin{array}{l}8 \\
8 \\
-1\end{array}$ & $\begin{array}{l}8 \\
8 \\
-1\end{array}$ & $\begin{array}{l}8 \\
8 \\
0 \\
n\end{array}$ & $\begin{array}{l}8 \\
\infty \\
\text { m }\end{array}$ & $\begin{array}{l}\stackrel{8}{ } \\
\infty \\
\text { m }\end{array}$ & 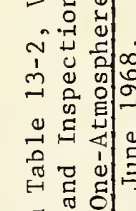 \\
\hline 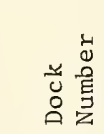 & 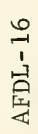 & 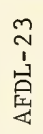 & 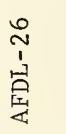 & 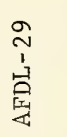 & 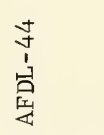 & 告 & $\begin{array}{l}0 \\
1 \\
\text { 孚 }\end{array}$ & 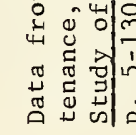 \\
\hline
\end{tabular}


PART SIX - SUMMARY AND RDT\&E PLAN

by J. J. Hromadik and D. A. Davis

\section{CONSTRUCTION PROCEDURES SUMMARY}

It is concluded that concrete is a feasible and practical construction material for large ocean platforms. It seems clear that existing construction technology can be successfully applied to the fabrication through an orderly process of development. Raw material quantities even for the largest platform at $3 \frac{1}{2}$ million cubic yards are not excessive. Cement requirement is nominally 7 million barrels, less than $2 \%$ of the 1968 production of 400 million barrels. Also, the aggregate production of one million tons per year can be readily accomplished. Neither the size nor shape of the components presents unusual construction requirements. The experience gained in the concrete ship building program is also indicative of the suitability of applying tried and proven techniques to the construction of concrete vessels. The success of these vessels, combined with substantial progress in concrete techniques during the intervening years, offers assurance that the structures under study can be built. It appears likely that the final selection of a MOBS platform will be more dependent upon stability, ease of assembly, and other factors related to design and cost rather than to feasibility vis-a-vis the state-of-the-art in concrete construction.

In view of the number of available alternatives - also constraints and limitations as yet undefined - a positive position on the construction techniques and sequences is not possible at this time. The study suggests the following as possibilities.

Elevated Platform

A complete floating deck will be launched and buoyant elements added at sea in the final assembly of a section, the size of which would be optimized during design. The deck will consist of precast, prestressed box-like elements post-tensioned into a complete deck module. The deck will be single tiered, multiple, or in combinations as required; size of the elements and/or modules will be optimized in final design. Construction and assembly of the deck will probably take place in a polder and dike. The buoyant elements will be precast, prestressed and post-tensioned into a complete buoyant column. Construction will be in an area adjacent to the deck, but the cast-in-place option using the slip-form method at sea should be considered. After all modules are assembled, the basin will be flooded, the dike broken, and the modules launched. Various schemes for assembly at sea are suggested, but none have been explored in depth for feasibility and practicability. Assembly location, logistics burden, and availability of heavy-duty equipment

*Volume approximately that of Hoover Dam 
will in al1 likelihood determine the "best" assembly method. Thus, if the choice is "to proceed" with elevated platforms, several at-sea assembly options should be investigated.

Semi-Submersible Platforms

The most attractive construction method appears to be one where the buoyant elements are assembled in the dry into a complete module and launched; the deck elements are added subsequently at sea; sizing in plan would be optimized during design. The buoyant cylindrical columns and hulls would consist of post-tensioned, precast, prestressed elements, although monolithic construction cannot be eliminated at this time as an option. The columns, hulls and necessary framing would be fabricated and assembled into a complete buoyant module. Construction would probably be best suited to a polder and dike. The draft would be held to a minimum by installing the deck after launch. The deck construction could be similar to that for the elevated platform, differing only in the final assembly aspects. Where a deeper draft could be tolerated, portions of the deck would be added before launch.

\section{Barge Platforms}

The construction sequence of this type platform is seen as somewhat similar to that for the semi-submersible, i. e., launching the completed buoyant module and adding the deck at sea. Monolithic construction of the hulls appears to be the choice, but as with the semi-submersible, alternatives require investigating. Portions of the deck could be monolithically cast (or assembled) with the hull before launching within draft limitations. The polder and dike appear to be a likely construction site.

\section{METHODOLOGY FOR COMPARING CANDIDATE PLATFORMS}

To avoid a premature selection of the concept (configuration, size, materials, construction techniques, etc.) a methodical, systematic approach is suggested. Such an approach has mechanisms available to further the concept formulation and establish the performance baseline. A number of attractive options for sub-systems should be explored and decision points reach before proceedings with the system definition. Accordingly, no attempt is made to rank the viable alternatives at this time.

Particularly lacking, and absolutely essential for a rational choice of alternatives, is a well-defined statement of mission objectives and operational requirements. This is a common situation in the early definition and development of a major R\&D program. A certain amount of flexibility is desirable prior to commitment of large amounts of resources. Eventually, however, a mission commitment will be made. From 
this decision will follow a logical sequence of events, including:

1. Completing a list of performance criteria which will be used in judging the ability of each candidate system to meet the mission goals. An additional task will be to define an acceptable or desirable standard of performance for each criteria.

2. Weighting the 1 ist of performance criteria to reflect the relative importance of each in achieving the mission goals.

3. Establishing the performance record of each viable candidate so that an estimate can be made of its ability to meet predetermined performance standards.

4. Selecting a suitable performance/cost model which results in "quantified" estimates of a candidate's overall worth.

Performance Criteria

A partial listing of these criteria was suggested in the text section on concept design optimization, Part 3. Specifically, those criteria pertinent to a preliminary estimate of size, weight and power required Fere discussed: (1) static stability, (2) dynamic stability, (3) drag under tow (mobility), (4) freeboard, and (5) station keeping properties. Future studies should consider also extendability, covertness, dependability, vulnerability and maintainability.

Extendability. This is a measure of the possibility of increasing the capacity of a system. For some systems the probability of increasing the platform's size and/or expanding its mission applicability is quite high. Also accounted for in this criterion is the amount of reworking necessary to extend a system's capacity.

Covertness. Covertness refers to a system's capability to remain undetected during operations at sea. This may become an important consideration for certain reconnaissance missions employing the small size platform. The great size of the larger platforms probably renders this criterion meaningless.

Dependability. This is a measure of a system's conventionality i. e., the degree to which the system exceeds the state-of-the-art.

Vulnerability. MOBS will be vulnerable to attack from a variety of weapons systems. In addition, the natural environment poses a threat. Although operations from MOBS may be restricted to moderate sea conditions, the platform must be capable of surviving storms of record magnitude.

Maintainability. Maintainability is an important consideration since it can have a great effect on operating costs and system life. One problem, closely allied with vulnerability, is the relative ease of repair or replacement of damaged buoyant elements. 
The foregoing, and any additional criteria deemed important, must be assigned standards of performance. For example a desirable standard for dynamic stability might be the requirement for safe aircraft operations in a sea state of 5. Platforms which meet or exceed this standard would be given the highest possible score, while a lower score would be awarded to candidate's falling short of the standard.

Some of the performance criteria are more important than others. This fact must be acknowledged by giving proportionately greater consideration to these. Personnel knowledgeable in the mission requirements should be assigned the task of establishing the relative worth of performance criteria.

\section{Performance Record}

As much information as possible must be accumulated concerning the projected operational characteristics of the candidate systems so that each candidate can be scored (its worth estimated) according to an established list of criteria. The required information could include, for example, analytical results and model test data of the dynamic response of candidate platforms in the seaway, the estimated life and maintenance requirements of important subsystems, and refined estimates of the power requirement for propulsion or tow, stations keeping and life support.

It will not be an easy task to assess the performance record of presently non-existent systems with the rigor required for a comprehensive worth determination. It is apparent, however, that studies leading to the establishment of a more complete performance record is the next logical step in the development program. Investigative efforts intended to supply the missing performance record include: (1) structural analysis, (2) materials, (3) assembly, (4) hydrodynamic response, (5) station keeping, (6) construction, (7) human factors, (8) support facilities, and (9) vulnerability. Many of the proposed efforts relate directly to the materials and fabrication phase. An RDT\&E plan for defining the MOBS performance record for FY 1971 and beyond is offered later in the text.

\section{Costs}

The cost estimates presented in this report ${ }^{*}$ are based on preliminary estimates of size, weight and assembly plant requirements and should, therefore, be interpreted as order of magnitude figures. Eventually more refined cost estimates will be available, and these, combined with the performance records, should be used in ranking alternative MOBS concepts.

\footnotetext{
See Part 5 .
} 
For the MOBS concepts under investigation, the important cost elements include R\&D, fabrication, storage costs (if applicable), transportation to site of operations, assembling (CONUS or remote), out= fitting, annual operating, and maintenance. Salvage value, if useful life exceeds operational life, should also be a consideration. The value for these cost elements should be based on best estimates from contractors and knowledgeable experts.

The overall cost would be the sum of the above cost elements with present value factors applied where appropriate. It will be possible to vary the size of the cost elements to determine how sensitive the total cost is to changes in subsystem costs. Maintenance costs, operating costs and storage costs will probably be about the same for all configurations. Costs for research and development, fabrication, transportation, and assembly are functions of the configurations and will be varied between reasonable limits to possibly expose critical components and/or procedures.

Where possible, the cost of improving a candidate's effectiveness, i. e., increasing its total worth according to the predetermined performance criteria, should be noted and the results discussed in sufficient detail to demonstrate what tradeoffs are possible and what key risks are associated with any particular system. This approach should provide some, if not all, of the information needed to evaluate the the "cost-effectiveness" of a given system for the (as yet) undefined missions.

Analysis

Candidate systems should be compared on at least two levels. The first objective would be to select one of the candidate MOBS base concepts for further evaluation. The approach should be to use all previously generated performance records and cost estimates in evaluating each base concept's relative worth, $i$. e., determining how nearly a candidate meets what are considered desirable MOBS performance goals. A suitable scheme which reflects the relative importance of the performance goals should be used in scoring the candidates (for example see Miller, 1967 or WSEIAC, 1965). Figure 6.1 outlines the selection methodology and indicates the crucial role played by the performance record in the selection process.

The first-level trade-off analysis can be conducted early in the MOBS program. The performance record need not be as precisely defined as that which will be required for comparing alternatives within a base concept category.

After selection of the most desirable base concept for each MOBS mission and after completion of necessary studies to construction a meaningful performance record for base concept alternatives, a second comparative analysis would be conducted to finalize the prototype MOBS design. In this second trade-off, the optimum buoyant support system, most efficient deck design, best assembly methods, and other critical options would be determined and finalized. 


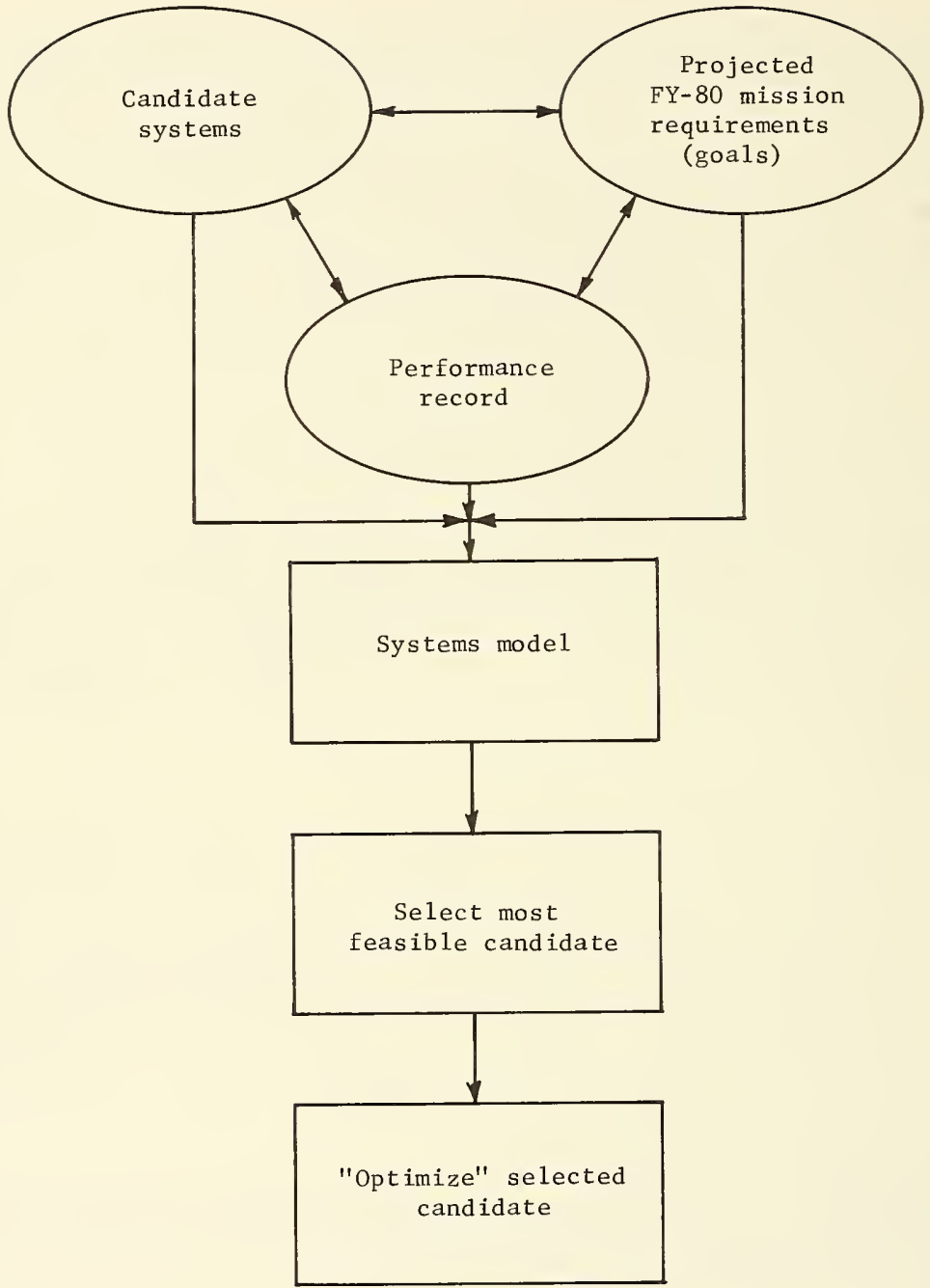

Figure 6.1. MOBS candidate selection methodology. 
Near-term RDT\&E efforts are identified, based on concept alternatives suggested by this study. The program described is intended to supply much of the data needed to determine the most desirable MOBS configuration, construction method, and choice of materials.

Structural/Materials Investigation

Structural investigations should be directed towards: (1) optimizing elements' shape and size and determining the maximum practical size and weight of buoyant support and deck structural elements for al1 stages of fabrication and assembly, from precasting of structural units, to launching of modules, to at-sea assembly, and (2) analyzing intersection of elements, in particular the column-to-hull and columnto-deck connections.

Regarding item (2) above, certain candidate configurations, e. g., the semi-submersible and elevated platforms, have a number of large diameter concrete elements which intersect with the deck and/or with submerged cylindrical pontoons. More information is needed regarding the stress distribution at these major intersections. Particularly significant for the semi-submersible concept is determining the optimum arrangement for effecting a minimum stress connection between the vertical and horizontal buoyant elements.

Materials Investigation. Findings from the present study suggest that significant material and cost savings are possible through the use of precast, prestressed structural elements. Such structural units, though, have not been used extensively in floating marine structures. Future investigations would concentrate on: (1) configuring structural elements of ordinary and lightweight concrete, (2) protective measures to arrest degradation of prestressing wires and cables and/or use of non-corroding metals and alloys for prestressing cables, and (3) compatibility of dissimilar materials in structural configurations under cyclic loads, e. g., modules constructed of combined lightweight concrete elements with ordinary concrete elements under repeated loading.

Maintenance of ocean structures can be optimized only if it is treated as a basic consideration during design, integrated with functional, structural and habitability requirements. Structural geometry and choice of materials may depend more on maintenance requirements than the others.

At-Sea Assembly. An operational analysis considering such functions as transporting, towing, positioning and connecting modules or sections is critical. Motions of the platform segments together with work barges need be considered. Consideration should include assembly in CONUS and at remote locations. Methods of assemblying and connecting modules/ sections into platforms must be developed. 
Dynamic Response of Modules, Sections and Platforms. Assembly atsea of modules and sections must be planned around expected motions (amplitude and frequency) of these bodies in the seaway. In addition, second order design of MOBS candidates must consider such motion dependent loads as hul1 slamming, hydrostatic forces due to cyclic submergence above and below the mean hull water line, payload inertial forces on decks and bulkheads and the inertial effects of the added-mass on the hull bottom. Motion (in both regular and random seas) will be predicted by analytical means, if possible, but experimentation will 1ikely be necessary for determing the effects of damping and added-mass. The latter effects will vary with each assumed buoyant support configuration. Eventually the most promising candidate(s) will be modeled, and the analytical predictions checked experimentally in a suitable wave tank. Analytical studies, backed by results from towing tests, will demonstrate the feasibility, or lack thereof, of towing or propelling large platform modules/sections. Directional stability will be evaluated at the same time these studies are conducted. Finally, the estimates of platform drag, hydrodynamic as well as aerodynamic, will be used as input in the design of mooring systems for alternative concepts.

\section{Station Keeping. Alternatives for maintaining the position of} platforms should be investigated. Wind and current loadings should be determined analytically and experimentally. A comparison of alternative station keeping techniques would consider conventional moorings and anchors, unconventional systems, and dynamic positioning.

Operational/logistic Requirements

Construction Sites. The objective would be to investigate the availability of construction materials, labor and equipment at sites suitable for construction. Factors to be considered in selecting a construction site include the potential and need for establishing (1) production plants (for the production of aggregate, cement, concrete mix and concrete products), (2) assembly plants (utilizing heavy materials handling and prestressing equipment), and (3) launching facilities. The study should consider potential sites in the Continental United States and Hawaii and be extended to include remote sites, particularly those in the Western Pacific.

Final assembly at sea will require work systems such as floating cranes and ships and barges for support of construction personnel and equipment. Estimates "ould be made of the logistic burden, i. e., types, numbers, range and duration of support vessels, and the critical resupply factors essential for maintaining the flotilla at remote sites.

Human Factors. Essentially, this considers the human factors engineering necessary to operate and maintain the platform on station; 
e. g., (1) number and skill of support personnel, (2) power requirements and other utilities necessary for mission and housekeeping functions, (3) habitability and life support systems. While habitability is principal1y characterized by conditions imposed upon manning personnel performing functional missions, considerations must also be directed to personnel comforts and recreation - and a psychological feeling of security.

Support Facilities. Considerations should include such items as (1) space requirements for storing, servicing and repairing of a11 types of air and sea craft, (2) water and POL needs for mission functions and storage locations, (3) schemes for docking all types and sizes of ships, (4) transfer of dry and liquid cargo, (5) drydocking for ship repair, and (6) special functions as may be determined in the interim through mission analyses.

Vulnerability

Due to its large size and relative lack of mobility, MOBS will be vulnerable to a whole host of threats, both from enemy weapons systems and the open sea environment. Vulnerability models should be developed which account for the physical properties of the candidates and which will assess the likelihood that certain critical platform subsystems - i11 be susceptible to damage or destruction from offensive weapon systems, and wave effects should be studied analytically and experimentally. Investigations in total should include damage assessment with options for repair and/or replacement of damaged portions.

Scheduling

A11 of the studies discussed above are essential milestones to determine the relative worth of competing MOBS platform configurations. Table 6.1 presents an estimate of the criticality of the various phases in accordance with the following definitions:

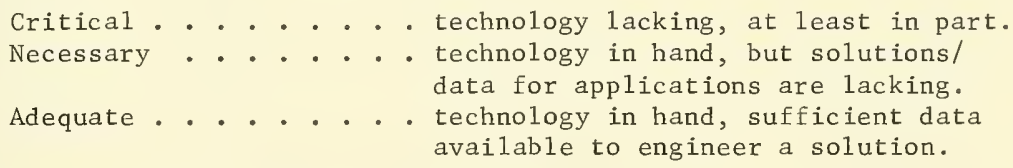

Selection, design, fabrication, and testing of the optimum concept(s) could begin by the mid $1970^{\prime}$ s by attending to the milestones through an orderly process of development. Priorities can be established on the basis of necessary lead time together with RDT\&E criticality; suggestions are offered in Table 6.2. Some condensing of the program is possible; or extending as necessary within budget limitations. 
Table 6.1. RDT\&E Criticality

\begin{tabular}{|c|c|c|c|c|}
\hline & & C & $\mathrm{N}$ & A \\
\hline Structural Analysis & $\begin{array}{l}\text { Deck elements } \\
\text { Buoyant elements } \\
\text { Intersection of elements }\end{array}$ & & $\begin{array}{l}X \\
X \\
X\end{array}$ & \\
\hline Materials & $\begin{array}{l}\text { Selection } \\
\text { Protective and maintenance } \\
\text { Behavior }\end{array}$ & & $\begin{array}{l}X \\
X \\
X\end{array}$ & \\
\hline As s emb 1y & $\begin{array}{l}\text { At-sea-positioning and connecting } \\
\text { Connection development } \\
\text { Transport/remote assembly }\end{array}$ & $\begin{array}{l}\mathrm{X} \\
\mathrm{X}\end{array}$ & $\mathrm{X}$ & \\
\hline Hydrodynamic Response & $\begin{array}{l}\text { Motions } \\
\text { Drag } \\
\text { Stability } \\
\text { Tow }\end{array}$ & $\mathrm{X}$ & $\mathrm{X}$ & $\mathrm{X}$ \\
\hline Station Keeping & $\begin{array}{l}\text { Moorings and anchors } \\
\text { Dynamic positioning }\end{array}$ & $\mathrm{x}$ & $\mathrm{X}$ & \\
\hline Construction & $\begin{array}{l}\text { Fabrication sites - CONUS } \\
\text { Fabrication - remote } \\
\text { Production }\end{array}$ & & $\mathrm{X}$ & $\mathrm{X}$ \\
\hline Human Factors & $\begin{array}{l}\text { Manpower } \\
\text { Power and utilities } \\
\text { Habitability and life support }\end{array}$ & & & $\begin{array}{l}\mathrm{X} \\
\mathrm{X} \\
\mathrm{X}\end{array}$ \\
\hline Support Facilities & $\begin{array}{l}\text { Aircraft storage/maintenance } \\
\text { Ship docking/cargo transfer } \\
\text { Dry docking }\end{array}$ & $\mathrm{x}$ & $\mathrm{X}$ & $\mathrm{X}$ \\
\hline Vulnerability & $\begin{array}{l}\text { Weapons effects (conv.) } \\
\text { Weapons effects (nuclear) } \\
\text { Environmental } \\
\text { Repair/replacement }\end{array}$ & $\mathrm{x}$ & $\begin{array}{l}\mathrm{X} \\
\mathrm{X} \\
\mathrm{X}\end{array}$ & \\
\hline
\end{tabular}

C - Critical

$\mathrm{N}$ - Necessary

A - Adequate 


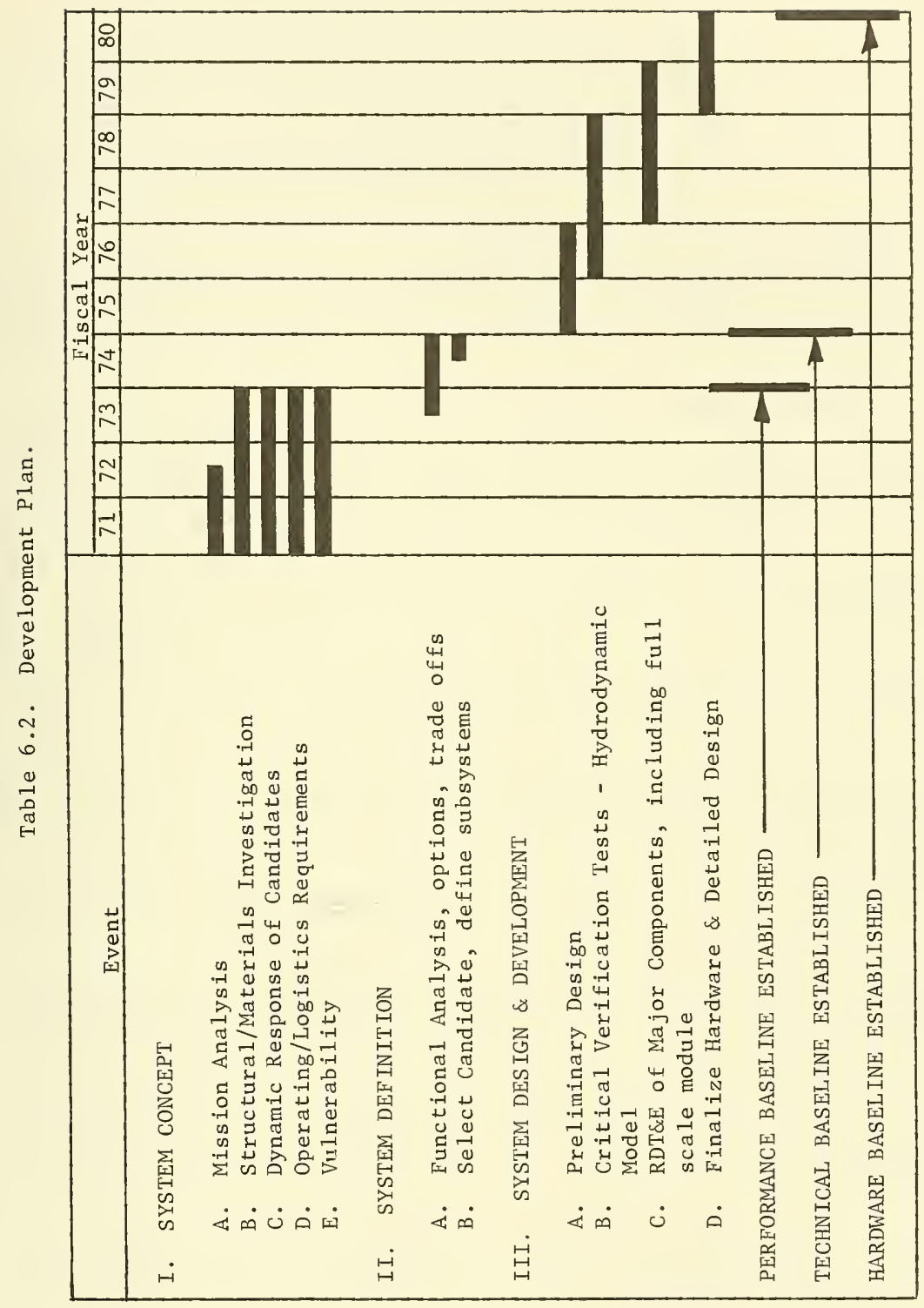





\section{REFERENCES}

1. American Society for Testing and Materials (1969). Standards for concrete and mineral aggregates. Book of ASTM standards, pt. 10 . Philadelphia, Pennsylvania, Nov. 1969.

2. (1969) ASTM C94-69: "Standard specification for ready-mixed concrete," in 1969 book of ASTM standards, pt. 10. Philadelphia, Pennsylvania, Nov. 1969, pp. 55-68. (Reprinted as NRMCA Pub. No. 124, Silver Spring, Maryland, National Ready-Mixed Concrete Association, 1969)

3. Andrew, C. E. (1940) "Building the world's largest floating bridge," Civil Engineering, vol. 10, no. 1, Jan. 1940, pp. 17-20.

4 .

(1941) "Problems presented by the Lake Washington floating bridge," American Concrete Institute, Journa1, Proceedings, vo1. 37, Jan. 1941, pp. 253-268; discussion, pp. 268-1 thru 268-4.

5 . (1951) "Floating tunnel for long water crossings," American Society of Civil Engineers, Transactions, vol. 116, 1951, pp. 708-720; discussion, pp. 721-728.

6. . (1959) "A floating highway bridge 6,470 ft long," Civil Engineering, vol. 29, no. 12, Dec. 1959, pp. 34-37 (vol. pp. 848-851).

7. Anon. (1947) Building the Navy's bases in World War II, vol. 1. Washington, D. C., Government Printing Office, 1947, pp. 217-219, 223.

8. Architectural Record. (1968) "High-rise hotel construction speeded by prefabbing concrete boxes off site," vol. 143, no. 1, Jan. 1968, pp. $163-166$.

9. Atwood, W. G. and Johnson, A. A. (1924) Marine structures; their deterioration and preservation. Washington, D. C., National Research Counci1, 1924, pp. 151-158; 221-448.

10. Billig, K. (1955) "Ships and floating structures," in Precast concrete, New York, D. Van Nostrand, 1955, pp. 319-326.

11. (1960) Structural concrete. London, Macmillan, 1960, pp. $850-8 \overline{52 .}$

12. Bond, J. R. (1970) "Catamarans - dream or reality," Naval Engineers Journal, vol. 82, no. 3, June 1970, p. 106. (complete article, pp. 95109). 
13. Boyd, R. W., et a1. (1921) "Report of special committee on concrete ships and barges," American Concrete Institute, Proceedings, vo1. 17, 1921, pp. 285-291.

14. Bruce, R. N. (1956) "Prestressed precast platform built in Gulf," Civil Engineering, vol. 26, no. 7, July 1956, pp. 41-43 (vo1. pp. 441443); and letter, vol. 26, no. 8, Aug. 1956, p. 66 (vo1. p. 534).

15. Bureau of Yards and Docks, Department of the Navy. (1963) Contract Report: Feasibility study of a multi-purpose harbor unit. Prepared by Hydraulics Laboratory (De1ft), Nedeco (The Hague) and The Netherlands Ship Model Basin (Wageningen), July 1963, pp. 12-13. (Contract N625582986) (AD 426740)

16. Cassie, W. F. (1967) "Lambot's boats," Concrete, vo1. 1, no. 11, Nov. 1967, pp. 380-382.

17. Cloyd, M. P. (1969) "Monopod," American Society of Civil Engineers, Transactions, vo1. 134, 1969, pp. 183-184.

18. Davis, D. A. and Wolfe, M. J. (1969) Feasibility study and comparative analysis of deep ocean load handling systems, Naval Civil Engineering Laboratory, Technical Report R-652, Port Hueneme, California, Dec. 1969. (AD 699172)

19. Engineerings News-Record. (1943) "Sea-going barges of concrete construction," vo1. 130, no. 24, June 17, 1943, pp. 878-883.

20. (1946) "Army engineers finish successful tests of floating seadrome model design," vol. 131, no. 13, Mar. 28, 1946, p. 449.

21. (1961) "The 'hard luck' bridge nears completion," vo1. 167, no. $2 \widehat{, \text { July } 13,1961, ~ p p . ~ 36-38, ~} 41$.

22. Fatim, A. (1954) Egypt Ports and Lighthouse Administration letter dated 20 January to $W$. R. Lorman (NCEL).

23. Freeman, J. E. (1918) "Developments in concrete barges and ships," American Concrete Institute, Proccedings, vol. 14, 1918, pp. 422-427.

24. Freyssinet, E. (1950) "Pre-stressed concrete; principles and applications," Institution of Civi1 Engineers, Journa1, vo1. 33, no. 4, Feb. 1950, p. 375. (complete article pp. 331-380)

25. Gerwick, B. C. (1948) "Precast concrete units simplfy construction of West Coast marine structures," Civil Engineering, vol. 18, no. 8, Aug. 1948, pp. 46-50, 84 (vo1. pp. 512-516, 550). 
26. - (1954) "Hollow precast concrete units of great size form bridge substructure," Civil Engineering, vol. 24, no. 4, Apr. 1954, pp. 59-63 (vol. pp. 235-239).

27. - (1959) "Prestressed concrete in marine structures," Civil Engineering, vo1. 29, no. 11, Nov. 1959, pp. 46-49 (vo1. pp. 782-785).

28. Gewertz, M. W. (1958) "Causes and repair of deterioration to a California bridge due to corrosion of reinforcing stee 1 in a marine environment: Part 1 - Method of repair," in Corrosion of reinforcing steel and repair of concrete in a marine environment, Highway Research Board, Bulletin 182, Washington, D. C., 1958, Pp. 1-17. (NRC pub. no. 546).

29. Gjorv, O. E. (1969) "Durability of reinforced concrete wharves in Norwegian harbours," Matériaux et Constructions/Materials and Structures, vo1. 2, no. 12, Nov.-Dec. 1969, pp. 467-476.

30. Grancher, R. A. (1969) "The 1ightweight aggregate boom," Rock Products, vo1. 72, no. 12, Dec. 1969, pp. 59-60, 62, 94-96.

31. Grim, O. (1959) "Die Schwingungen von schwimmenden, zweidimensionalen Körpern. Berechnung der hydrodynamischen Kräfte. (The oscillation of a floating, two-dimensional form. Calculations of the hydrodynamic force.)" Hamburg Mode1 Basin, Report n. 1171, Hamburg, Germany, Sept. 1959.

32. Haviland, J. (1962) "American concrete steamers of the First and Second Wor1d Wars," American Neptune, vo1. 22, no. 3, 1962, pp. 157-183.

33. Hiroi, I: (1904) "The preparation and use of concrete blocks for harbour works," American Society of Civil Engineers, Transactions, vol. 54, pt. A, 1904, pp. 211-220.

34. Hoerner, S. F. (1965) Fluid dynamic drag; practical information on aerodynamic drag and hydrodynamic resistance $2 \mathrm{~d}$ ed. Midland Park, New Jersey, The author, 1965 .

35. Horwege, A. A. (1929) "Methods used in the construction of twelve pre-cast concrete segments for the Alameda County, California estuary subway," American Society of Civil Engineers, Transactions, vo1. 93, 1929, pp. 547-564; discussion, pp. 565-570.

36. Jackson, G. W. and Sutherland, W. M. (1969) Concrete boatbuilding; its technique and its future. London, George A1len and Unwin, 1969.

37. Kaplan, P. and Putz, R. (1962) The motions of a moored constructiontype barge in irregular waves and their influence on construction operation, Report On Contract NBy-32206, Marine Advisers, Inc., La Jo1la, California, Aug. 1962. 
38. Kohler, C. M. J. W. (1970) "A study of large graving docks," Dock and Harbour Authority, vol. 50, no. 594, Apr. 1970, pp. 506-508.

39. Lea, F. M. (1956) The chemistry of cement and concrete, Rev. ed. New York, St. Martin's Press, 1956.

40. Lightweight Processing Company. Rocklite lightweight concrete reference manual. Los Angeles, California.

41. Lorman, W. R. (1965) Repairing cracked and spalled concrete. Special report to BuDocks, encl (1) to NCEL 1 tr ser 640 of 30 Mar. 1965.

42. Lyse, I. (1961) "Durability of concrete in sea-water," in RILEM International Symposium on the Durability of Concrete, preliminary report. Prague, Czechoslovak Academy of Science, 1961, pp. 183-191.

43. Macleay, F. R. (1950) "Thin wall concrete ship construction," American Concrete Institute, Journa1, Proceedings, vol. 46, no. 3, Nov. 1949, pp. 193-204; discussion, by J. J. Polivka, vo1. 46, Feb. 1950, p. 479 .

44. Mather, B. (1957) Factors affecting durability of concrete in coastal structures, Army Corps of Engineers, Beach Erosion Board, Technical Memorandum 96, Washington, D. C., June 1957.

45. - (1969) "Behavior of concrete exposed to the sea," paper presented at American Society of Civil Engineers Ocean Engineering Conference, Miami Beach, Florida, Dec. 10-12, 1969.

46. McLaughlin, R. E. (1944) "Powered concrete ships of World War II," Engineering News-Record, vol. 133, no. 16, Oct. 19, 1944, pp. 472-476.

47. Miller, J. R. (1967) A systematic procedure for assessing the worth of complex alternatives, Air Force Systems Command, Electronic Systems Division, Technical Report ESD-TR-67-90, L. G. Hanscom Field, Massachusetts, Nov. 1967 (Contract AF 19(628)-5165) (AD 662001).

48. Minetti, H. (1956) Concrete and Constructional Ingineering, vol. 51, no. 1, Jan. 1956, pp. 99-100

49. Morgan, R. G. (1968) "Lambot's boats," Concrete, vol. 2, no. 3, Mar. 1968, p. 128 .

50 . - (1970) "Obituary of a pioneer: the coaster SS Armistice," Concrete, vol. 4, no. 2, Feb. 1970, pp. 59-61.

51. Murphy, G. J. and Tanner, D. N. (1966) "The BART trans-bay tube," Civil Engineering, vo1. 36, no. 12, Dec. 1966, pp. 51-55. 
52. Nawy, E. G. and Bright, C. B. (1967) "Floating V/STOL airport proposed," Civil Engineering, vol. 37, no. 7, July 1967, p. 45.

53. Nervi, P. L. (1956) Chapter 4: "Ferro-cemento," in Structures. New York, F. W. Dodge, 1956,

54. Nichols, C. C. (1964) "Construction and performance of Hood Canal floating bridge," in Symposium on Concrete Construction in Aqueous Environments, Seattle, Washington, Sept. 28-29, 1962. Detroit, Michigan, American Concrete Institute, 1964, pp.97-106. (ACI Special Publication 8).

55. Noble, A. M. (1964) "Concrete pontoon for marinas," in Symposium on Concrete Construction in Aqueous Environments, Seattle, Washington, Sept. 28-29 1962. Detroit, Michigan, American Concrete Institute, 1964, pp. 107-114. (ACI Special Publication 8)

56. NRMCA. (1957) Publication No. 73: Standards for operation of truck mixers and agitators. Washington, D. C., Apr. 1957.

57. - (196i) Publication No. 96: The technical control of ready mixed concrete. Washington, D. C., Feb. 1961.

58. (1962a) Publication No. 44: Control of ready-mixed concrete, 5th ed. Silver Spring, Maryland, Oct. 1962.

59. - (1962b) Publication No. 109: Recommended guide specifications cover $\overline{i n g ~} \mathrm{p}$ lant and accessory equipment for ready mixed concrete in construction for highways. Silver Spring, Maryland, Nov. 1962.

60. (1964) Publication No. 116: Disposal of truck mixer wash water and unused concrete. Silver Spring, Maryland, 1965.

61. and Associated General Contractors of America. (1965) Statement of responsibility. Silver Spring, Maryland, 1965.

62. and Truck Mixer Manufacturers Bureau. (1966): Truck Mixer and agitator standards of the Truck Mixer Manufacturers Bureau. 8th rev., 1968 printing. Silver Spring, Maryland, 1966.

63. - (1967a) Production and value of ready mixed concrete in 1967, by C. I. Malloy and P. L. Suto. Silver Spring, Maryland, 1967.

64. - (1967b) Instructions and check 1 ist for certification of ready-mixed concrete production facilities, 1st rev., Silver Spring, Maryland, July 1967. 
65. and Concrete Plant Manufacturers Bureau. (1967) Concrete plant standards of the Concrete Plant Manufacturers Bureau, 3rd rev., Silver Spring, Maryland, Mar. 1967.

66. Ocean Industry. (1969) "New type of oil storage for Dubai," vo1. 4, no. 9, Sept. 1969, pp. 9-11.

67. O'Connor, G. A. (1964) "Long concrete cylinder piles for deep-water platform," American Society of Civil Engineers, Transactions, vo1. 129, 1964, pp. 165-166.

68. Palmer, W. F. (1957) "The 24-mile Lake Ponchartrain prestressed bridge," in Proceedings of World Conference on Prestressed Concrete, San Francisco, California, July 29-Aug. 3, 1957. San Francisco, California, World Conference on Prestressed Concrete, Inc., 1957, pp. A10-1 thru A10-10.

69. Parkes, W. (1863) "Description of 1ighthouses lately erected in the Red Sea," Institution of Civil Engineers, Minutes of Proceedings, vo1. 23, 1863, pp. 1-44.

70. Peck, R. L., ed. (1969) Concrete industries yearbook, 31st ed. Chicago, Illinois, Pit and Quarry Publications, Inc., 1969.

71. Peyton, H. R. (1968) "Ice and marine structures," Ocean Industry, vol. 3, no. 3, Mar. 1968, pp. 40-44.

72. Pit and Quarry Publications, Inc. (1969a) Lightweight aggregate map., Chicago, I1linois, 1969.

73. (1969b) Portland cement map. Chicago, Illinois, 1969.

74. (1970) Pit and Quarry directory of the nonmetallic minerals industries, 1970 ed. Chicago, Illinois, pub. 1969.

75. Podolny, W. (1969) "Understanding the losses in prestressing," Prestressed Concrete Institute, Journa1, vo1. 14, no. 5, Oct. 1969, pp. 43-53.

76. Portland Cement Association. (1964) Cement and concrete reference book. Chicago I11inois, 1964.

77. Ralph M. Parsons Company. (1969) Final Report on Contract FA-69WA-2073: Evaluation of construction methods for offshore airports. Los Angeles, California, Aug. 1969, p. 94. (FAA Rept. no. RD-69-42) (AD 693185) 
78. Raymond International Inc. Catalog CP-5: Raymond concrete cylinder piles. New York, N. Y.

79. Rennie, G. (1857) "Employment of concrete in works of construction," Institution of Civil Engineers, Minutes of Proceedings, vol. 16, 1857, pp. 423-448.

80. Rick, R. ed. (1969) Pit and Quarry handbook and purchasing guide, 62nd ed. Chicago, I1linois, Pit and Quarry Publications, Inc,. 1969.

81. Sellner, E. P. "Concrete for marinas," American Society of Civil Engineers, Transactions, vol. 129, 1964, pp. 482-483.

82. Shapiro, A. H. (1961) Shape and flow. Garden City, New York, Doubleday (Anchor), 1961, p. 136-137.

83. Shel1 U. K. Limited. (1969) Report on the use of floating concrete construction. Prepared by Harris and Sutherland and Archibald Shaw and Partners. London, England, 1969.

84. Smith, F. L., (1958) "Effect of aggregate quality on resistance of concrete to abrasion," in Cement and concrete; presented at 2nd Pacific area national meeting, Los Angeles, California, Sept. 19-20, 1956. Philadelphia, Pennsylvania, American Society for Testing and Materials, 1958, pp. 91-106. (ASTM STP-205)

85. Stanford, A. (1951) Force Mulberry. New York, Morrow, 1951, pp. 47, 61, 69, 72-74; plates $3 \& 4$ following p. 176. (See also vol. 2 of reference 7, pp. 101-102, 105-107).

86. Stanford, H. R. (1916) "Pear1 Harbor dry dock," American Society of Civil Engineers, Transactions, vol. 80, 1916, pp. 223-294; discussion, pp. 295-337.

87. Szilard, R. (1969) "Survey on durability of prestressed concrete structures in the United States, Canada, and Pacific and Far Eastern countries," Prestressed Concrete Institute, Journal, vol. 14, no. 5, Oct. 1969, pp. 62-73.

88. Tremper, B. (1958) "Causes and repair of deterioration to a California bridge due to corrosion of reinforcing steel in a marine environment: Part II - Fundamental factors causing corrosion," in Corrosion of reinforcing steel and repair of concrete in a marine environment, Highway Research Board, Bulletin, 182, Washington, D. C., 1958, pp. 18-41 (NRC pub. no. 546).

89. Tuthil1, L. H. (1945) "Concrete operations in the concrete ship program," American Concrete Institute, Journal, Proceedings, vo1. 41, no. 3, Jan. 1945, pp. 137-177; discussion, pp. 180-1 thru 180-7. 
90. Van Buren, M. (1957) "Concrete bridge across Lake Ponchartrain completed in record time," Civil Engineering, vol. 27, no. 2, Feb. 1957, pp. 33-37 (vo1. pp. 73-77).

91. Vitruvius. The ten books on architecture, translanted by M. H. Morgan. Cambridge, Massachusetts, Harvard University Press, 1914; reprinted by Dover Publications, New York, 1960.

92. Wakeman, C. M., et al. (1958) "Use of concrete in marine environments," American Concrete Institute, Journal, Proceedings, vo1. 54, no. 10, Apr. 1958, pp. 841-856; discussion, Dec. 1958, pt. 2, pp. 13091346 .

93. Walker, S. (1961) What quality guarantee should the customer expect from the ready-mixed concrete producer? National Ready Mixed Concrete Association, Publication No. 99, Washington, D. C., May 1961.

94. Waugh, W. R. (1969) "Deterioration of concrete in Eisenhower Lock," American Society of Civil Engineers, Transactions, vol. 134, 1969, pp. $172-173$.

95. Weidlinger, P. (1970) "Floating airport," Ocean Industry, vol. 5, no. 5, May 1970 , pp. 47-49.

96. Wentworth-Shields, F. E. (1956) Concrete and Constructional Engineering, vol. 51, no. 1, Jan. 1956, pp. 25-29.

97. Western Construction (1967a) "The aggregate plant at Arrow Dam," vol. 42, no. 2, Feb. 1967, p. 46. (complete article pp. 46-47, 104)

98. - (1967b) "The trans-bay tube project," vol. 42, no. 2, Feb. $1967, \overline{\mathrm{pp} .} 31-35$.

99. Wood, C. R. J. (1948) "Phoonix" and "Reinforced-concrete pier pontoons and intermediate pierhead pontoons," in the civil engineer in war, vol. 2, London, Institution of Civil Engineers, 1948, pp. 336-368; pp. $401-425$.

100. WSEIAC. (1965) Prediction-measurement, concepts, task analysis, principles of model construction, Weapon System Effectiveness Industry Advisory Committee (WSEIAC) final report of Task Group II. Air Force Systems Command, Technical Report AFSC-TR-65-2-vo1. 2, Andrews Air Force Base, Maryland, Jan. 1965. 
Appendix A

HEAVE RESPONSE OF AN ELEVATED PLATFORM

by H. S. Zwibe 1

In order to assist in the initial elimination of unsuitable MOBS candidates, computer program HEAVE was written to determine the heave response for a raised deck platform. In this appendix, the mathematics for the computer program is discussed.

A general motion of a floating object requires the specification of six degrees of freedom. If the floating object is sufficiently symmetric and the waves are coming at it from a symmetry direction, then these motions become uncoupled. The MOBS elevated platform is sufficiently symmetric so that with head-on waves, the heave motion is decoupled from the other five degrees of freedom.

Even with the restriction to head-on seas and a consideration of only the heave motion, the exact solution of the problem is extremely difficult. As a first step in simplification, the motion is considered to be small amplitude and the water inviscid. Fortunately these approximations do not invalidate the results that will be obtained. The general philosophy is that if the candidate is unsuitable for small waves it will undoubtably be unsuitable for large waves. Even with the small amplitude approximation, the problem is still difficult. Consider for a moment the sequence of events for waves of definite frequency incident head-on on our floating structure. These incident waves are diffracted by the structure giving rise, therefore, to two sets of waves, the incident wave and the diffracted wave. The combination of these two waves produce forces that set the structure into motion. The motion of the floating structures, in turn, generates its own wave trains which carry energy away and out to infinity. The general problem, therefore, consists of solving for the reflected wave, the radiated waves, and the motion of the object. The incident and the reflected waves do not depend on the motion of the platform; the transmitted waves, however, are directly dependent on the amplitude of motion for the platform. These radiated waves give rise to vertical forces on the structure that can be considered to be broken up into two parts. One part is in phase with the acceleration and the other part is in phase with the velocity. The former is usually considered to be an added mass effect since it is in phase with the object's acceleration. The latter is a damping force since damping forces are proportional to the velocity. A rigorous solution to the problem, therefore, would be to calculate for given incident waves, the reflected waves and for a given vertical motion of the object, the radiated waves. Once these radiated waves are determined the added mass force and damping force could be calculated. In terms of these parameters and assuming steady-state harmonic motion, the following equation is satisfied by the heave motion $Z(t)$ for the platform. 


$$
\left[-\left(M+M_{A}(\omega)\right) \omega^{2}-i \omega \gamma(\omega)+\rho g A\right] Z_{0}=F_{W}(\omega)
$$

where the heave as a function of time is equal to the real part of $\mathrm{z}_{\mathrm{o}} \mathrm{e}^{-i \omega t}$. The other terms are

$$
\begin{aligned}
& M-\text { mass of platform } \\
& M_{A}(\omega) \text { - added mass factor } \\
& Y(\omega) \text { - damping due to wave making } \\
& \rho \text { - density of fluid } \\
& g \text { - acceleration of gravity } \\
& A \text { - waterplane area of platform } \\
& \omega \text { - frequency of waves (radians/sec) } \\
& Z_{O}-\text { complex amplitude of heave } \\
& F_{W}(\omega) \text { - force exerted on platform due to waves }
\end{aligned}
$$

Simple division by the bracket on the left side of the equation gives an immediate solution. However, there are still complications. Exact expressions for the added mass, damping, and waves forces are not known. Approximate formuli for these quantities were obtained by use of Grim's (1959) coefficients. These coefficients were generated for use in the strip method for analyzing ship motions, and their use in the present case is justified primarily for purposes of expediency.

In the strip theory, the floating structure is mathematically divided into thin transverse strips. The wave forces, added mass, and damping coefficients are calculated for each strip on the assumption that the presence of one strip does not influence the waves incident on other strips. The total effect is then obtained by integrating over all the strips. In general, the coefficients generated by Grim depend on the wave frequency as well as the beam, draft and section fullness of the ship. Kaplan and Putz (1962) using Grim's formulation, obtain the following formuli for the forces on a thin section of the structure:

$$
\begin{aligned}
& \mathrm{dM}_{\mathrm{A}}(\zeta)=\mathrm{C} \frac{\rho \pi \mathrm{B}^{2}(\zeta)}{8} \mathrm{~d} \zeta \\
& \mathrm{d} \gamma(\zeta)=\mathrm{C}_{Z} \rho \frac{\mathrm{W}}{\mathrm{K}^{2}}\left(\overline{\mathrm{A}}_{Z}\right)^{2} \mathrm{~d} \zeta \\
& \mathrm{dF}_{W}(\zeta)=\mathrm{dF}_{W}{ }^{\mathrm{I}}(\zeta)+\mathrm{dF}_{W}{ }^{\mathrm{B}}(\zeta)+\mathrm{dF}_{W}{ }^{\mathrm{D}}(\zeta)
\end{aligned}
$$

where

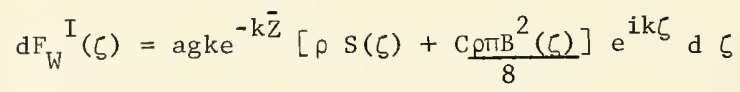




$$
\begin{aligned}
& \mathrm{dF}_{\mathrm{W}}{ }^{\mathrm{B}}(\zeta)=\rho g \text { a } \mathrm{B}(\zeta) e^{\mathrm{ik \zeta}} \mathrm{d} \zeta \\
& \mathrm{dF}_{\mathrm{W}}^{\mathrm{D}}(\zeta)=i g \mathrm{C}_{\mathrm{Z}} \mathrm{P}_{\overline{\mathrm{k}}}(\overline{\mathrm{A}})_{\mathrm{Z}}^{2} \mathrm{~d}^{-\mathrm{k} \overline{\mathrm{Z}}} \mathrm{e}^{\mathrm{ik \zeta}} \mathrm{d} \zeta
\end{aligned}
$$

The variable, $\zeta$, is the longitudinal position of the section. B is the beam and $S$ is the transverse submerged area. The coefficients supplied by Grim are $C, \bar{A}_{z}$, and are dependent on the wave frequency, section fullness and beam to draft ratio. $k$ is the wave number of the incident wave (i. e., $2 \pi / \lambda$, where $\lambda$ is the wave length) and $a$ is the wave amplitude. $C_{Z}$ is an additional correction to the wave making resistance due to the three-dimensionality of the problem, rather than two-dimensional as assumed by Grim.

The total added mass, damping, and wave forces are obtained by integrating these expressions over the length of the structure. In order to carry out the integrations for the multi-legged elevated platform it is assumed that $R / \lambda<<1$, where $R$ is the radius of a supporting leg. Also, the coefficients $C$ and $\bar{A}_{7}$ are not really available for the shape considered, hence average valules are taken. This is not too serious an approximation, since the effect of the coefficients are only predominant near resonance. It does mean, however, that a variety of different values of $C$ and $\bar{A}_{Z}$ should be used for each problem. It will then be readily apparent tor what range of frequencies the results are reliable. For this reason, program HEAVE, superimposes the graphical output from multiple cases. 

Appendix B

MATER IALS

by W. R. Lorman

According to Morgan (1970), "Large concrete vessels have in the past behaved extremely well under impact and proved their seaworthiness in severe weather, but it must be remembered that all these vessels were grossly overdesigned. As design methods and constructional techniques become more sophisticated and critical, the previous record of good behaviour of concrete vessels ceases to be valid. It must not be assumed that modern vessels will be as sound as their predecessors which had very large factors of safety inherent in their design. Floating structures, especially large prestressed powered vessels, present complex problems in both design and construction over and above those met in land-based structures and the prospects are exciting."

Deterioration of reinforced concrete in maritime structures occurs mostly above the high-water mark and sometimes anywhere within the tidal range. Deterioration occurs also on horizontal surfaces, above sea level, that are subject to seawater spray. The deleterious effects begin as the seawater evaporates, creating concentrated solutions of magnesium sulfate which usually attack most of the constituents of the hardened cement paste matrix in the concrete. The sodium chloride concentrations promote corrosion of the steel reinforcement. The alkalies (sodium and potassium) present in the concentrated solutions may react with the aggregate in the concrete. The reaction between calcium hydroxide crystals, formed in the hydration of portland cement, and the magnesium sulfate (from the seawater) results in the formation of calcium sulfate and magesium hydroxide. The insoluble products of this reaction occupy a greater volume than do the calcium hydroxide crystals that are replaced; consequently these products are the cause of disruptive forces which are evidenced by cracking of the concrete cover over the steel and subsequent spalling. The situation is worsened by the corroding steel and possibly by the alkali-aggregate reaction. To minimize these problems, the concrete must incorporate a sulfate-resistant portland cement (ASTM Type $V$ preferably or Type II) and the steel reinforcement must be covered with at least 3 inches of watertight concrete (i.e., low permeability). In warm seawater, the deterioration is usually due to chemical action; in cold seawater, due to thermal changes.

Steel reinforcement embedded in concrete is at first in an alkaline environment which inhibits corrosion of steel. To minimize the possible adverse effect of chlorides present in the seawater, not only is a watertight concrete mandatory but supplementary alkalinity is needed to protect the embedded steel. This protection can be attained by using ime-saturated freshwater in the concrete mixture; 5 grams of calcium hydroxide per liter of water is known to prevent corrosion of stee 1 in concrete containing as much as $7 \%$ calcium chloride admixture (by weight of cement). 
A pozzolan, as partial replacement of the cement, is another effective precautionary measure. The pozzolanic silicate combines, in the presence of moisture, with any excess calcium hydroxide present in the concrete. This reaction precludes any leaching of the lime, due to evaporation at the concrete surface, since additional cementitious compounds (calcium silicates) are created within the mass of concrete. These additional silicates strengthen the concrete to resist cracking; they improve its durability by increasing its resistance to the effects of the sulfates present in the seawater.

Cement content, water/cement ratio, and workability are the fundamental factors relative to durability of concrete. The least permeable concrete is usually the most durable concrete. The cement content should not be less than 8 bags per cubic yard of concrete. The aggregate/cement ratio should not be less than 2.6 (by weight).

The durability of concrete exposed to freezing and thawing in seawater is enhanced by incorporating an air-entraining admixture. As the effects of freezing and thawing are much more severe in seawater than in freshwater, the optimum amount of entrained air should be from 10 to $20 \%$ by volume (Lyse, 1961). The maximum size of aggregate is of minor importance relative to frost resistance of the concrete in a seawater environment.

The resistance of the concrete to abrasion varies directly with both cement content and compressive strength of the concrete, and inversely with the water/cement ratio. This relation is valid regardless of the aggregate quality or the combinations of aggregate used (Smith, 1958).

If the precast units are cured in a high-pressure steam environment, their potential volume change (shrinkage due to drying and swellage due to wetting) is minimized and their strength (flexural, torsional, compressive) is maximized. Note, however, that improving the strength by increasing the cement content tends to increase the potential shrinkage, whereas improving the strength by complete compaction of the freshly mixed concrete serves in reducing the potential shrinkage.

The concrete inspection program should provide not only quality control of concrete at the mixing plant, but should be so comprehensive that no discrepancies occur in the formwork, reinforcement, prestressing, concreting, curing, and post-tensioning. ACI Standard 311 contains recommended practice.

The following are apparent advantages of prestressed concrete in a floating structure: The concrete is in compression, high prestress tends to increase durability of the concrete, fatigue resistance is high, elasticity is equally good in cold or warm water, and the small steel area warrants thinner members which are more flexible than conventionally reinforced concrete members.

Precast prestressed concrete structural elements are desirable because they can be standardized, but it is vital that the strength/ weight ratio always be high. Prestressed deck slabs can be connected transversely by post-tensioning to make them act as a lateral girder in 
the plane of the deck. Shortening of beams and slabs may occur because of creep and may result in troublesome joints and undesirable tensile stresses. This problem can be minimized by using high-strength concrete, avoiding extreme prestress, and curing the concrete adequately (at least one month) before installing the components. Connections must be designed to distribute stresses caused by shortening and thus can minimize cracking. A girder designed as a simple beam must not be raised or supported at the center since tensile cracking will develop due to negative moment. Units must always be raised or supported at the designed bearing points.

Lightweight prestressed concrete is not used as extensively in marine structures as in buildings located inland. Gerwick (1959) states that excellent durability in seawater is attainable if the proper type of lightweight aggregate is used; supposedly, he is referring to expanded shale aggregate in pellet form ( $i$. e., aggregate that has been fired after, rather than before being graded). The use of natural sand with lightweight coarse aggregate is recommended because concrete containing all lightweight aggregate has a lower modulus of elasticity, undergoes greater deflection in bending, and creeps more than conventional sandand-gravel concrete; blending natural sand with lightweight coarse aggregate serves to counteract these effects. The submerged weight of 1 ightweight concrete ${ }^{*}$ is about half that of conventional concrete.

Increasing the thickness of concrete cover over prestressed strands causes considerable increase in cost. Gerwick (1959) considers a 2-inch cover adequate for most American harbor structures, but recommends further research to ascertain the most economical use of prestressed concrete in marine structures.

Loss of prestress in prestressed concrete may be due to relaxation of prestressing steel, steam-curing of concrete, shrinkage of concrete, elastic shortening of the structural member, creep of concrete, anchorage slip, and friction of the steel tendons during post-tensioning. In an assembled structure some of these losses occur simultaneously and affect each other. The structural designer must know the causes and magnitudes so that the completed assemblage will perform satisfactorily (Podolny, 1969).

Lightweight-aggregate concrete usually undergoes greater shrinkage and swellage, due to moisture change, than does normal-weight-concrete. Nevertheless, corrosion of steel reinforcement is no greater in fully compacted structural grade lightweight concrete, incorporating chemically inert aggregate such as expanded shale, than in conventional concrete. Moreover, such lightweight-aggregate concrete is more fire resistant than is concrete containing sand and gravel.

\footnotetext{
*Portland Cement Association (Design and Control of Concrete Mixtures, 11th Edition, 1968) defines structural lightweight concrete as having a 28-day compressive strength in excess of 2,500 psi and an air-dry unit weight of less than $115 \mathrm{lb}$. per cu ft.
} 
The unit weight of lightweight concrete for structural purposes ranges from 85 to 120 pcf. The greatest strengths are attained with aggregates derived from shale, clay, or slate and expanded into pellets by means of the rotary-kiln process. Lightweight aggregates should conform to ASTM Standard Specification C330, and should have a unit weight within the 85 to 120 pcf limits, in order to assure a concrete compressive strength of at least 2,500 psi.

The lightweight concrete mixture should be designed in accordance with ACI Standard 211.2, and due regard given to the cement content rather than the water/cement ratio. As lightweight aggregate absorbs mixing water more readily than does natural aggregate, the slump and cement content are more important than water/cement ratio in controlling the quality of concrete. On the basis of equal workability, the slump of lightweight concrete is usually one-half to two-thirds that of conventional concrete.

Improved workability for a given slump and a simultaneous improvement in strength $c$ an be attained by using water-reducing and set-retarding admixtures that conform to ASTM Standard Specification C494. An air-entraining admixture also should be used to assure optimum workability. The amount of entrained air needed in lightweight concrete normally ranges between 6 and $8 \%$ whereas conventional concrete requires fxom 3 to $5 \%$; however, as explained previously, higher percentages are needed to resist freezing and thawing in seawater.

slump, air content, and unit weight are the principal physical characteristics utilized on controlling quality of lightweight concrete. Testing samples of the freshly mixed concrete with regard to these three characteristics is more important than testing 28-day compressive strengths. Maintaining uniformity is facilitated if the tolerance in unit-weight variations is restricted to +1 pcf, the slump is the lowest compatible with practicable placement and full compaction, and the air content is determined by the volumetric method specified in ASTM Standard Test Method C173.

Compacting freshly mixed lightweight concrete by vibration must be done carefully to preclude segregation of the aggregate. The fine aggregate usually consititues about one-half the volume of the total aggregate, but the weight of the fine portion is about double that of the coarse portion. 


\section{Concrete Ships}

ACI Proc., 14: 422-427. (1918)

ACI Proc., 15: 285. (1919)

ACI Proc., 16: 161-166. (1920)

ACI Proc., 17: 291. (1921)

ACI Proc., 18: 83-114; especially 83, 84, 87. (1922)

ACI Proc., 41: 137-147, 180-1 thru 180-7. (1954)*

ACI Proc., 46: 204, 479 (1950)

\section{Concrete Seadromes}

R. M. Parsons Co. (1969). "Evaluation of Construction Methods for Offshore Airports." Final Report, FAA Contract FA69WA-2073, Los Angeles. See pp. 126, 127, 155-164, A-17, A-18, A-47, A-48, A-69 thru $\mathrm{A}-73$, and A-115 thru A-117.

\section{Materials and Maintenance}

ACI Proc., 14: 433-464, especially 462-463; 505-516. (1918)

ACI Proc., 15: 24-62, especially 25-30; 257-269; 272-273 (1919)

ACI Proc., 25: 751-762, especially 759 (1929)

ACI Proc., 39: 593 (1943)

ACI Proc., 41: 147-180 (1945)

ACI Proc., 46: 193-200 (1550)

ACI Proc., 54: 841-856 (1957)**

ACI Proc., 57: 1575-1584 (1960)

ASCE Trans., 132: 152-153, 180-181 (1967)

\section{Prestressed Concrete}

Proceedings Wor $1 \mathrm{~d}$ Conference on Prestressed Concrete, San Francisco, (1957). See pp. A2-1 thru A2-9, A5-1 thru A5-14, A6-1 thru A6-12, A8-1 thru A8-7, A9-1 thru A9-8, A20-1 thru A20-8, A25-1 thru A25-12, A26-1 thru A26-14, A31-1 thru A31-8, A35-1 thru A35-6, 6-1 thru 6-10, 13-1 thru 13-11, and 18-1 thru 18-12.

Best recommendations regarding quality control of concrete for ship construction.

战

Best recommendations regarding quality of concrete that resists seawater attack. 


\section{DISTRIBUTION LIST}

\begin{tabular}{|c|c|c|c|}
\hline SNDL & No. of & Tota 1 & \\
\hline - & 1 & 2 & Defense Documentation Center \\
\hline FKAIC & 1 & 10 & Naval Facilities Engineering Command \\
\hline FKNT & 6 & 6 & NAVFAC Engineering Field Divisions \\
\hline FKN5 & 9 & 9 & Pub1ic Works Centers \\
\hline FA25 & 1 & 1 & Public Works Center \\
\hline- & 9 & 9 & $\begin{array}{l}\text { RDT\&E Liaison Officers at NAVFAC } \\
\text { Engineering Field Divisions and } \\
\text { Construction Battalion Centers }\end{array}$ \\
\hline- & 213 & 213 & $\begin{array}{l}\text { NCEL Special Distribution List No. } 9 \\
\text { for Government activities interested } \\
\text { in reports on Deep Ocean Studies }\end{array}$ \\
\hline
\end{tabular}


UNCLASS IF IED

Security Classification

DOCUMENT CONTROL DATA $R$ \& D

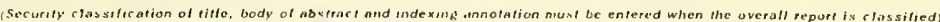

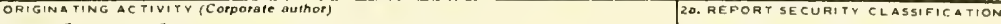

Naval Civil Engineering Laboratory

Port Hueneme, California 93043 Unclassified

REPORT TITLE

MOBILE OCEAN BAS ING SYSTEMS - A CONCRETE CONCEPT

4. OESCRIPTIVE NOTES (Typo of roport and inclusive dates)

Not fina $1 ; 1$ January 1970 - 30 June 1970

5. AUTHOR(S) (Fleat nams, middo intilal, last mamo)

J. J. Hromadik, D. A. Davis, D. F. Griffin, W. R. Lorman, M. J. Wolfe and H. S. Zwibel

\begin{tabular}{|c|c|c|}
\hline $\begin{array}{l}\text { 6. REPORT OATE } \\
\text { January } 1971\end{array}$ & $\begin{array}{l}\text { 7a. TOTAL NO OF PAGES } \\
131\end{array}$ & $\begin{array}{l}\text { 7b. NO OF REFS } \\
118\end{array}$ \\
\hline B. CONTRACT OR GRANT NO. & \multirow{2}{*}{\multicolumn{2}{|c|}{$\begin{array}{l}\text { 9. ORIGINA TOR'S REPORT NUMBERIS\} } \\
\text { TN- } 1144\end{array}$}} \\
\hline B. PROJECTNO YF 51.543.009.01.001 & & \\
\hline d. & \multicolumn{2}{|c|}{$\begin{array}{l}\text { 98. OTHER RERORT NO(S) (Any othar numbere that may bo asalened } \\
\text { thie report) }\end{array}$} \\
\hline
\end{tabular}

proprietary information; January 1971. Other requests for this

document must be referred to the Naval Civil Engineering Laboratory.

11. SUPPLEMENTARY NOTES

2. SPONSORING MILITARY ACTIVITY

Naval Facilities Engr. Command

Office of Naval Research

Large floating ocean platforms are envisioned as satisfying basing requirements of the Navy in the mid $80^{\prime} \mathrm{s}$. The floating platforms would consist of structural components mass-produced, contructed into modules ashore, launched, towed to the site and assemble into platforms.

This investigation studied various configurations using concrete as the construction material. The scope of effort included synthesis of concepts, concrete production, construction methodology and cost, and an RDT\&E plan. It is concluded that concrete is a feasibile and practical construction material for large ocean platforms.

\section{DD FORM 1473 (PAGE 1)}

$S / N 0101.807 .6801$
UNCLASS IF IED Security Classification 


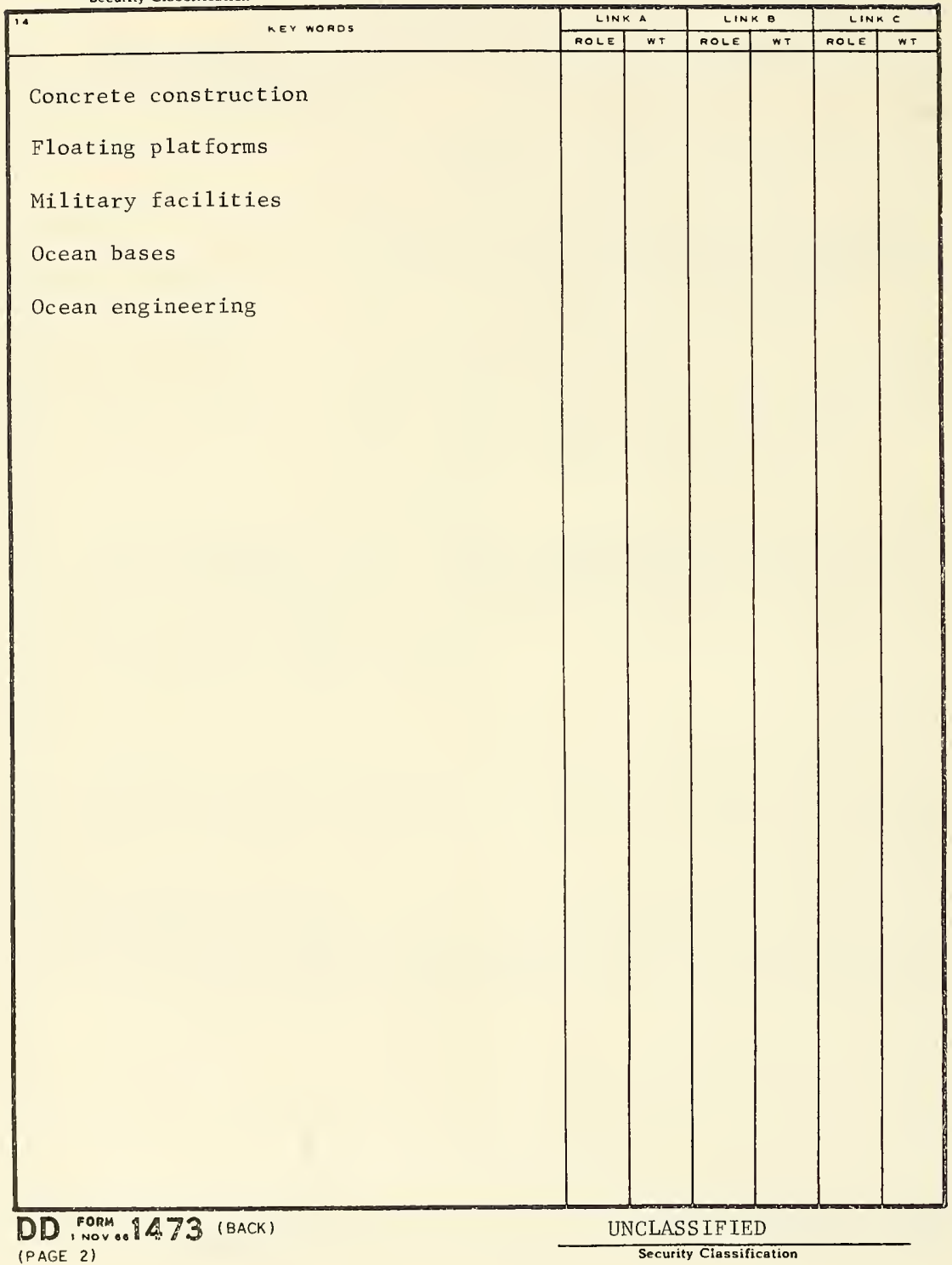


Tecrnic I Tote N -1144

Naval Civil Enginering Laboratory Nobile Cean Basing Sustems AUTHOR Concrete Concept 
